by

Elizabeth Jean Abraham

Bachelor of Science in Civil Engineering, Marquette University, 2005

\author{
Submitted to the Graduate Faculty of \\ The School of Engineering in partial fulfillment \\ of the requirements for the degree of \\ Master of Science
}

University of Pittsburgh 


\section{UNIVERSITY OF PITTSBURGH \\ SCHOOL OF ENGINEERING}

This thesis was presented

by

Elizabeth Jean Abraham

It was defended on

November $10^{\text {th }}, 2006$

and approved by

Dr Amir Koubaa, Academic Coordinator and Lecturer, Department of Civil and Environmental Engineering

Dr. Piervincenzo Rizzo, Assistant Professor, Department of Civil and Environmental Engineering

Dr. Kent A. Harries, Assistant Professor, Department of Civil and Environmental Engineering Thesis Advisor 
Copyright $(\mathrm{C}$ by Elizabeth Abraham

2006 


\title{
CONCEPTUAL INVESTIGATION OF PARTIALLY BUCKLING RESTRAINED BRACES
}

\author{
Elizabeth Abraham, M.S. \\ University of Pittsburgh, 2006
}

\begin{abstract}
Although in its infancy, leveraging high strength fiber reinforced polymer (FRP) materials for retrofit of steel structures has been the focus of recent investigations. Studies include the application of FRP to steel for flexural and fatigue or fracture retrofit as well as improving steel member stability. The research presented in this thesis attempts to introduce the concept of an FRP-stabilized steel member through a retrofit application creating a Partially Buckling Restrained Brace (PBRB). A PBRB seeks to increase steel brace stability and hysteretic energy dissipation during a seismic event through the strategic application of bonded FRP materials along its length.
\end{abstract}

Six 65 1/2” long A992 Gr. 50 WT6x7 steel braces were tested under cyclic compressive loading to failure. Two braces were retrofitted with carbon FRP (CFRP) and two braces were retrofitted with glass FRP (GFRP). One brace was encased in an HSS 7 x 0.125 " steel tube and filled with grout to create a conventional Buckling Restrained Brace (BRB). The final brace was an unretrofit control specimen. Two arrangements of FRP materials were used for both the CFRP and GFRP retrofit braces: (1) 2" wide strip was applied to each side of the stem of the WT, and (2) 1" wide strips were applied to each side of the stem in an effort to optimize the retrofit application.

The GFRP specimens increased the axial capacity of the brace by $6 \%$ and $9 \%$, whereas the CFRP specimens had no effect. The observed variability in axial capacity was largely a result 
of initial loading eccentricities. The GFRP specimens did however show greater control over residual deflections suggesting that the retrofit can delay the formation of a plastic hinge within the brace and maintain compressive capacity through several cyclic loading loops. All of the FRP-retrofit specimens reduced weak-axis lateral displacement of the braces and showed increased control of local behavior. However, the brace is not dominated by local behavior due to its length, and this application may be better suited to shorter braces, similar to those found as cross frames between bridge girders, or to control local buckling in steel I-shaped beams. 


\section{TABLE OF CONTENTS}

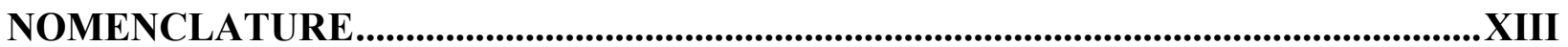

ACKNOWLEDGEMENTS ................................................................................................ XVII

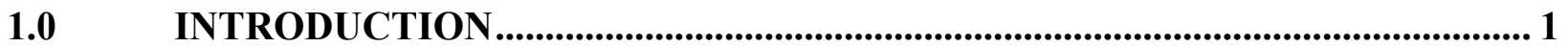

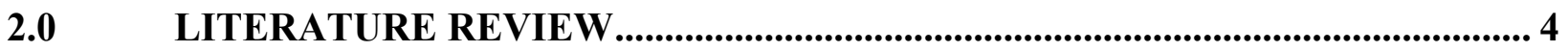

2.1 FRP MATERIALS.............................................................................................. 4

2.2 REPAIR OF CONCRETE USING FRP MATERIALS .................................... 7

$2.3 \quad$ APPLICATIONS OF FRP IN STEEL STRUCTURES...................................... 8

2.3.1 Strengthening Steel Structures ........................................................................ 8

2.3.2 Fatigue and Fracture Repair of Steel with FRP .......................................... 11

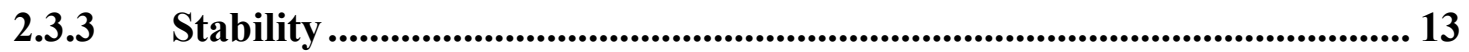

2.4 LIMITATIONS TO THE USE OF FRP RETROFIT MEASURES FOR STEEL ....................................................................................................................... 17

2.5 BUCKLING RESTRAINED BRACED (BRB) FRAMES ............................... 23

2.5.1 Braced Frames ........................................................................................... 23

2.5.2 Concentrically Braced Frames ...................................................................... 24

2.5.3 Desired Hysteretic Behavior During Seismic Events................................... 25

2.6 BUCKLING RESTRAINED BRACES …............................................................ 30

2.7 SEISMIC APPLICATIONS OF BRBS _.......................................................... 35

2.7.1 Performance Based Aspects .......................................................................... 35 
2.7.2 Seismic Performance of BRBs .................................................................... 37

2.8 RELATIONSHIP TO PRESENT WORK.......................................................... 48

3.0 EXPERIMENTAL PROGRAM

3.1 WT-SECTION BRACE SPECIMENS ..................................................................5 50

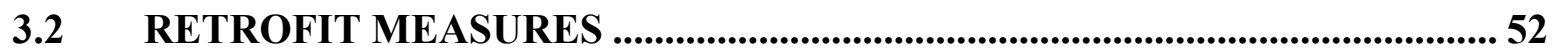

3.2.1 FRP Retrofit Braces..................................................................................... 52

3.2.2 Application of FRP to Test Specimens........................................................... 53

3.2.2.1 Steel Substrate Preparation ........................................................................ 54

3.2.2.2 Preparation of the FRP Material ........................................................5 54

3.2.2.3 Application of the FRP to the Steel.......................................................... 55

3.2.3 Buckling Restrained Brace Retrofit .....................................................56

$3.3 \quad$ SPECIMEN DESIGNATION ....................................................................................5 56

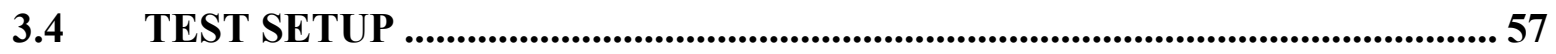

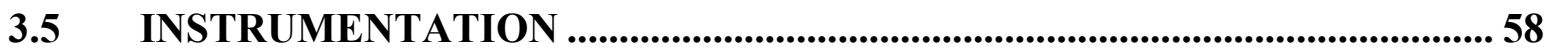

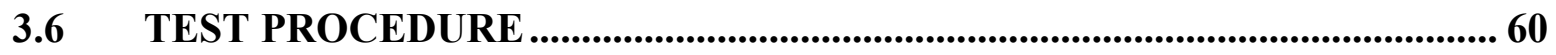

3.7 PREDICTED SPECIMEN BEHAVIOR ............................................................... 61

3.7.1 Predicted WT 6x7 Brace Behavior ................................................................ 61

3.7.2 Predicted BRB Behavior ................................................................................... 63

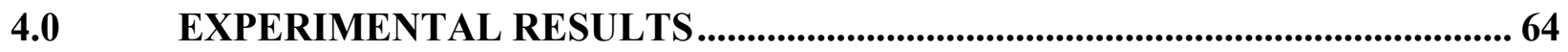

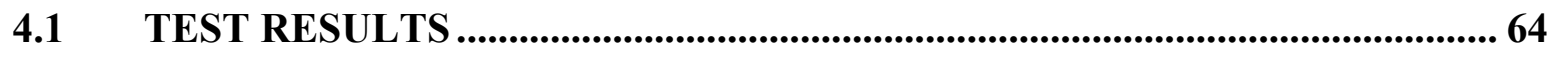

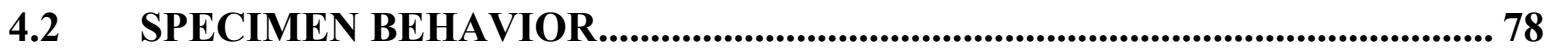

4.2.1 Specimen C ...................................................................................................... 78

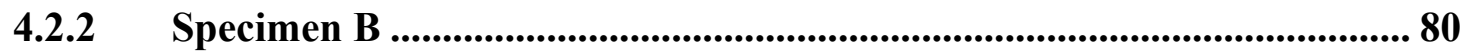


4.2.3 Specimen CFRP-2 …...................................................................................... 81

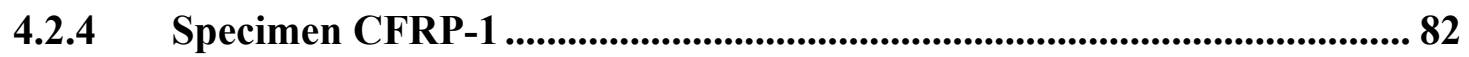

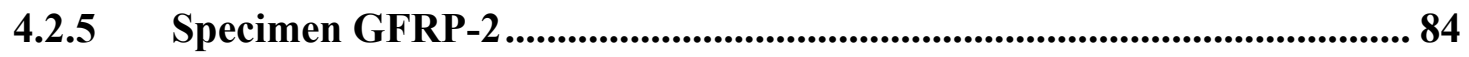

4.2.6 Specimen GFRP-2 ….......................................................................................... 85

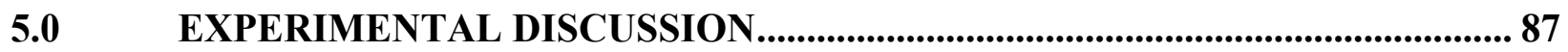

5.1 SPECIMEN AXIAL BEHAVIOR........................................................................... 87

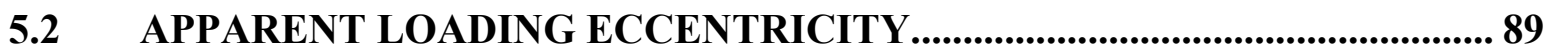

5.3 SPECIMEN RESPONSE INCLUDING APPARENT LOADING EQUIVALENT ECCENTRICITY......................................................................... 90

$5.4 \quad$ RESIDUAL DISPLACEMENT RESPONSES _.............................................. 97

5.5 FRP DEBONDING ................................................................................................. 100

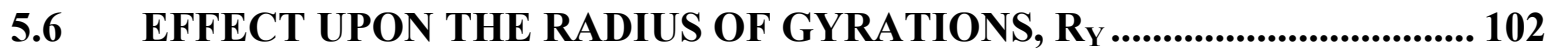

6.0 SUMMARY, CONCLUSIONS, AND RECOMMENDATIONS ......................... 105

6.1 SUMMARY OF TEST PROGRAM ........................................................................ 105

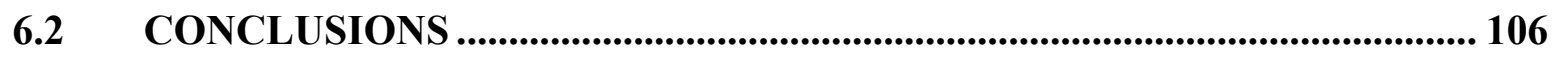

6.3 RECOMMENDATIONS....................................................................................... 110

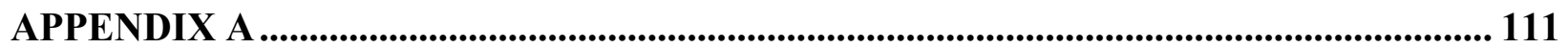

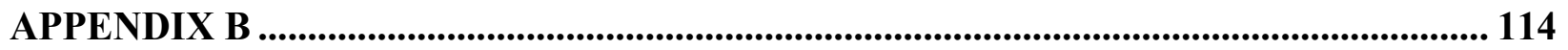

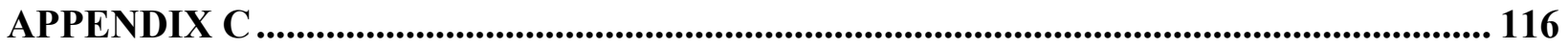

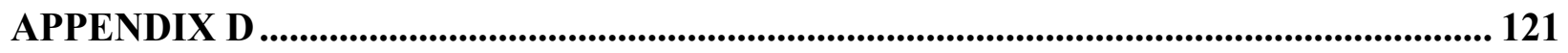

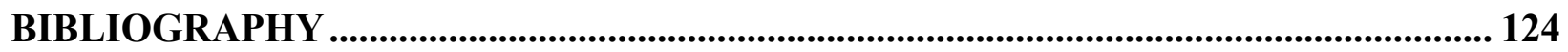




\section{LIST OF TABLES}

Table 2.1 Typical Properties of Steel-Adhesive-FRP systems ......................................... 6

Table 2.2 Table C1-8 of FEMA 356, Target Building Performance Levels and Ranges ........... 36

Table 3.1 Manufacturer's Reported Material Properties...................................................... 51

Table 3.2 WT 6x7 Stem and Flange Properties ............................................................. 61

Table 4.1 Summary of displacement results from brace cyclic loading. ............................... 65

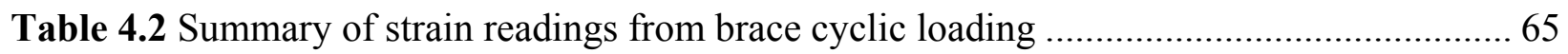

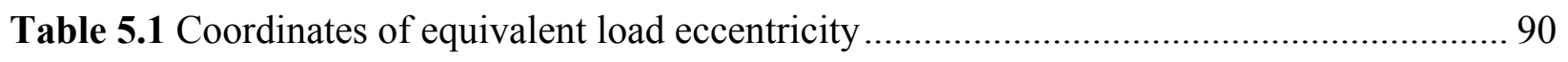

Table 5.2 Displacement performance parameters and bifurcation load for all specimens. ........ 95

Table 5.3 Residual displacement and strains following the cycle to 50,000 lbs.................... 99

Table 5.4 FRP debonding strains and occurence ..................................................... 101

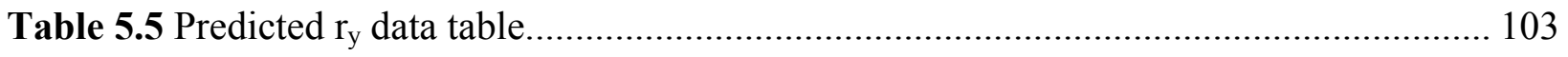




\section{LIST OF FIGURES}

Figure 2.1 Analytical load-deflection behavior of GFRP stabilized steel cantilever................. 17

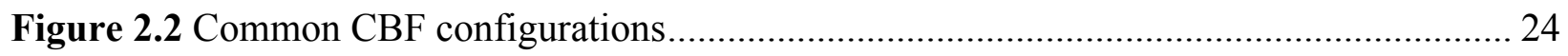

Figure 2.3 Sample hysteresis of brace under cyclic loading ............................................. 25

Figure 2.4 Behavior of Conventional Brace and BRB................................................ 30

Figure 2.5 Schematic of unbonded buckling-restrained brace and its components.................. 32

Figure 2.6 Unbonded braces (BRBs) awaiting testing at E-Defense .................................... 32

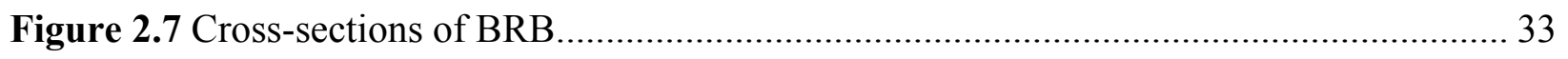

Figure 2.8 Dynamic braced frame model................................................................ 41

Figure 2.9 Load-displacement relationship of structure with BRB .................................... 44

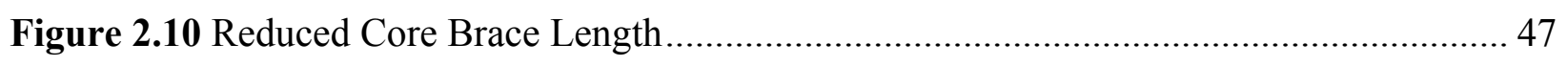

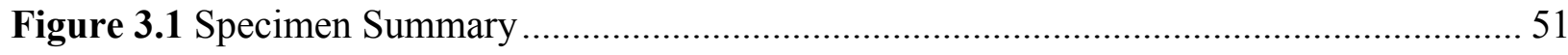

Figure 3.2 Details of brace connection used for testing................................................... 52

Figure 3.3 Photograph of steel surface preparation. .................................................... 54

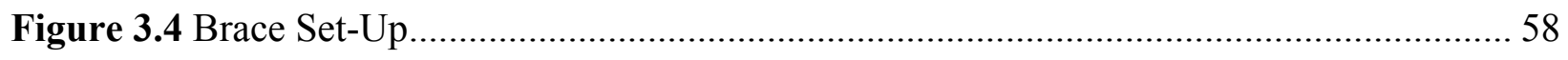

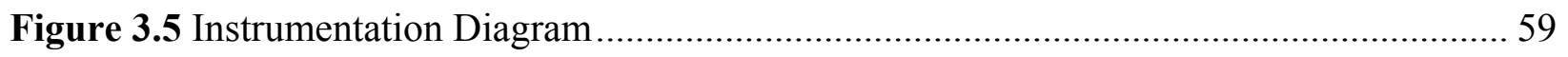

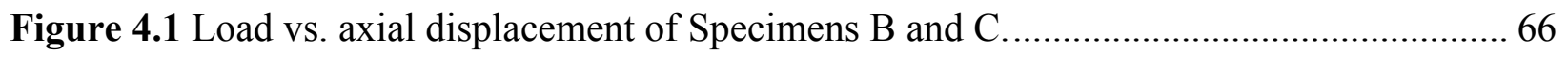

Figure 4.2 Load vs. axial displacement of Specimens CFRP-2 and C . ................................ 66 
Figure 4.3 Load vs. axial displacement of Specimens CFRP-1 and C. 67

Figure 4.4 Load vs. axial displacement of Specimens GFRP-2 and C. 67

Figure 4.5 Load vs. axial displacement of Specimens GFRP-1 and C................................ 68

Figure 4.6 Load vs. weak-axis lateral displacement of Specimens B and C. ......................... 68

Figure 4.7 Load vs. weak-axis lateral displacement of Specimens CFRP-2 and C................. 69

Figure 4.8 Load vs. weak-axis lateral displacement of Specimens CFRP-1 and C................. 69

Figure 4.9 Load vs. weak-axis lateral displacement of Specimens GFRP-2 and C................. 70

Figure 4.10 Load vs. weak-axis lateral displacement of Specimens GFRP-1 and C................ 70

Figure 4.11 Load vs. strong-axis lateral displacement of Specimens B and C....................... 71

Figure 4.12 Load vs. strong-axis lateral displacement of Specimens CFRP-2 and C.............. 71

Figure 4.13 Load vs. strong-axis lateral displacement of Specimens CFRP-1 and C.............. 72

Figure 4.14 Load vs. strong axis lateral displacement of Specimens GFRP-2 and C. .............. 72

Figure 4.15 Load vs. strong-axis lateral displacement of Specimens GFRP-1 and C.............. 73

Figure 4.16 Load vs. steel strain in the stem tip for Specimens B and C. ............................. 73

Figure 4.17 Load vs. strain in the stem tip and FRP for Specimens CFRP-2 and C. ............... 74

Figure 4.18 Load vs. strain in the stem tip and FRP for Specimens CFRP-1 and C. ............... 74

Figure 4.19 Load vs. strain in the stem tip and FRP for Specimens GFRP-2 and C............... 75

Figure 4.20 Load vs. strain in the stem tip and FRP for Specimens GFRP-1 and C............... 75

Figure 4.21 Load vs. strain in flange tips of Specimens B and C...................................... 76

Figure 4.22 Load vs. strain in flange tips of Specimens CFRP-2 and C. .............................. 76

Figure 4.23 Load vs. strain in flange tips of Specimens CFRP-1 and C. ............................... 77

Figure 4.24 Load vs. strain in flange tips of Specimens GFRP-2 and C. ............................. 77

Figure 4.25 Load vs. strain in flange tips of Specimens GFRP-1 and C.............................. 78 
Figure 4.26 Specimen C

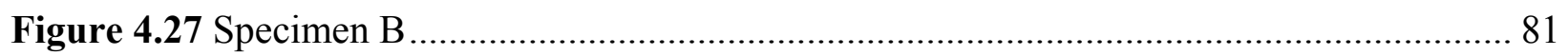

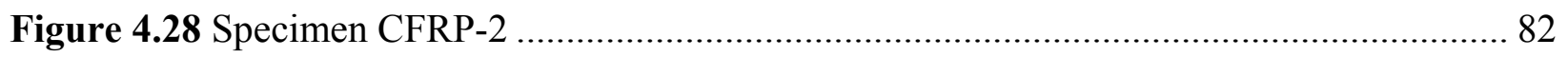

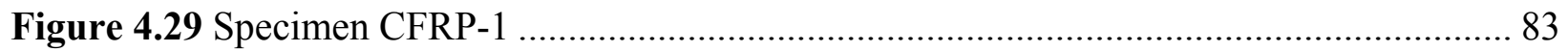

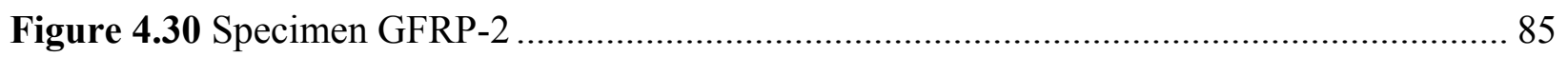

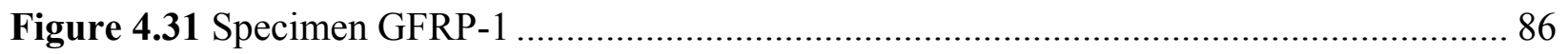

Figure 5.1 Load vs. axial displacement backbone curve for all specimens ............................ 88

Figure 5.2 Load centroid location for each specimen ..................................................... 90

Figure 5.3 Load vs. weak-axis lateral displacement backbone curves including initial load

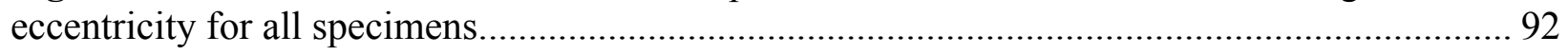

Figure 5.4 Load vs. weak-axis lateral displacement backbone curves including initial load

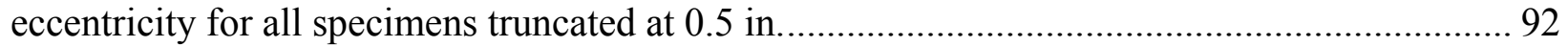

Figure 5.5 Load vs. strong-axis lateral displacement backbone curves including initial load

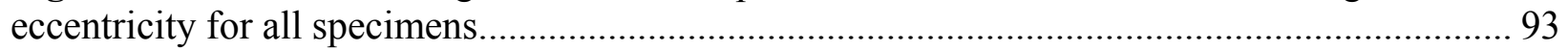

Figure 5.6 Definition of displacement performance parameters........................................ 94

Figure 5.7 Cycle to 50,000 lbs illustrating residual axial displacement for all specimens ......... 97

Figure 5.8 Cycle to 50,000 lbs illustrating residual weak-axis lateral displacement for all

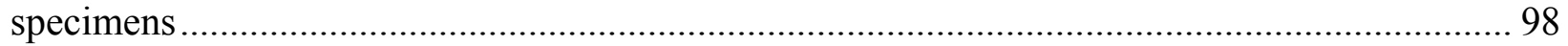

Figure 5.9 Cycle to 50,000 lbs illustrating residual strong-axis lateral displacement for all

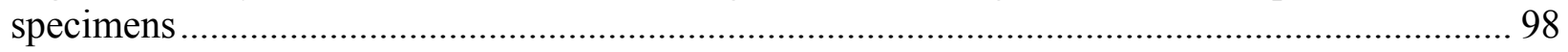

Figure 6.1 Modified sample hysteresis of brace under cyclic loading to illustrate the effect of the

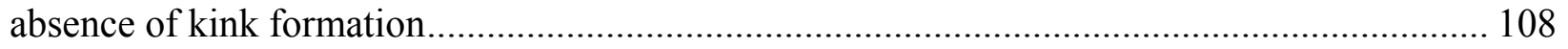




\title{
NOMENCLATURE
}

\author{
Abbreviations
}

AASHTO

AISC

ASCE

BRB

$\mathrm{BRBF}$

$\mathrm{CBF}$

CFRP

CTE

DBE

DWT

EBF

FEMA

FRP

hmCFRP

hsCFRP
American Association of State Highway and Transportation

\section{Officials}

American Institute of Steel Construction

American Society of Civil Engineers

buckling restrained brace

buckling restrained braced frame

concentrically-braced frames

carbon fiber-reinforced polymer

coefficient of thermal expansion

design basis earthquake

draw wire transducer

eccentrically braced frame

Federal Emergency Management Agency

fiber-reinforced polymer

high modulus carbon fiber-reinforced polymer

high strength carbon fiber-reinforced polymer 


$\begin{array}{ll}\text { GFRP } & \text { glass fiber-reinforced polymer } \\ \text { LRFD } & \text { load and resistance factor design } \\ \text { MCE } & \text { maximum considered earthquake } \\ \text { MDOF } & \text { multiple degrees of freedom } \\ \text { OCBF } & \text { ordinary concentrically-braced frame } \\ \text { PBD } & \text { performance based design } \\ \text { PBRB } & \text { partially buckling restrained brace } \\ \text { SMF } & \text { special moment frame } \\ \text { SCBF } & \text { special concentrically braced frame } \\ \text { SDOF } & \text { single degree of freedom } \\ \text { uhmCFRP } & \text { ultra high modulus carbon fiber-reinforced polymer }\end{array}$

Notation

$\begin{array}{ll}A_{i} & \text { cross sectional area of yielding portion of the brace core } \\ \alpha & \text { post-yield stiffness } \\ \beta & \text { compressive strength adjustment factor } \\ \beta_{1} & \text { distributed spring constant } \\ C_{0} & \text { damping constant } \\ C_{\mathrm{r}} & \text { first buckling load of bracing members } \\ \text { d } & \text { axial deformation } \\ \delta & \text { lateral displacement at midlength }\end{array}$




\begin{tabular}{|c|c|}
\hline$e_{x}$ & loading eccentricity about the strong axis \\
\hline$e_{y}$ & loading eccentricity about the weak axis \\
\hline $\mathrm{E}$ & Young's modulus \\
\hline $\mathrm{E}_{\mathrm{B}} \mathrm{I}_{\mathrm{B}}$ & flexural stiffness of concrete encasing member \\
\hline $\mathrm{E}_{\mathrm{S}} \mathrm{I}_{\mathrm{S}}$ & flexural stiffness of encased brace member \\
\hline $\mathrm{E}_{\mathrm{t}}$ & tangent elongation modulus \\
\hline $\mathrm{F}_{\mathrm{y}}$ & yield stress \\
\hline $\mathrm{F}_{\text {crtt }}$ & flexural torsional buckling capacity \\
\hline $\mathrm{F}_{\text {cry }}$ & critical buckling stress \\
\hline $\mathrm{H}$ & flexural constant \\
\hline $\mathrm{I}_{\mathrm{i}}$ & moment of inertia of inner steel core \\
\hline$I_{0}$ & elastic moment of inertia \\
\hline K & pre-yielding stiffness \\
\hline $\mathrm{k}_{\mathrm{con}}$ & stiffness of the connection portion at each end of the brace \\
\hline $\mathrm{k}_{\mathrm{i}}$ & elastic stiffness of yielding portion of the brace \\
\hline KL & effective buckling length \\
\hline $\mathrm{L}_{\mathrm{c}}$ & length of yielding portion of brace core \\
\hline$\lambda$ & $\mathrm{KL} / \mathrm{r}$ slenderness ratio \\
\hline$\lambda_{\mathrm{p}}$ & limiting width-thickness ratio \\
\hline$\lambda_{\mathrm{c}}$ & column slenderness parameter \\
\hline $\mathrm{m}$ & mass \\
\hline$\omega$ & strain hardening factor \\
\hline & axial load \\
\hline
\end{tabular}




$\begin{array}{ll}\mathrm{P}_{c r} & \text { critical buckling load } \\ \mathrm{Q}_{s} & \text { Euler buckling reduction factor } \\ \mathrm{R} & \text { response modification factor } \\ \mathrm{r}_{\mathrm{y}} & \text { radius of gyration about the weak axis } \\ \sigma_{\mathrm{y}} & \text { yield stress of the core } \\ \mathrm{t}_{\mathrm{w}} & \text { section web thickness } \\ \theta & \text { brace angle } \\ \mathrm{u}(\mathrm{t}) & \text { axial deformation of the brace } \\ \mathrm{u}_{\mathrm{y}} & \text { yield displacement } \\ \ddot{u}_{\mathrm{g}}(\mathrm{t}) & \text { ground excitation } \\ z(t) & \text { hysteretic dimensionless quantity }\end{array}$




\section{ACKNOWLEDGEMENTS}

I would first like to thank my advisor and committee chair, Dr. Kent Harries, for his support and encouragement throughout the development and execution of my thesis. I am very grateful for the time, wisdom, and education he has given me.

I'd also like to acknowledge and thank my committee members, Dr. Piervincenzo Rizzo and Dr. Amir Koubaa. Thank you for your support and constructive criticism.

I'd like to extend my gratitude and appreciation to my fellow graduate students, Keith Coogler and Patrick Minnaugh for helping with the execution of this research. I'd also like to thank the undergraduate students that assisted in performing this research: Bem Atim, David Bittner, J.P. Cleary, Lou Guiltieri, and Derrick Mitch.

I would also like to thank my fiancé, Tim Hoekenga, for his unending support and patience throughout the conception, execution, and completion of this thesis. I truly would not have been able to do this without him.

Finally, I would like to thank the following people and companies for supplying the materials necessary to make this research possible: Sarah Cruikshank and Ed Fyfe of Fyfe Company LLC, San Diego, CA, Hardwire LLC, and Fox Industries. 


\subsection{INTRODUCTION}

The research presented in this thesis document was carried out in an attempt to introduce a unique and previously untested concept of FRP-stabilized steel members. The specific application investigated for this innovative concept is that of a Partially Buckling Restrained Brace (PBRB). In this application, fiber reinforced polymer (FRP) composite materials are applied to a steel bracing member in an attempt to enhance the members' buckling capacity and hysteretic behavior when subjected to seismic loading. This application is analogous to the application of Buckling Restrained Braces (BRB) which have been investigated and applied in the U.S. in recent years. PBRBs, however, are not expected to provide the same degree of buckling restraint as BRBs and thus represent a point on the spectrum between plain braces and BRBs.

The proposed FRP retrofit of existing steel braces is thought to present a practical alternative for regions of moderate seismicity where the high degree of buckling restraint provided by a BRB is not necessary. An FRP retrofit application could be completed with minimal disruption to the intended operation and use of the structure. The ease of manufacturing, handling and erecting FRP composites also contributes to their appeal as a retrofit application.

In contrast to the large strides taken in reinforced concrete retrofit with FRP materials, there is comparatively little research concerning the use of FRP materials for retrofit of steel members. The majority of work performed in this area concerns the application of Carbon FRP 
(CFRP) strips for flexural retrofit. Previous studies indicate the use of conventional FRP to strengthen steel structures results in little improvement in the elastic range of behavior but great improvement in the inelastic range. This behavior is easily explained by considering transformed sections: when the steel is elastic, the addition of relatively small amounts of FRP material has relatively little effect on the sectional properties (such as the moment of inertia). However as the steel becomes inelastic and its modulus becomes negligible, the now proportionally stiffer FRP enhances the effective sectional properties considerably. This concept is the premise behind the concept of FRP-stabilized steel members.

The proposed application of the work presented in this thesis document differs from previous work in its objective of strategically locating modest amounts of FRP on a steel cross section to control the manifestation of local buckling in a steel brace member. Under the large cyclic demands imposed on a braced frame during a seismic event, it is essential that local buckling be controlled to allow for greater energy dissipation within the system. The application of FRP as a retrofit measure for braces subjected to seismic loading is an attractive and practical alternative to current retrofit practices.

The integrity of a steel-FRP retrofit application is contingent upon the strength of the bond. Several studies have been performed to better understand and quantify the bond mechanism between steel and FRP materials. There are several challenges and limitations associated with bonding FRP to steel which can be avoided by taking caution with a few key steps. Future work is necessary to better understand the behavior of the bond between steel and FRP materials, however this thesis does not focus specifically on that topic.

The present work proposes the use of bonded FRP materials to affect a level of buckling restraint to axially loaded braces. It is not intended to develop a brace as robust as existing 
BRBs. Nonetheless, it is suggested that through the use of Performance Based Design (PBD), a spectrum of behavior falling between that of Ordinary Concentrically Braced Frames (OCBFs) and Buckling Restrained Brace Frames (BRBFs) is possible and has applications in practice. 


\subsection{LITERATURE REVIEW}

The research presented in this thesis document was carried out in an attempt to introduce the concept of FRP-stabilized steel members. This is a unique and essentially untested concept, and the research presented herein provides the necessary background and is an initial step towards further investigation of FRP stabilization of structural steel members. The specific application investigated for this innovative concept is that of a Partially Buckling Restrained Brace (PBRB). In this application fiber reinforced polymer (FRP) composite materials are applied to a steel bracing member in an attempt to enhance the members' buckling capacity and hysteretic behavior. This application is analogous to the application of Buckling Restrained Braces (BRB) which have been investigated and applied in the US in recent years. PBRBs, however, do not provide the same degree of buckling restraint as BRBs and thus represent a point on the spectrum between plain braces and BRBs. An overview of FRP materials, their applications to steel, steel brace behavior in concentrically braced frames, and BRB frames is presented in this chapter as necessary background information for the proposed concept.

\subsection{FRP MATERIALS}

Fiber reinforced polymer (FRP) composite materials utilized in structural engineering applications combine high strength, high modulus fibers in a relatively high fiber-volume 
fraction with a (comparatively) low-modulus polymeric matrix to produce a (typically) uniaxial strip or sheet material. The type and architecture of the fiber, as well as the matrix material determine the strength, stiffness and in-service performance of the FRP composite. Fiber materials used in civil applications include carbon, glass, aramid, and occasionally hybrid combinations of these. In addition to various fibers types, FRP composites are available in different forms including continuous strands, woven fabrics, pultruded plates, and preformed shapes. Given the anisotropic nature of the FRP composite, the fibers may be oriented to provide capacity in any direction required, although for civil infrastructure applications, unidirectional strips and sheets are most common.

Typically carbon (CFRP) and glass (GFRP) FRP materials are best suited for structural retrofit. The selection of fiber material is based upon required strength and stiffness as well as allowable budget. While GFRP is the least expensive, it also has a much lower modulus than CFRP. CFRP is available as high strength (hsCFRP), high modulus (hmCFRP) and ultra-high modulus (uhmCFRP) varieties. The tensile strength of CFRP generally decreases with increasing modulus, resulting in a lower rupture strain.

The visco-elastic displacement of the low-modulus polymeric matrix distributes the load to the high strength and high modulus fibers. The matrix also maintains chemical and thermal compatibility between fibers, provides stability and serves to protect the fibers from abrasion and environmental corrosion. Polymer matrix materials used in structural engineering are commonly polyesters, vinyl esters and epoxies. Epoxy adhesives are typically used for structural retrofits using preformed FRP materials due to their good adhesion to many substrates and low shrinkage during polymerization. 
The ease of manufacturing, handling and erecting FRP composites contributes to their appeal as a retrofit application. They are available in a wide variety of forms; preformed plates or strips being the preferred products for structural retrofit. Retrofit of a steel member using FRP pultruded plates results in a steel-adhesive-FRP interface region. This composite system is most effective when the unique characteristics of its components are tailored to address the intended retrofit. Table 2.1 summarizes the basic material properties of each component of such a system.

Table 2.1 Typical Properties of Steel-Adhesive-FRP systems (Harries and El-Tawil, 2006)

\begin{tabular}{|c|c|c|c|c|c|c|c|}
\hline & \multirow{2}{*}{$\begin{array}{l}\text { Mild } \\
\text { Steel }\end{array}$} & \multicolumn{4}{|c|}{ FRP Strips } & \multicolumn{2}{|c|}{ Adhesive $^{1}$} \\
\hline & & hsCFRP $^{1}$ & hmCFRP $^{1}$ & uhmCFRP $^{1}$ & GFRP $^{2}$ & $\begin{array}{c}\text { high } \\
\text { modulus }\end{array}$ & $\begin{array}{c}\text { low } \\
\text { modulus }\end{array}$ \\
\hline $\begin{array}{l}\text { tensile modulus } \\
\text { MPa (ksi) }\end{array}$ & $\begin{array}{l}200 \\
(29)\end{array}$ & $\begin{array}{l}166 \\
(24)\end{array}$ & $\begin{array}{l}207 \\
(30)\end{array}$ & $\begin{array}{l}304 \\
(44)\end{array}$ & $\begin{array}{l}42 \\
(6)\end{array}$ & $\begin{array}{c}4.5 \\
(0.65)\end{array}$ & $\begin{array}{c}0.4 \\
(0.06)\end{array}$ \\
\hline $\begin{array}{l}\text { tensile strength } \\
\mathrm{MPa}(\mathrm{ksi})\end{array}$ & $\begin{array}{l}276-483 \\
(40-70) \\
\end{array}$ & $\begin{array}{l}3048 \\
(442) \\
\end{array}$ & $\begin{array}{l}2896 \\
(420) \\
\end{array}$ & $\begin{array}{l}1448 \\
(210)\end{array}$ & $\begin{array}{c}896 \\
(130) \\
\end{array}$ & $\begin{array}{c}25 \\
(3.6) \\
\end{array}$ & $\begin{array}{c}4.8 \\
(0.7)\end{array}$ \\
\hline ultimate strain, $\%$ & $18-25$ & 1.8 & 1.4 & 0.5 & 2.2 & 1.0 & $>10$ \\
\hline $\begin{array}{c}\text { density } \\
\mathrm{kg} / \mathrm{m}^{3}\left(\mathrm{lb} / \mathrm{ft}^{3}\right)\end{array}$ & $\begin{array}{l}7530 \\
(490) \\
\end{array}$ & $\begin{array}{l}\sim 1618 \\
(\sim 101)\end{array}$ & $\begin{array}{l}\sim 1618 \\
(\sim 101)\end{array}$ & $\begin{array}{l}\sim 1618 \\
(\sim 101)\end{array}$ & $\begin{array}{l}\sim 2146 \\
(\sim 134)\end{array}$ & $\begin{array}{l}\sim 1201 \\
(\sim 75)\end{array}$ & $\begin{array}{l}\sim 1201 \\
(\sim 75)\end{array}$ \\
\hline $\begin{array}{c}\mathrm{CTE} \\
10^{-6} /{ }^{\circ} \mathrm{C}\left(10^{-6} /{ }^{\circ} \mathrm{F}\right)\end{array}$ & $\begin{array}{l}21.6 \\
(12)\end{array}$ & $\sim 0$ & $\sim 0$ & $\sim 0$ & $\begin{array}{c}8.8 \\
(4.9)\end{array}$ & $\begin{array}{l}162 \\
(90)\end{array}$ & n.r. \\
\hline $\begin{array}{l}\text { strip thickness } \\
\text { mm (in.) }\end{array}$ & - & $\begin{array}{c}1.3 \\
(0.05)\end{array}$ & $\begin{array}{c}1.3 \\
(0.05)\end{array}$ & $\begin{array}{c}1.3 \\
(0.05)\end{array}$ & $\begin{array}{c}1.5 \\
(0.06)\end{array}$ & - & - \\
\hline strip width & - & \multicolumn{4}{|c|}{ typically up to $150 \mathrm{~mm}$ (6 in.) } & - & - \\
\hline $\begin{array}{c}\mathrm{T}_{\mathrm{g}}^{4} \\
{ }^{\circ} \mathrm{C}\left({ }^{\mathrm{o}} \mathrm{F}\right)\end{array}$ & - & $149(300)$ & $149(300)$ & $149(300)$ & resin & $63(145)$ & - \\
\hline $\begin{array}{l}\text { shear strength } \\
\mathrm{MPa}(\mathrm{psi})\end{array}$ & - & - & - & - & - & $\begin{array}{c}24.8 \\
(3600)\end{array}$ & $\begin{array}{c}9.0 \\
(1300)\end{array}$ \\
\hline $\begin{array}{l}\text { bond strength } \\
\mathrm{kPa}(\mathrm{psi})\end{array}$ & - & - & - & - & - & $\begin{array}{l}\sim 20.7 \\
(\sim 3000)\end{array}$ & $\begin{array}{l}\sim 5.0 \\
(\sim 725)\end{array}$ \\
\hline \multicolumn{8}{|c|}{$\begin{array}{l}\text { Tepresentative data from single manufacturer (SIKA Corporation); a number of companies provide similar products } \\
2 \text { data from single manufacturer (Tyfo), there is only one known preformed GFRP product offered in the infrastructure market } \\
3 \text { traditionally, high modulus adhesive systems are used in strengthening applications; an example of a very low modulus adhesive is provided to } \\
\text { illustrate range of properties } \\
{ }^{4} \mathrm{~T}_{\mathrm{g}}=\text { glass transition temperature } \\
\text { n.r. = not reported }\end{array}$} \\
\hline
\end{tabular}




\subsection{REPAIR OF CONCRETE USING FRP MATERIALS}

In recent years, the application of FRP composites for the repair and retrofit of existing structures has increased significantly. The effectiveness of externally bonded FRP systems used as a retrofit for reinforced concrete structures in particular, has been well researched and documented. Such retrofits range from flexural and shear strengthening of beams and slabs to strengthening and seismic retrofit of columns. Originally, retrofit methods utilized FRP material simply as a replacement for steel. More specifically, the high strength-to-weight ratio and excellent corrosion resistance of FRP plates represented an attractive alternative to the heavy and awkward steel plate bonding methods of traditional retrofit techniques (Meier et al. 1993).

A significant amount of current research concerning reinforced concrete systems retrofitted with FRP addresses the bond mechanism. To ensure the effectiveness of the FRP, it is essential that the interfacial region be capable of transferring stress between the concrete and FRP. Failure of this interfacial bond is likely to occur either by debonding of the FRP or failure within the substrate (the concrete). The integrity of this bond can be upheld with certain quality control measures; however FRP-concrete systems are ultimately only as strong as the substrate concrete. Conversely, failure of the bond between FRP and steel is manifest largely through adhesive failure at the steel-FRP interface or cohesive failure in the FRP-itself owing to the considerable homogenous strength of the steel substrate. 


\subsection{APPLICATIONS OF FRP IN STEEL STRUCTURES}

\subsubsection{Strengthening Steel Structures}

In contrast to the large strides taken in reinforced concrete retrofit with FRP materials, there is comparatively little research concerning the use of FRP materials for retrofit of steel members. The majority of work performed in this area concerns the application of CFRP strips for flexural retrofit. Early research involved the application of CFRP materials for the repair of naturally deteriorated steel bridge girders (Mertz and Gillespie, 1996). Miller et al. (2001) report a field application of this concept involving the bonding of CFRP strips to the tension flange of a heavily corroded bridge girder in an attempt to increase the member's capacity. This study evaluated the rehabilitation of four heavily corroded steel girders using single layers of full length CFRP plates bonded to the top and bottom surfaces of the deteriorated tension flange. The girders were removed from a bridge spanning Rausch Creek in Schuylkill County, PA. An increase of $10 \%$ to $37 \%$ in elastic stiffness was reported for the four CFRP retrofit girders. In addition, a $17 \%$ to $25 \%$ increase in ultimate capacity was reported for two of the retrofit girders. This repair essentially restored the stiffness and capacity of the deteriorated girders to that of the undamaged girders. Miller et al. then applied this retrofit in a field installation to a bridge that carries I-95 over Christina Creek outside of Newark, DE. One girder was selected to be retrofit and load tested. It exhibited an $11.6 \%$ increase in flexural stiffness.

Another field application was reported by Chacon et al. (2004) on Delaware's Ashland Bridge which carries State Route 82 over Red Clay Creek. The Delaware Department of Transportation deemed the bridge structurally deficient and in need of rehabilitation. In addition to replacing the concrete deck, two floor beams were retrofitted with CFRP plates. Several 
diagnostic load tests before and after the retrofit showed a modest decrease in floor beam steel strains due to live load of 5.5\%. The authors concluded that thicker CFRP plates should provide further improvements.

Sen et al. (2001) studied the feasibility of using CFRP laminates to strengthen damaged composite steel bridge girders. The objective of the study was to develop a procedure for strengthening composite steel girders with CFRP laminates, evaluate the benefits of such a retrofit, and assess whether a non-linear finite element computer program can predict experimental results. Six composite steel bridge girders were investigated, three with 0.078 " ( 2 $\mathrm{mm})$ thick laminates, and three with $0.197 "(5 \mathrm{~mm})$ thick laminates attached to the bottom of their tension flanges. Although an appreciable increase in stiffness was not observed, the authors reported an increase in ultimate strength between $9 \%$ and $52 \%$, as well as a considerable extension of the elastic region of the section between $20 \%$ and $67 \%$. The larger increases correspond to the thicker 0.197 " $(5 \mathrm{~mm})$ CFRP laminates. The strengthening effect is largely confined to the post-yield region and is affected by better engaging the capacity of the composite concrete deck. The study concluded that much thicker laminates are needed to achieve significant strengthening, which may not be feasible given that the weakest link of the retrofit is the bond interface region, and that further research must be conducted concerning bond performance.

In attempt to strengthen undamaged composite steel beams, Tavakkolizadeh and Saadatmanesh (2003a) bonded one, three, and five layers of CFRP strips to their tension flanges. The CFRP retrofit resulted in up to $76 \%$ increase in ultimate load-carrying capacity; however the effect on the elastic stiffness was insignificant. Also, the efficiency of the CFRP decreased as the 
number of sheets increased. The steel strain in the tension flange was reduced by up to $53 \%$ in the post-elastic region although, a minimal effect was observed in the elastic region.

In a related study, Tavakkolizadeh and Saadatmanesh (2003b) investigated the effectiveness of repairing damaged composite steel girders with CFRP sheets bonded to the tension flange using epoxy. Similar to the previously mentioned study, the girders were strengthened with one, three and five layers of CFRP sheet; however prior to retrofit the steel girders were cut to simulate $25 \%, 50 \%$ and $100 \%$ loss of tension flange. The retrofit girders were loaded monotonically and achieved ultimate load-carrying capacities greater than that of the undamaged girder. Tavakkolizadeh and Saadatmanesh also reported significant improvement in the elastic stiffness, and a more pronounced affect on the post-elastic stiffness of the retrofit girders.

Al-Saidy et al. (2004) also studied the repair of damaged composite steel beams using CFRP plates. A portion of the composite beams' bottom flanges were removed to simulate both $50 \%$ and $75 \%$ damage. The repair scheme was also varied: the first scheme bonded CFRP plates to the bottom of the web of the W8x15 steel beam, while the second scheme also included CFRP plates bonded to the bottom (tension) flange. All six of the composite steel beams were tested monotonically in four-point flexure. Results indicated that about $50 \%$ of the elastic flexural stiffness of the damaged beams can be recovered and the original undamaged strength can be restored to damaged beams using bonded CFRP plates.

The majority of prior research utilized conventional modulus CFRP to strengthen and repair steel members. Dawood et. al. (2006a) and (2006b) of North Carolina State University studied the strengthening of composite steel bridges with high modulus CFRP (hmCFRP) materials which have recently become commercially available. These materials have a modulus 
of elasticity of approximately equal to and thus compatible with that of steel. This study included three phases: the first two addressing the feasibility of three different configurations of CFRP strengthening systems and the last addressed the behavior of strengthened composite beams under overloading conditions. It was determined that by doubling the reinforcing ratio, the elastic stiffness was essentially doubled, and the yield load approximately tripled, thus illustrating that increasing the reinforcement ratio of hmCFRP did not decrease the efficiency of the retrofit.

As noted in all the studies discussed above, the use of conventional CFRP to strengthen steel structures results in little improvement in the elastic range of behavior but great improvement in the inelastic range. This behavior is easily explained by considering transformed sections: when the steel is elastic, the addition of relatively small amounts of CFRP material has relatively little effect on the sectional properties (such as the moment of inertia). However as the steel becomes inelastic and its modulus becomes negligible, the now proportionally stiffer CFRP enhances the effective sectional properties considerably. This concept is the premise behind the concept of FRP-stabilized steel members.

\subsubsection{Fatigue and Fracture Repair of Steel with FRP}

The third phase of the previously mentioned Dawood et al. (2006a, 2006b) study investigated the fatigue durability of the hmCFRP strengthening system. Two different bonding techniques were studied: the first being the typical procedure of grit blasting, cleaning and solvent wiping of the steel prior to application of the adhesive and FRP ; the second procedure used the same method but increased the thickness of the cured adhesive layer and used a silane adhesion promoter. A third, unretrofit beam was also tested as a control. All three beams were subjected to fatigue loading resulting in a stress range in the tension flange of 17 to $29 \mathrm{ksi}$ (115 
to $200 \mathrm{MPa}$ ) for three million cycles at a frequency of $3 \mathrm{~Hz}$. None of the beams exhibited any signs of failure following the fatigue loading sequence. The strengthened beams exhibited a mean increase in deflection due to cycling of $10 \%$ while the control beam exhibitted a $30 \%$ increase. No significant difference was found between the two strengthened beams indicating that the bond technique had no effect for fatigue loading conditions studied.

The application of CFRP overlays for repair of fatigue cracks and increasing fatigue life was studied by Jones and Civjan (2003). The specimens consisted of 29 cold-rolled A36 steel bars subjected to either a center hole with crack initiator or an edge notch. Several different variables were measured for the retrofit including CFRP length, material, steel surface preparation, debonding at regions of crack initiation, and CFRP application after a crack was formed. Jones and Civjan concluded that the steel fatigue life increase with the application of CFRP overlays. It was conjectured that prestressing the CFRP would result in an even greater improvement in performance. The study demonstrated the importance of proper mixing of the epoxy materials, and determined that impregnating epoxies performed better than the paste epoxy material. The application of CFRP to an existing crack resulted in a $170 \%$ increase in remaining fatigue life, illustrating the effectiveness of this repair technique. It was also noted that the application of the overlays to only one side of the steel member, though it would be more convenient from a construction standpoint, introduced eccentric loading, rendering that retrofit arrangement ineffective.

The concept of increasing a member's fatigue life using CFRP plates bonded to steel girders was studied by Tavakkolizadeh and Saadatmanesh (2003c). The tension flanges of the steel beams were cut to simulate a fatigue crack and then retrofit with a CFRP patch. The fatigue loading scheme, a medium cycle fatigue study, included three separate stages: (1) start to 10,000 
cycles, (2) 10,000 to 100,000 cycles, or failure, and (3) 100,000 cycles to failure. The applied stress ranged from $10 \mathrm{ksi}$ to $55 \mathrm{ksi}(69$ to $379 \mathrm{MPa}$ ). For all specimens and stress ranges, the CFRP patch retrofit proved to significantly increase the member's fatigue life and arrest crack growth. The retrofit also aided in effectively upgrading the fatigue detail's AASHTO category from $\mathrm{D}$ to $\mathrm{C}$. The unretroffited specimens showed a decrease in stiffness when fatigue cracks grew to about $0.57 "(14.5 \mathrm{~mm})$. Conversely, the retrofitted specimens did not show a decrease in stiffness until the cracks were at least $0.885 "(22.5 \mathrm{~mm})$ long. The decrease in stiffness of the retrofit specimens was noted at much larger crack lengths when compared to the unretrofit specimens, and the crack growth rate decreased significantly as a result of the retrofit.

\subsubsection{Stability}

Recently, research has been conducted to investigate enhancing steel section stability using FRP materials. In this application, the high stiffness and linear behavior of FRP materials provides "bracing" against the manifestation of local buckling. This application is aimed at providing stability to the section in an attempt to constrain plastic flow, and can essentially be referred to as an FRP-stabilized steel section.

Ekiz et al. (2004) studied the effect of wrapping of a double channel member subjected to reversed cyclic loading with CFRP. The double channel member was chosen as a model of a chord member in a special truss moment frame and the CFRP wrapping was applied in an attempt to improve the plastic hinge behavior of the member. Four different specimens were tested including two unwrapped control members, one member partially wrapped in CFRP and one member fully wrapped in CFRP. The study determined that the application of CFRP significantly improved the structural behavior of the member by increasing the size of the 
yielded plastic hinge region, inhibiting local buckling, and delaying lateral torsional buckling. Both wrapping methods reduced strain demands, increased rotational capacity, and considerably increased the energy dissipation capacity in the plastic hinge region.

The effect of CFRP bonding to the slender webs of I-section steel beams in order to delay local buckling was investigated by Sayed-Ahmed (2004). This concept was numerically investigated using the finite element technique for four different I-sections of varying web thickness. Two of the I-sections qualified as compact sections, while the remaining two were classified as non-compact sections controlled by local bucking of the web before achieving the plastic moment and yield moment respectively. CFRP strips of constant length and width were applied at the mid-height of the web mimicking the configuration of mid-height steel stiffeners for plate girders. Sayed-Ahmed reported an increase in critical buckling load from $20 \%$ to $60 \%$ with a $2 \%$ to $9 \%$ increase in the beam's ultimate strength. Analytically, Sayed-Ahmed assumed that the presence of the mid-height CFRP served as a nodal restraint and the results stemmed from this assumption. It is unlikely that such "perfect" restraint would be affected in a physical application. Nonetheless, the concept of FRP-stabilization of a steel member was introduced.

Shaat and Fam (2004) focused on the increase in axial strength and stiffness of short hollow structural square (HSS) steel columns using CFRP wraps. The parameters studied included the number of CFRP layers, fiber orientation, and type of CFRP (one possessing a higher modulus and the other with a larger thickness). Each specimen was cut to a height of 6.89" $(175 \mathrm{~mm})$ and exhibited post-yielding buckling failure when loaded concentrically. Results indicated that wrapping the members with transversely oriented CFRP is most efficient for increasing axial load capacity, while CFRP oriented longitudinally is more efficient for increasing the elastic stiffness of the member especially when it is confined by an outer layer of 
transverse CFRP. Additionally, the thicker CFRP material resulted in better strengthening, despite the other CFRP material having a higher modulus. Axial load capacity increase ranged from $8 \%$ to $18 \%$ while the stiffness increase ranged from $21 \%$ to $28 \%$

A follow-up study by Shaat and Fam (2006) addressed long, non-slender HSS steel columns and the effect of CFRP sheets on their local and global bucking behavior. Five long columns, measuring 93.7" (2380 mm) in length having a slenderness ratio of 68 were tested. The columns included one unretrofit control specimen, specimens strengthened with one, three and five layers of CFRP respectively on two sides, and one specimen strengthened with three layers of CFRP on all four sides. The authors reported a $13 \%$ to $23 \%$ increase in axial strength that showed no correlation with the number of CFRP strips applied. The authors attribute the lack of correlation to variation among specimens caused by out-of-straightness of the specimens themselves as well as minor misalignment within the test set-up. After quantifying these initial imperfections, it was observed that, as expected, larger initial imperfections correspond to a lower peak load. Failure of the long HSS sections was due to global buckling followed by local buckling. The study concluded that further research should be conducted on thin-walled sections having larger $\mathrm{b} / \mathrm{t}$ ratios.

The proposed application of the work presented in this thesis document differs from previous work in its objective of strategically locating modest amounts of FRP on a steel cross section to control the manifestation of local buckling in a steel brace member. Under the large cyclic demands imposed on a braced frame during a seismic event, it is essential that local buckling be controlled to allow for greater energy dissipation within the system. The application of FRP as a retrofit measure for braces subjected to seismic loading is an attractive and practical alternative to current retrofit practices. This subject is visited later in this chapter. 
The current proposed work is a follow-up to a preliminary analytical study performed by Accord et al. (2005 and 2006). Accord et al. performed an analytical study using nonlinear finite element modeling to investigate the effects that bonded low-modulus GFRP strips have on the inelastic cross-sectional response of I-shaped sections that develop plastic hinges under a moment gradient loading. The chosen cantilevered I-shaped section had a flange width and thickness of $b=5.98 "(152 \mathrm{~mm})$ and $t_{\mathrm{f}}=0.394 "(10 \mathrm{~mm})$, a web thickness of $t_{w}=0.25 "(6.4$ $\mathrm{mm})$, a depth of $\mathrm{d}=15$ " $(381 \mathrm{~mm})$ and was $150 "(3810 \mathrm{~mm})$ long. The 1" $(25 \mathrm{~mm})$ wide by $0.25 "(6.4 \mathrm{~mm})$ thick GFRP strips were located on the top and bottom of the compression flange. The length and cross-sectional location of the GFRP were varied in the study. The steel I-section was modeled using 4-node nonlinear shell finite elements; 8-node continuum elements were used to model the GFRP and adhesive interface.

Accord et al. subjected the model cantilever beam to a concentrated load at its free end and measured deflection, rotation and fixed-end moment. This study determined that the presence of the GFRP strips enhanced the structural ductility of the cross-section as shown in Figure 2.1. The GFRP strips essentially provided continuous bracing of the compression flange inhibiting the formation of local buckling. As the transverse location of the GFRP strip was moved toward the flange tips a greater structural ductility was observed reflecting the strip's increased efficiency as a bracing element against plate buckling. It must be noted that through the work of Accord et al., "perfect" bond was assumed between the GFRP and substrate steel. Although adhesive and GFRP stiffness and thus deformation was modeled, no slip relationship was imposed at the cross section. Thus the results represent an idealized condition. Nonetheless, the current experimental program presented in this thesis leverages some of the analytical results 
of Accord's work by applying FRP strips to bracing elements to improve local buckling resistance.
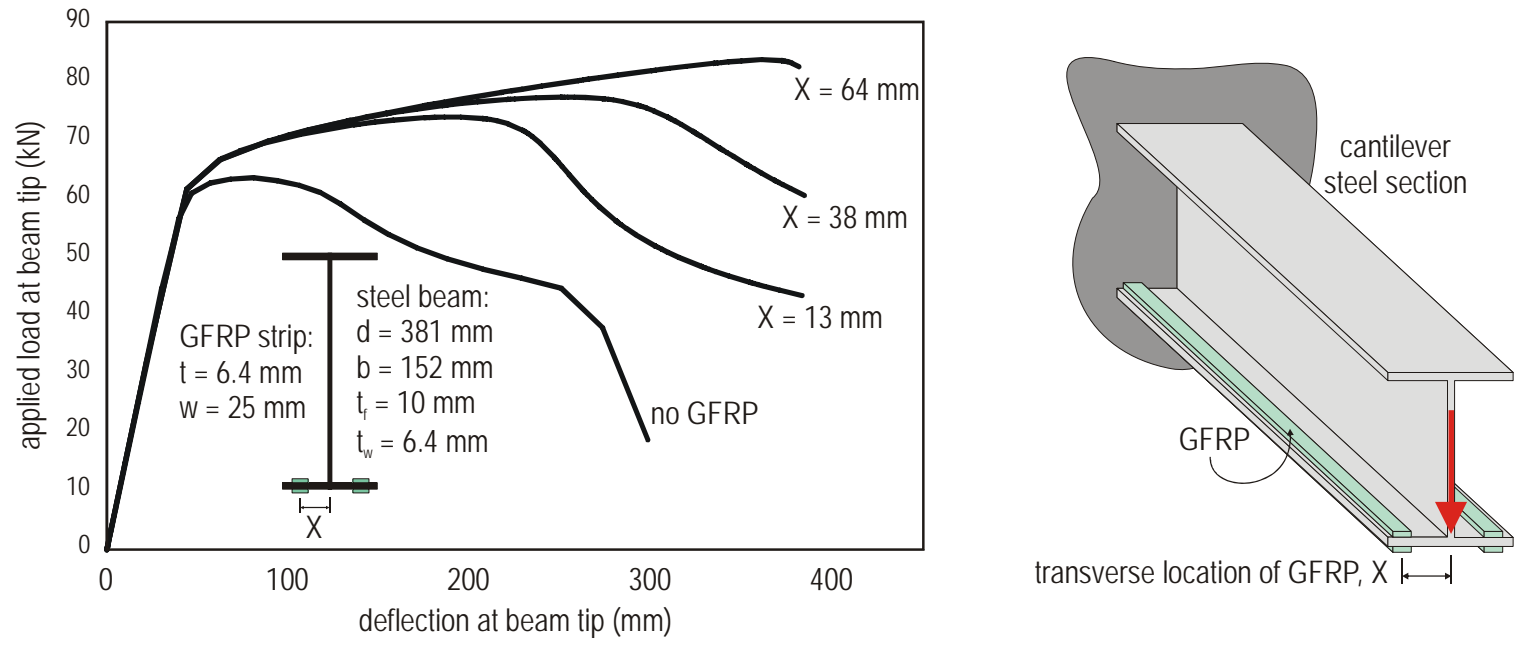

Figure 2.1 Analytical load-deflection behavior of GFRP stabilized steel cantilever (Accord et al. 2005)

\subsection{LIMITATIONS TO THE USE OF FRP RETROFIT MEASURES FOR STEEL}

Joints or connections in civil engineering applications must maintain their continuity while exposed to harsh environments and loading conditions. The service life of FRP-steel composite retrofit measures depends on the durability and strength of the bond. Some of the challenges and limitations associated with bonding FRP to steel include ensuring proper substrate preparation, strength and durability of the adhesive, bond length, effects of environmental exposure, and the potential for galvanic corrosion. As previous research indicates, all of these potential barriers are becoming better understood and can be avoided by taking caution with a few key steps. 
An effective bond to steel requires adequate substrate preparation. Such preparation starts with abrasive blasting of the steel substrate followed closely by application of a primer to prevent corrosion and contamination (Cadei et al. 2004). This primer is often a silane which is thought to act as an adhesion promoter by enhancing the chemical interaction between substrate and adhesive. Promotion of adhesion notwithstanding, it is generally agreed that silanes are effective as corrosion inhibiters and can protect the adherend's surface until bonding takes place (Hollaway, 2005). Schnerch et al. (2005) asserts that grit blasting is the most effective means of surface preparation, and that grit size does not affect the initial joint strength or long-term durability.

Bond defects present significant limitations to the application of steel-FRP bonded joints. In addition to surface preparation deficiencies, these defects include voids and porosity and thickness variation in the bond layer (Holloway, 2005). Defects in the adhesive at the end of a strengthening plate can be very detrimental to the effectiveness of the retrofit (Stratford and Chen, 2005). Uniform pressure must be applied to the FRP strip when bonding to steel to ensure uniform adhesive thickness and to mitigate the presence of air pockets within the adhesive. Stratford and Chen (2005) suggest modifying the geometry of the FRP plate and adhesive at the end of the plate to reduce maximum adhesive stresses. Various fillet details are discussed and assessed in this work. However, experience in the realm of FRP-concrete retrofits suggest that simply extending FRP materials beyond the location where such end-peeling stresses are critical or providing positive anchorage (Quattlebaum et al. 2005) is a preferable alternative to providing oftentimes complex details at the FRP termination.

The integrity of a steel-FRP retrofit application is contingent upon the strength of the bond. Several studies have been performed to better understand and quantify the bond 
mechanism between steel and FRP materials. Holloway (2005) reported on the advances in bonding FRP composites to metallic structural materials, specifically steel. This study investigated the cases of 1) FRP prepegs bonded on site with adhesive films under controlled curing conditions; and 2) preformed FRP plates bonded with a conventional two-part adhesive resin (as is done in the present study). The strength of the resulting bonds were tested using double strap butt joints and a flexural retrofit test was performed using FRP bonded to geometric shapes using adhesive film only. Holloway concluded that the adhesive film performed well compared to the two-part adhesive system exhibiting higher failure loads. Additionally, the flexure tests showed good bond strength and residual strength of the CFRP/GFRP retrofit combination.

Several different failure modes of steel-FRP composites have been identified. These include rupture of the laminate at its ultimate strength, debonding at the end of the laminate (end peel), debonding failure at the middle of the laminate, and inter-laminar FRP failure at the end of the laminate (Al-Emrani et al. 2005). Holloway (2005) also describes a cohesive failure within the adhesive, which, along with an inter-laminar FRP failure, is suggested to be failure indicative of a well-bonded composite joint. Xia and Teng (2005) studied the behavior of FRP-to-steel bonded joints through a series of single shear pull-off tests. The type and thickness of the adhesives were varied in the test program. Results indicated that for a thicker adhesive layer (greater than 0.79 " $(2 \mathrm{~mm})$ ) brittle failure by plate delamination is likely to occur. When using a more realistic adhesive thickness (less than 0.79 " $(2 \mathrm{~mm})$ ) a ductile failure within the adhesive layer is more likely. The strength of joints that experience debonding failure is very close to the tensile strength of the adhesive itself. Interfacial fracture energy, however, depends on the ultimate tensile strain of the adhesive and the thickness of the adhesive layer. 
Liu et al. (2005) studied the behavior of CFRP-steel bonded joints subjected to fatigue loading. Three layers of CFRP material were applied as double strap joints and subjected to a prescribed number of fatigue cycles ranging from 0.5 million to 6 million at different amplitudes. Fatigue failure was not observed when the applied load was less than $40 \%$ of the ultimate static strength, and the influence of the fatigue conditioning was not significant when the applied load was less than $35 \%$ of the ultimate strength. Failure modes were either debonding or rupture, the latter being attributed to the use of high-modulus CFRP.

Research regarding the development length of the steel-FRP composite bond has also been performed. Nozaka et al. (2005) investigated the effective bond length of CFRP strips bonded to cracked steel bridge girders and presented an equation to estimate the effective bond length for that particular application. The experimental test setup consisted of a W14x68 section with an additional steel plate bolted to the bottom flange for ease of CFRP removal upon test completion and reuse of the test setup. Variables in this test included CFRP and adhesive material, crack width, bond configuration and bond length. The retrofit consisted of one to three layers of CFRP spanning the crack. Effective bond lengths were determined for specific FRP and adhesive material combinations. Ultimately, the authors determined that adhesives with the highest shear ductility are necessary to achieve high strains in the CFRP strip. The effective bond length before failure can be described as the sum of the bond length where the adhesive has yielded and the length over which the adhesive is carrying load and remains elastic. The authors developed an analytical as well as numerical method to predict the tensile strain distribution within a CFRP strip and the results correlated well with those obtained experimentally. They concluded that if the ultimate shear strain of the adhesive is known, it is possible to estimate the effective bond length. 
Any retrofit measure must address the potential for environmental conditions to affect the behavior of the system. Recognizing that bond durability is integral to the success of a steel-FRP retrofit scheme, Karbhari and Shulley (1995) studied the durability of a composite bond subjected to various environmental schemes, including synthetic sea water, hot water, roomtemperature water, freezing, freeze thaw, and ambient conditions. Five different fiber types were tested, three carbon and two glass. A wedge test was performed to create a high stress concentration at the bond interface between the steel and the FRP material. The wedge was inserted into the bondline and crack length was measured at various points within seven days. Evaluation of the performance in each environment of the various fiber materials indicated that the environmental durability not only depends on the characteristics of the adhesive, but the fiber composition as well. An S-glass system was found to be the most durable within the environments tested. The hot-water environment was the most detrimental environment, while the environment where the bond remained most durable was the subzero environment. Freezethaw environmental loading also had substantial effect on the bond, creating cracks that allowed the ingress of moisture within the bond layer.

Yang et al. (2005) investigated the bond strength and durability between CFRP and steel when exposed to various environments including man-made seawater and a hot/wet cycle. Several different adhesives and types of FRP plates were subjected to both of these conditions. Shear stresses of the joints submerged in seawater decreased significantly with time. The author presented a bilinear model to predict the shear stress of the CFRP-steel bond as a function of the time exposed in seawater. The effect of the hot/wet cycle was determined to be contingent upon three factors. First, the high temperatures aided in completing the chemical bonding reactions more quickly. Second, the presence of water on the steel surface results in a decline of bond 
strength. Finally, the difference in thermal expansion coefficients for steel, adhesive, and FRP results in a cyclic thermal stress applied to the bond that is disproportionate between the three constituents. The overall effect of the hot/wet cycle is determined by the combination of these three factors, and the contribution of each determines whether the result is to increase or decrease bond strength. In the experiments reported, an increase in shear strength was reported for the joints subjected to the hot/wet cycle.

Galvanic corrosion occurs when two dissimilar conducting materials having sufficient difference in potential are in direct electrical contact and exposed to an electrolyte. The electrolyte can be seawater or simply surface moisture on one of the materials. The potential difference is a measure of how noble the material is, the less noble material becoming the anode while the more noble material is the cathode, ultimately forming a corrosion cell. Carbon is a very noble material and acts as the cathode driving the corrosion of the steel substrate. The prevention of galvanic corrosion can be achieved by electrically isolating the two materials from each other. Although the adhesive material can effectively isolate the two materials, this is most often achieved by including a GFRP layer between the steel and carbon. Schnerch et al. (2005) point out that the GFRP layer may be less durable than the adhesive itself due to its susceptibility to attack from salts and moisture. Also, after a few years, the GFRP materials may become worndown and less effective in preventing corrosion. Schnerch et al. suggests that further investigation should be conducted to monitor the effectiveness of the GFRP layer as an insulator. 


\subsection{BUCKLING RESTRAINED BRACED (BRB) FRAMES}

\subsubsection{Braced Frames}

In the past, steel-framed structures were considered to exhibit excellent performance when subjected to seismic loading, due to the ductility of the material and members. However, our understanding of steel structure behavior was proven inadequate following the 1985 Mexico City earthquake and more recently, the 1994 Northridge and the 1995 Hyogo-ken Nanbu (Kobe) earthquakes. The damage to steel structures during these earthquakes included structural collapse as well as brittle weld fractures in beam to column connections in moment-resistant frames. One effect of these disasters was accelerated research efforts investigating the enhancement of braced frame structures as an alternative structural system. Although significant research was performed to study the behavior of bracing components within braced frames in the 1970s and 1980s, current research is underway to develop innovative methods of improving their seismic performance.

Braced frames were originally designed to resist wind loading. Typically, these frames were designed in conjunction with masonry-infilled frames and moment frames to provide lateral load resistance (Bruneau et al., 1998). Virtually none of the lateral load is carried by the beamcolumn connections in a braced frame, rather, the system relies on the axial forces developed in its bracing members. Bracing systems advanced in the 1960s and 1970s in terms of seismic applications and have long been regarded as an economical alternative to moment frames due to the reduced material requirements and ease of fabrication and erection resulting in lower labor costs. These systems also provide an efficient restriction of lateral frame drift which was realized following the 1971 San Fernando earthquake (Bruneau et al., 1998). 


\subsubsection{Concentrically Braced Frames}

The braces of a Concentrically Braced Frame (CBF) are positioned such that their lines of action intersect the center line of the beam-column connections forming a vertical truss system. This system possesses a high elastic stiffness that is achieved through the development of internal axial forces in the bracing members. The key components of a $\mathrm{CBF}$ are the diagonal bracing members and their connections. Figure 2.2 illustrates common CBF configurations.

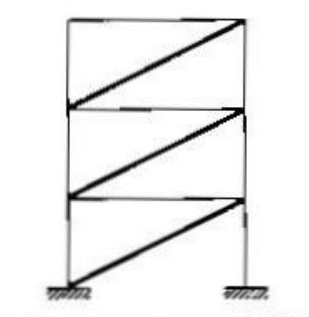

a. Diagonal braced CBF

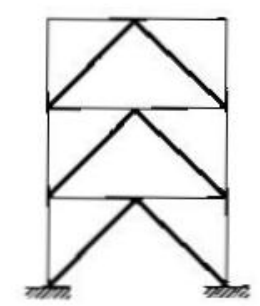

b. Inverted V-braced CBF

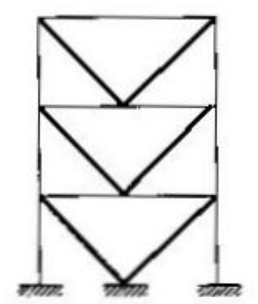

c. $\mathrm{V}$-braced CBF

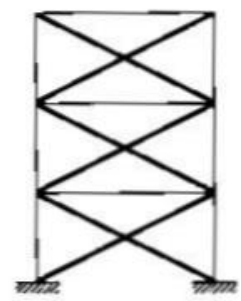

d. X-braced CBF

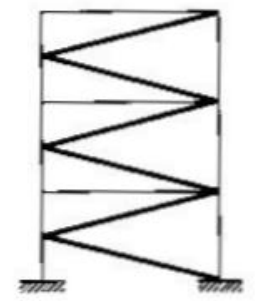

e. K-braced CBF

Figure 2.2 Common CBF configurations

(Bruneau, 1998)

In the past, CBFs have not performed well during seismic events. The system's poor behavior is a result of the significant inelastic deformations in the post-buckling range seen in the bracing members and their connections. The performance of a CBF is defined by the hysteretic energy dissipation capacity of its braces. 


\subsubsection{Desired Hysteretic Behavior During Seismic Events}

In order to understand the desired behavior of a braced frame during a seismic event, it is essential to understand its hysteretic behavior. The area under the P (axial load) versus $\delta$ (axial deformation) curve for a brace subjected to cyclic loading indicates the amount of hysteretic energy the member can dissipate. Figure 2.3 illustrates sample hysteretic behavior of a bracing member (Bruneau et al., 1998). In Figure 2.3 the axial load (P), axial deformation ( $\delta$ ), and lateral displacement at mid-length $(\Delta)$ are utilized to express this behavior.

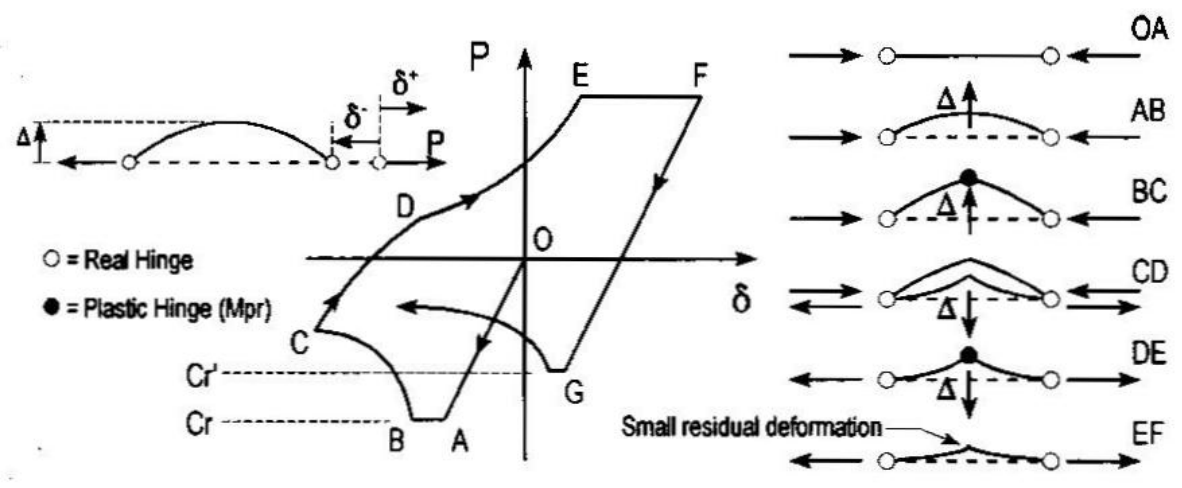

Figure 2.3 Sample hysteresis of brace under cyclic loading (Bruneau et al., 1998)

Adhering to the convention of compressive forces being negative, the plot initiates at point $\mathrm{O}$ and the brace is compressed elastically. Buckling occurs at point $\mathrm{A}$, and assuming a sufficiently slender member, the brace will deflect laterally at that sustained load (illustrated by the plateau $\mathrm{AB}$ ). At point $\mathrm{B}$ a plastic hinge forms in the member when the brace meets its point of maximum transverse displacement and plastic moment. A further increase in axial displacement results in a corresponding increase in $\Delta$ as the plastic hinge is rotating (segment $\mathrm{BC}$ ). Notice the residual axial deflection that remains upon unloading (point $\mathrm{C}$ to $\mathrm{P}=0$ ). The brace is then loaded elastically in tension to point D where a "kink" is formed. From point D to E 
the reverse plastic hinge is rotating, reducing a part of the kink $(\Delta)$ (although this kink will never be fully recovered) left from point $\mathrm{C}$. This allows for the loading to continue past $\mathrm{D}$ until the axial force in the brace reaches its tensile yield capacity. When the brace is reloaded in compression, the residual lateral displacement $(\Delta)$ serves to reduce the compressive buckling capacity of the brace (point G). The remaining buckling capacity of the brace is defined as follows.

$$
C_{r}^{\prime}=\frac{C_{r}}{1+0.50\left(\frac{K L}{\pi r} \sqrt{\frac{0.5 F_{y}}{E}}\right)}
$$

Where $\mathrm{C}_{\mathrm{r}}=$ first buckling load of bracing members (point $\mathrm{A}$ in Figure 2.3); $\mathrm{KL} / \mathrm{r}=$ slenderness ratio of the brace; $\mathrm{F}_{\mathrm{y}}=$ yield stress of brace; and $\mathrm{E}=$ Young's modulus. Note that with subsequent inelastic cycles this maximum compressive load decreases. This equation is based largely on the slenderness ratio. However, in a study performed by Lee and Bruneau (2005), the question of the utility of slender braces to impose global buckling and avoid damage to braces in compression was examined. Lee and Bruneau collected previous experimental data quantifying the energy dissipation of braces in compression and their loss of compressive strength over large axial displacements. After normalizing the data it was apparent that the energy dissipation capacities of braces characterized by moderate to high slenderness ratios (described as intermediate or slender braces) are very similar. This would suggest that reliance on the energy dissipation capacity of a compression brace is effective only for very low KL/r values (described as stocky braces) but may be overly optimistic for braces having more common slenderness ratios. The investigation also concluded that tubular bracing members suffer the least degradation of compressive strength and normalized energy dissipation while this behavior was most severe for the $\mathrm{W}$-shaped braces with a $\mathrm{KL} / \mathrm{r}$ above 80 . This study is one of many 
investigations, both experimental and analytical, conducted over the last 25 years concerning the inelastic behavior of bracing components. These studies resulted in the identification of three major parameters affecting the hysteretic behavior of bracing members including slenderness ratio $(\lambda)$, end conditions, and section shape.

A slender brace, having a high slenderness ratio $(\lambda=\mathrm{KL} / \mathrm{r})$ will have a large tension to compression capacity ratio. Slender braces also dissipate less energy as represented by smaller areas contained within the load-displacement hysteretic response (Figure 2.3). Given that slender braces exhibit little stiffness in a buckled configuration, the stiffness of slender concentric braces will decrease significantly following brace buckling. The tensile straightening following buckling of the brace can produce an impact loading that could lead to brace damage or connection failure (CSA, 2001). Additionally, repeated inelastic deformation of the brace imposes permanent deformations that cannot be relieved with the removal of the load. Inelastic deformation demands lead to increased local buckling, which under cyclic loading will result in decreased fracture life of the brace. Early brace fractures have led to story drifts of 6-7\% which lead to excessive ductility demands placed on the beams and columns as well as possible collapse (Goel, 1998).

A study by Black et al. (1980) investigated the hysteretic behavior of axially loaded steel struts of varying shape, slenderness ratio and end conditions. This study served as a basis for the understanding of brace cyclic behavior. Slenderness ratios considered ranged from 40 to 120 and the shapes included W shapes, double-channel sections, double-angle sections, WT sections and round and square tubes. End-connection details considered were both ends pinned or one pinned and one fixed. All specimens were subjected to axial load reversal cycles. Black et al. (1980) concluded that the maximum compressive loads deteriorate more rapidly for slender members. 
Further, the effective length factors, which are a function of end connections, reasonably predict behavior for cyclically loaded members in the inelastic range. The authors also determined that the hysteretic performance is somewhat influenced by cross-sectional shape, depending on the members' susceptibility to lateral-torsional buckling and local buckling. In order of increasing performance, starting from the least effective, the five shapes tested were double angle, WTsection, W-section, HSS sections, and thick walled tubular HSS Section.

Several major problems associated with concentric bracing systems limit their effectiveness in resisting seismic forces in the inelastic range. First, a braced structure is initially stiffer than other systems and therefore will attract a greater proportion of seismic forces. As previously mentioned, the hysteretic loops of CBF braces deteriorate with the number of cycles decreasing their ability to dissipate the seismic energy applied to the system. Also, the system has an inherent low redundancy and risks premature brace failure and fracture. CBFs are also susceptible to soft-story response in which earthquake damage is concentrated in a few stories due to the system's limited ability to redistribute inelastic demands throughout the height of the structure. Nonetheless, significant strides have been made over the past 25 years to enhance the performance and ductility of CBFs and are illustrated by the recently enhanced provisions for design requirements (AISC 2005).

The AISC Seismic Provision for Structural Steel Buildings (2005) identifies two categories of concentrically braced frame systems: Special Concentrically Braced Frames (SCBF) and Ordinary Concentrically Braced Frames (OCBF). Design provisions promulgated prior to 1997 provided only provisions for what is now referred to as ordinary concentrically braced frames. OCBFs are designed with slightly higher loads than SCBFs due to an inherently lower ductility of the system as outlined above. SCBF systems require special design measures 
to ensure stable and ductile behavior during a seismic event. Design codes place an emphasis on increasing brace strength and stiffness by use of a higher design forces aimed at minimizing inelastic demands. Width-to-thickness ratios are also kept within a smaller range to delay the onset of local buckling, ultimately increasing the fracture life of the brace. To avoid an unsymmetric response of the structure, tension-only X-braces and diagonal bracing (Figure $2.2 \mathrm{~d}$ and a) are not permitted for use in SCBF. Design of chevron-braced SCBF (Figure $2.2 \mathrm{~b}$ and c) must carefully consider the possibility of development of out-of-balance forces on the beams when the compression braces buckle and become ineffective. Similarly, K-braced frames (Figure 2.2 e) are not permitted for any seismic application due to the likelihood of unbalanced forces being applied to the column which can lead to very global structural stability effects.

While new code requirements have been implemented for CBFs, alternative bracing systems have been proposed and researched that utilize the inherent advantages and address the limitations of OCBF and SCBF under cyclic loading. The goal of these systems is to attain a more stable and full hysteretic behavior, limit lateral deflections and increase the fatigue life of the braces. Alternative brace systems include the use of friction energy dissipaters in the form of bolted connections or specially designed devices having a prescribed load at which they begin slipping, thus dissipating greater amounts of energy. Similarly, energy-dissipating devices, such as visco-elastic dampers designed to yield in shear, have been applied at the apex of chevron bracing. Brace fuse systems and "weak gusset-strong brace" designs have been proposed as a means of forcing the buckling damage away from the brace. All of these systems are summarized in Tremblay (2001). Each of these systems increases performance by imposing the damage on members other than the brace itself. Rather, the Buckling Restrained Brace system seeks to develop the brace's full compressive capacity through large inelastic deformations. 


\subsection{BUCKLING RESTRAINED BRACES}

The idea of Buckling Restrained Brace (BRB) frames was born from the need to enhance the compressive capacity of braces while not affecting the stronger tensile capacity in order to produce a symmetric hysteretic response. A BRB consists of a core steel brace encased in a (typically) steel tube that is filled with concrete or grout. The concrete fill is effectively debonded from the brace thus effectively restraining lateral and local buckling of the brace over its entire length without increasing the nominal capacity (squash load) of the brace. Imposing restraint on the buckling of braces sustains the integrity of a brace under cyclic loading. The ideal hysteretic behavior is achieved by allowing the core brace to deform longitudinally independent of the encasing system. This ultimately allows the brace to attain large inelastic capacities, thus dissipating the seismic energy and allowing the remainder of the structure to remain elastic. This conceptual behavior of conventional and BRB braces, showing the difference in hysteretic behavior is illustrated in Figure 2.4.
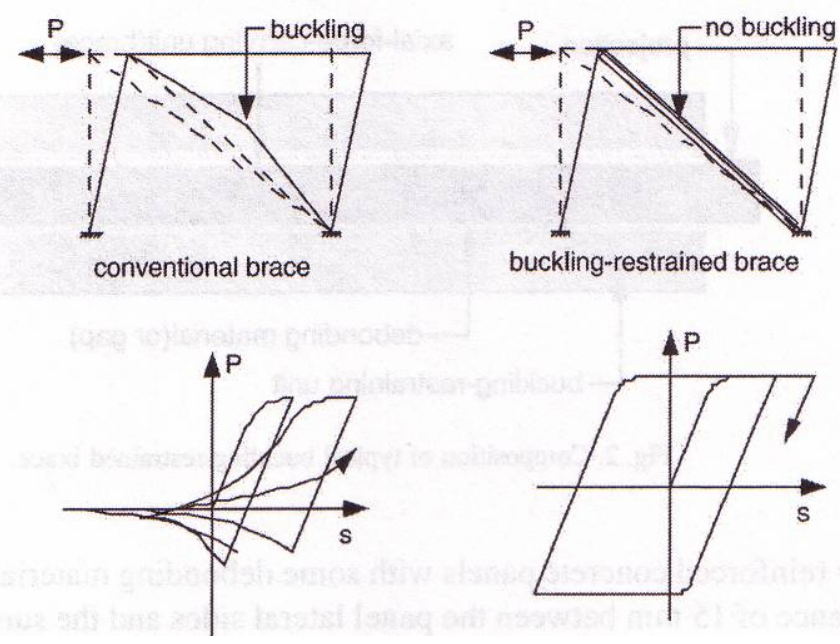

Figure 2.4 Behavior of Conventional Brace and BRB

(Xie, 2004). 
The concept of BRBs was first researched over 30 years ago. Yoshino et al. (1971) tested flat steel plates encased in reinforced concrete panels separated by debonding materials; a system referred to as "shear wall with braces". Yoshino et al. concluded from this study that a shear wall with spacing provided between the reinforced concrete wall and the steel plates exhibited higher energy dissipation capacity than a shear wall without any spacing. In effect, the steel plate cannot act compositely with the concrete wall, rather it must be debonded to develop its full capacity. Wakabayashi et al. (1973a and 1973b) studied the combination of reinforced concrete panels and steel plates separated by an unbonded layer. This led to the further investigation of testing debonding materials, and performance tests of reduced-scale brace systems and large scale twostory frames with the proposed brace systems.

The first test of steel braces encased in steel tubes, rather than concrete panels, was conducted by Kimura et al. (1976). The testing of these steel braces in mortar-filled square steel tubes without any debonding material demonstrated initial restraint of buckling, however, the transverse deformation of the mortar left permanent void spaces which eventually became large enough to allow local buckling of the brace.

Utilizing the concept of an unbonded brace, Mochizuki et al. (1979) studied braces encased in reinforced concrete square cross-section members. This study concluded that under repetitive loading the concrete lost a significant amount of its capacity for buckling restraint after the concrete cracked. Eventually the concept of utilizing a debonding material was effectively applied by a team of investigators in Japan (Watanabe et al. 1988; Wada et al. 1989; Watanabe and Nakamura 1992) and resulted in the BRB known in Japan as the "Unbonded Brace". These braces are used widely in Japan today and consist of four key parts: the brace to carry axial force, a stiffened transition section between the connection and the brace, a buckling restraining tube to 
encase the brace and prevent buckling, and a separation phase between the brace and bucklingrestraint filled with a debonding material (Xie, 2004). Figure 2.5 illustrates the components of an unbonded brace. Figure 2.6 shows a number of such braces awaiting testing at the Japanese EDefense shake table facility.

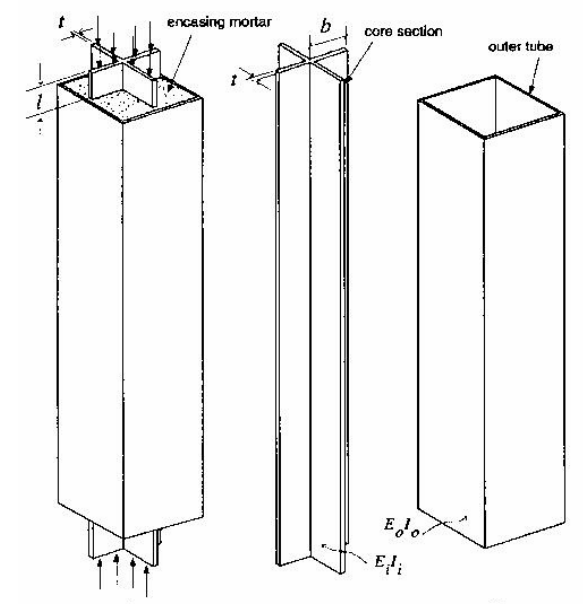

Figure 2.5 Schematic of unbonded buckling-restrained brace and its components (Black et al., 2004).
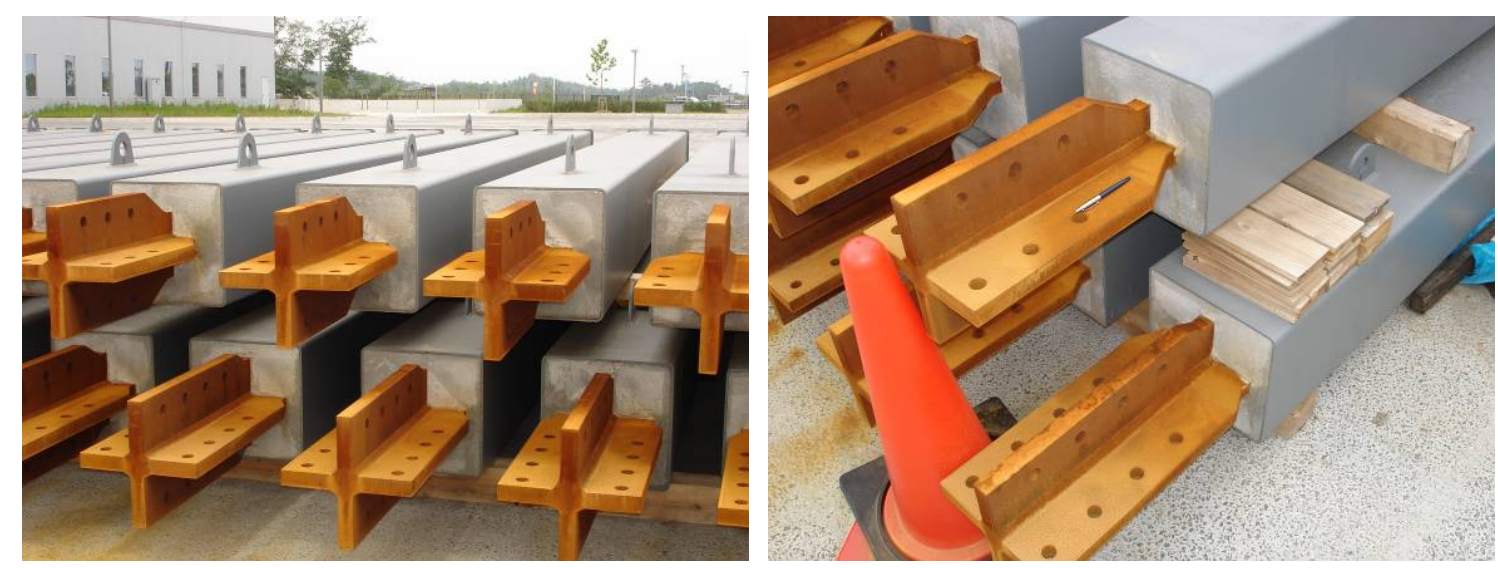

Figure 2.6 Unbonded braces (BRBs) awaiting testing at E-Defense (photos: Harries).

Figure 2.7 illustrates several different configurations of BRB including mortar-filled steel tubes (a), reinforced concrete steel tubes (b), and built-up members ( $\mathrm{d}, \mathrm{j}, \mathrm{k}, \mathrm{l})$ among others. It is 
noted that sections (e)-(i) utilize no infilling material. Currently, the most common configuration used in the United States is similar to (1), while Japanese practice favors (c), as shown in Figure 2.6.

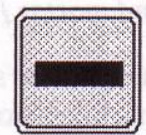

(a)

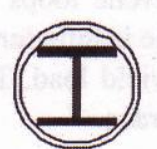

(e)

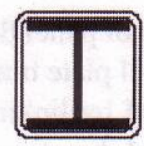

(i)

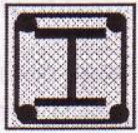

(b)

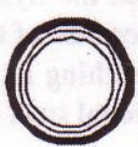

(f)

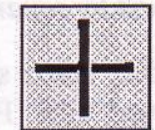

(c)

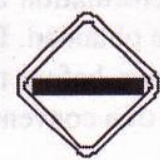

(g)

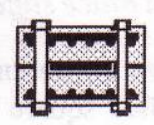

(d)

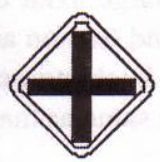

(h)

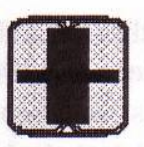

(I)

Figure 2.7 Cross-sections of BRB (Xie 2004).

In the design of a BRB, several key aspects must be addressed. In order to allow the restraint mechanism to affect only the lateral and local buckling of the brace, sufficient separation must be provided between it and the brace core. This will ensure that the brace core can slide freely inside the restraint mechanism when axial loading is applied. That is to say there is no strain compatibility across the brace core-confining material interface. This requires the use of a debonding material. Several options for debonding materials have been proposed including epoxy resin, silicon resin, vinyl tapes and combinations of these. The gap between the brace member and encasing material should also be considered to allow for transverse expansion of the brace (Xie, 2004). It is also important to address local buckling of brace projections. The projecting steel core length is relatively short (see Figure 2.6) so that the steel core can typically support an axial compressive stress as large as the yield stress (Black et al. 2004). In typical tube BRBs, enlarging the moment of inertia of the projections of the brace by changing or enlarging 
the brace cross-section, or adding stiffening plates to the core braces will address this issue (Xie, 2004).

The 2005 AISC Seismic Provisions (hereafter referred to as the Provisions) define buckling restrained braced frames (BRBF) and address design specifications pertaining to the design of these in Chapter 16 and Appendices R and T. This is a new addition to the Provisions and is based on the provisions recommended by Sabelli (2004). They state that BRBFs ductility and energy dissipation is comparable to that of a special moment frame (SMF), while their stiffness is close to that of an Eccentrically Braced Frame (EBF). This is truly the optimization of behavior: high energy absorbing capability in a stiff (and thus damage resistant) system. This excellent behavior is reflected in the Provisions recommended Response Modification Factor (R), which is suggested, in the absence of code-specified factors, for BRBF to be 7 or 8 , similar to those values specified for EBFs and SMFs. The Provisions require brace testing before utilization to qualify their behavior during a design earthquake under the performance requirements of the Provisions. Consistent with ASCE 7 (ASCE, 2002) and the 2003 NEHRP Recommended Provisions (FEMA, 2003), a minimum 2 percent story drift is required for detailing. Also, an adjusted brace strength is necessary for member and connection design. This adjustment is made through the application of a compressive strength adjustment factor, $\beta$, and a strain hardening adjustment factor, $\omega$. The Provisions also provide guidelines concerning the core of the braces, testing of the braces, bracing connections and configurations, beams and columns within the system, and splices. 


\subsection{SEISMIC APPLICATIONS OF BRBS}

\subsubsection{Performance Based Aspects}

In recent years, the high economic cost and social losses resulting from major earthquakes have forced earthquake engineers to evaluate the objectives of earthquake resistant design. Conventional building codes (ICBO 2003, for instance) do not attempt to limit damages to the structure and its non-structural components, and state expectations of performance without any guarantees. The intent of the current building codes in terms of seismic design is to prevent the loss of life and to maintain safety. The codes provide minimum acceptable standards without guidance on optimization of structural systems or structural materials, making it difficult to assess operational or financial risk. A new paradigm of earthquake-resistant design, termed Performance Based Design (PBD), has been adopted by the US Federal Emergency Management Agency (FEMA) as the next logical step to account for various limits of structural and nonstructural failure and to better illustrate the expected performance of the structure during a seismic event. The development of BRBF systems is largely based on a performance-based approach rather than a more traditional strength-based design approach. Similarly, the partial buckling restrained braces introduced in this work are founded in PDB objectives.

Performance-based design is an approach to structural design based on a consensus of performance goals and objectives. This method of design is the emerging leader for future design codes due to the availability of highly-technical analysis tools and advanced computational capabilities. It is a more in-depth method of risk management that extends the code's single

requirement of life safety performance to include a spectrum of other performance-based objectives and goals. Much like now-conventional LRFD design methods, PBD seeks to address 
the serviceability state as well as the failure state. The objectives are measured based on predetermined performance levels when the building is subjected to several different earthquake scenarios. Performance levels are specified for both structural and non-structural components. The combination of desired performance levels determines the building performance level. Table 2.2, from FEMA 356 (2000), illustrates the spectrum of building performance level designation.

Table 2.2 Table C1-8 of FEMA 356, Target Building Performance Levels and Ranges

\begin{tabular}{|c|c|c|c|c|c|c|}
\hline \multirow[b]{2}{*}{$\begin{array}{c}\text { Nonstructural } \\
\text { Performance } \\
\text { Levels }\end{array}$} & \multicolumn{6}{|c|}{ Structural Performance Levels } \\
\hline & $\begin{array}{c}\text { S-1 } \\
\text { Immediate } \\
\text { Occupancy }\end{array}$ & $\begin{array}{c}\text { S-2 } \\
\text { Damage } \\
\text { Control Range }\end{array}$ & $\begin{array}{c}\text { S-3 } \\
\text { Life } \\
\text { Safety } \\
\end{array}$ & $\begin{array}{c}\text { S-4 } \\
\text { Limited } \\
\text { Safety Range }\end{array}$ & $\begin{array}{c}\text { S-5 } \\
\text { Collapse } \\
\text { Prevention } \\
\end{array}$ & $\begin{array}{c}\text { S-6 } \\
\text { Not } \\
\text { Considered } \\
\end{array}$ \\
\hline $\begin{array}{c}\mathrm{N}-\mathrm{A} \\
\text { Operational }\end{array}$ & Operational 1-A & $2-A$ & $\begin{array}{c}\text { Not } \\
\text { Recommended }\end{array}$ & $\begin{array}{c}\text { Not } \\
\text { Recommended }\end{array}$ & $\begin{array}{c}\text { Not } \\
\text { Recommended }\end{array}$ & $\begin{array}{c}\text { Not } \\
\text { Recommended }\end{array}$ \\
\hline $\begin{array}{c}\text { N-B } \\
\text { Immediate } \\
\text { Occupancy }\end{array}$ & $\begin{array}{c}\text { Immediate } \\
\text { Occupancy 1-B }\end{array}$ & $2-B$ & 3-B & $\begin{array}{c}\text { Not } \\
\text { Recommended }\end{array}$ & $\begin{array}{c}\text { Not } \\
\text { Recommended }\end{array}$ & $\begin{array}{c}\text { Not } \\
\text { Recommended }\end{array}$ \\
\hline $\begin{array}{c}\mathrm{N}-\mathrm{C} \\
\text { Life Safety }\end{array}$ & $1-C$ & $2-C$ & Life Safety 3-C & $4-C$ & $5-C$ & $6-C$ \\
\hline $\begin{array}{l}\text { N-D } \\
\text { Hazards } \\
\text { Reduced }\end{array}$ & $\begin{array}{c}\text { Not } \\
\text { Recommended }\end{array}$ & $2-D$ & 3-D & 4-D & $5-D$ & $6-\mathrm{D}$ \\
\hline $\begin{array}{c}\mathrm{N}-\mathrm{E} \\
\text { Not Considered }\end{array}$ & $\begin{array}{c}\text { Not } \\
\text { Recommended }\end{array}$ & $\begin{array}{c}\text { Not } \\
\text { Recommended }\end{array}$ & $\begin{array}{c}\text { Not } \\
\text { Recommended }\end{array}$ & $4-E$ & $\begin{array}{c}\text { Collapse } \\
\text { Prevention 5-E }\end{array}$ & $\begin{array}{c}\text { No } \\
\text { Rehabilitation }\end{array}$ \\
\hline
\end{tabular}

The next step of the PBD method is to determine a seismic hazard level(s) at which the structure is expected to meet its target performance level. The hazard level is contingent upon the building's location. Parallel to advances made in structural systems, there have also been significant advances in estimating seismic hazard, simulating seismic response, and characterizing seismic performance in probabilistic terms within the past decade (Sabelli et al. 2003). The hazard level is defined in terms of the probability of exceedance and/or mean return period corresponding to ground motions of certain intensity. Ground shaking is characterized by a hazard curve typically provided in the form of an acceleration response spectra. The response spectra is dependent upon local site geology and seismicity. The two typical hazard levels considered for design are the Maximum Considered Earthquake (MCE) which corresponds to a 
$2 \%$ probability of exceedance in 50 years (return period of 2475 years), and the Design Basis Earthquake (DBE) which corresponds to $2 / 3$ of the intensity calculated for the MCE spectrum and is intended to correspond to a $10 \%$ probability of exceedance in 50 years (return period of 474 years). Thus complete performance objectives are given in terms of a structural performance level at a given hazard level. The conventional PBD objectives are usually: Life Safety at the Design Basis Earthquake and Collapse Prevention at the Maximum Credible Event.

To generate a performance-based design the engineer must have a firm understanding of seismic, inelastic and dynamic behavior of structures. PBD requires much more detailed and sophisticated analysis which demands a certain aptitude from the engineer and a relatively wellunderstood and detailed model of structural response, both at the member and structure level.

\subsubsection{Seismic Performance of BRBs}

Several analytical and experimental studies have been performed recently to determine the performance and behavior of BRBFs. Much of this research led to the formulation of the Provisions and future work will continue to develop an understanding of the behavior and consequently optimal design of BRBFs. Recent studies have focused on the design of BRBs themselves, as well as design and behavior of frames utilizing BRBs.

Black et al. (2004) reports the results of comprehensive component testing of BRB systems and also presents an approach to analytically determine their stability. The authors identified three distinct buckling modes in the stability analysis of a BRB:

(1) global flexural buckling of the entire brace,

(2) buckling of the inner core in higher modes, and 
(3) plastic torsional buckling of the projection of the steel core outside of the confining tube.

Global flexural buckling is determined by application of the Euler buckling criteria of the outer tube. Refer to Figure 2.5 for the schematic of an unbonded BRB and illustrated variable definitions

$$
\sigma_{c r}=\frac{P_{c r}}{A_{i}}=\frac{P_{e}}{A_{i}} \approx \frac{\pi^{2} E_{0} I_{0}}{A_{i}(K L)^{2}}
$$

where $A_{i}$ is the cross sectional area of the yielding portion of the brace core, $E_{0}$ and $I_{0}$ are Young's modulus and elastic moment of inertia of the outer tube respectively, and KL is the effective buckling length of the brace.

The critical buckling of the inner core in higher modes can be obtained by following an energy method or by direct integration and is given by

$$
\sigma_{c r}=\frac{P_{c r}}{A_{i}}=\frac{2 \sqrt{\beta_{1} E_{t} I_{i}}}{A_{i}}
$$

where $\beta_{1}$ is the distributed spring constant with dimension $[\mathrm{F}] /\left[\mathrm{L}^{2}\right]$ representing the stiffness per unit length of the encasing mortar and $I_{i}$ is the moment of inertia of the inner steel core. The tangent elongation modulus, $\mathrm{E}_{\mathrm{t}}$, is defined as the change in axial stress over the change in axial strain.

The third possible buckling mode of a BRB is the plastic torsional buckling of the portion of the inner core that protrudes beyond the confining tube (denoted length " $l$ " in Figure 2.5). In the stability analysis each flange of the cruciform is considered as a uniformly compressed plate simply supported along three sides and free along the fourth side. The critical stress under plastic torsional buckling is therefore given as: 


$$
\sigma_{c r}=\frac{E_{t}}{3}\left[\frac{\pi^{2}}{3} \frac{b^{2}}{l^{2}}+1+3 \frac{\sigma_{y}}{E_{t}}\right] \frac{t^{2}}{b^{2}}
$$

where $E_{t}$ is the tangent elongation modulus of the core, $\sigma_{y}$ is the yield stress of the core, and 1 is the length, $b$ is the width, and $t$ is the thickness of each of the four flanges of the protruding cruciform section. Similar torsional buckling relationships may be derived for other brace core shapes by examining the equilibrium of the flanges in its deformed configuration and applying the incremental theory of plasticity. The detailed derivations for the three buckling modes presented here can be found in Black et al. (2002).

In the previously mentioned study by Mochizuki et al. (1979) the buckling limit of the composite BRBs consisting of unbonded braces and reinforced concrete panels was written as:

$$
N_{c r}=\frac{\pi^{2}}{l^{2}}\left(E_{S} I_{S}+k E_{B} I_{B}\right)
$$

where $E_{B} I_{B}$ is flexural stiffness of concrete encasing member, $E_{S} I_{S}$ is flexural stiffness of encased brace member and $\mathrm{k}$ is a coefficient representing the stiffness degradation of the concrete encasing member where $0<\mathrm{k}<1$. It is assumed $\mathrm{E}_{\mathrm{S}}=0$ after the steel brace yields under axial force N. Applying this scenario to Equation. 2.5, the required stiffness of encasing member can be obtained from the following equation:

$$
\frac{\pi^{2}}{l^{2}} k E_{B} I_{B} \geq N_{y}
$$

This introduces the issue of balancing the stiffness and strength of the encasing member. A high stiffness and low strength will result is susceptibility to damage of the encasing member resulting in degradation of stiffness. Likewise, a low stiffness will not be able to restrain global buckling deformations. Therefore, in design of such systems, it is critical to find a balanced combination of stiffness and strength of the encasing member (Xie, 2004). 
Black et al. (2004) presented computed stiffness values for comparison with measured stiffness values of BRBs. The measured stiffness values were a result of relating measured displacements of the tested braces to the measured force applied. The authors described the total elastic stiffness of the brace as the sum of the individual stiffnesses of the brace core cross section and the protruding brace cross section given by:

$$
K_{\text {total }}=\frac{1}{\left(\frac{1}{K_{i}}+2 \frac{1}{K_{c o n}}\right)}
$$

where $\mathrm{K}_{\mathrm{i}}=\mathrm{EA}_{\mathrm{i}} / \mathrm{L}_{\mathrm{i}}$, the elastic stiffness of the yielding portion of the brace and $\mathrm{K}_{\mathrm{con}}=\mathrm{EA}_{\mathrm{con}} / \mathrm{L}_{\mathrm{con}}$, the stiffness of the connection portion at each end of the brace (hence the factor 2). The reported difference between the measured stiffness and computed stiffness was within $0.5 \%$.

The secondary (post yield) stiffness of the brace depends on the loading history and is expressed by the post-yielding ratio:

$$
\alpha=\frac{K_{2}}{K_{i}}=\frac{E_{t}}{E_{i}}
$$

The model used by Black et al. (2004) to approximate the nonlinear hysteretic behavior of a BRB is

$$
P(t)=\alpha K u(t)+(1-\alpha) K u_{y} z(t)
$$

This hysteretic model was first proposed by Bouc (1971), extended by Wen $(1975,1976)$, and is referred to as the Bouc-Wen model. In this model $\mathrm{u}(\mathrm{t})$ is the axial deformation of the brace, $\mathrm{K}$ is the pre-yielding stiffness, $\mathrm{K}=\mathrm{E}_{\mathrm{i}} \mathrm{A}_{\mathrm{i}} / \mathrm{L}_{\mathrm{i}}, \mathrm{u}_{\mathrm{y}}$ is the yield displacement, and $\mathrm{z}(\mathrm{t})$ is the hysteretic dimensionless quantity governed by the differential equation: 


$$
u_{y} \dot{z}(t)+\gamma|\dot{u}(t)| z(t)|z(t)|^{n-1}+\beta \dot{u}(t)|z(t)|^{n}-\dot{u}(t)=0
$$

In this differential equation, $\beta, \gamma$, and $\mathrm{n}$ are dimensionless quantities that control the shape of the hysteretic loop.

The dynamic analysis of a structure containing BRBs proceeds by investigating the effect of the yielding brace on a linear structure subject to ground excitation, $\ddot{u}_{g}(t)$. Dynamic equilibrium gives:

$$
m \ddot{u}(t)+C_{0} \dot{u}(t)+K_{0} u(t)+P(t) \cos (\theta)=-m \ddot{u}_{g}(t) \quad(\text { Eqn 2.11) }
$$

Figure 2.8, showing a single bay frame illustrates the variables $\mathrm{K}_{\mathrm{o}}$ (elastic lateral stiffness), $\mathrm{C}_{\mathrm{o}}$ (damping constant), $\mathrm{m}$ (mass), $\mathrm{u}(\mathrm{t})$ (lateral displacement of the frame), and $\theta$ (angle of brace).

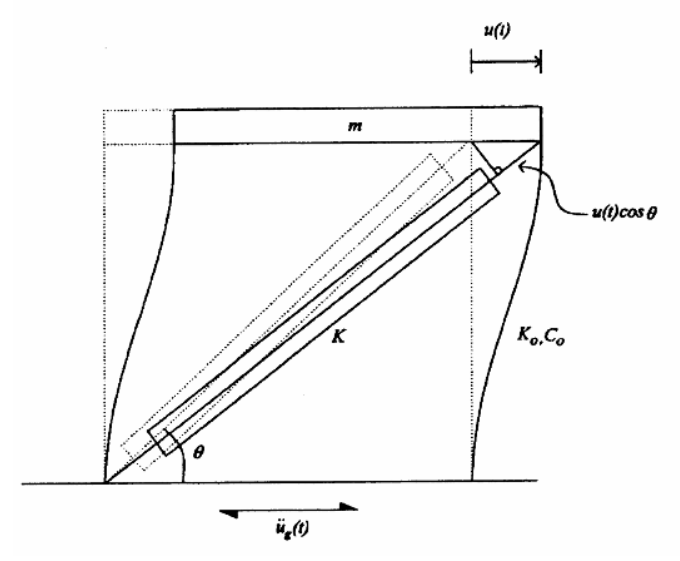

Figure 2.8 Dynamic braced frame model (Black et al. 2004).

The axial force resulting from the inclined brace is defined by Equation 2.9 modified to account for the brace angle in the first term of the equation. Introduction of the normalized force and substitution into Eqn 2.11 produces a dynamic equilibrium to be integrated simultaneously 
with hysteretic behavior model (Eqn 2.10) to compute the dynamic response of BRB structures. Black et al. (2004) found this method represents the behavior of BRBs well. For the overall study, the authors demonstrated that BRBs exhibited stable hysteretic behavior at each end signifying uniform yielding throughout the member. Also, the maximum compressive brace force was $13 \%$ higher than the maximum tensile force.

A study by Merritt et al. (2003) reports the testing of six BRBs made by CoreBrace using a shake table facility. This report served to qualify the BRB for use in a structural system. Two of the specimens utilized flat core plates (Figure 2.7a), while the remainder were cruciform in shape (Figure 2.7c and Figure 2.6). The braces were subjected to both longitudinal and transverse deformations as now required by the Provisions. The braces were loaded according to the standard loading protocol outlined in the Provisions, as well as a low-cycle fatigue loading protocol. If the specimens did not fracture during the specified low-cycle fatigue loading, the same test was repeated until fracture. No fractures were observed under the standard loading protocol, however all specimens eventually fractured under low-cycle fatigue loading. Overall, the cumulative ductility ranged from 600 to $1,400 \times 1000$ kip-in which is significantly higher than that required by the Provisions (which require a cumulative ductility of 140 for uniaxial testing).

The 2005 AISC Seismic Provisions were largely influenced by this previously described work and recommended provisions provided by Sabelli (2004). One contributing study by Sabelli et al. (2003) presents a series of model 3 and 6 storey buildings with chevron BRBs designed and analyzed when subjected to earthquake ground motions representing various seismic hazard levels. The braces were modeled with a secondary post-yield stiffness equal to zero, full cross-sectional tension capacity (i.e.: $\mathrm{A}_{\mathrm{i}} \mathrm{f}_{\mathrm{y}}$ ) and a compression capacity of $110 \%$ of the 
tension capacity. For this study, a suite of earthquakes representing seismic hazard levels of 50, 10 and $2 \%$ in 50 years for downtown Los Angeles were considered. Close attention was given to beam design for the possible out-of-balance forces induced from the difference in tensile and compressive capacities of the braces. Sabelli et al. (2003) concluded that BRBs provide a solution to many problems associated with SCBFs. Also, the response of the BRBF was not sensitive to $\mathrm{R}$ factors in the range of 6 to 8 . The authors recommended evaluation of taller structures ( 9 and 20 stories) as well as the development of models to simulate the bending and shear forces applied to BRBs.

Fahnestock et al. (2003) presented time history analyses of a four story BRBF that was designed using a conventional approach. Special consideration was given to the hardening behavior of the brace elements in the model to effectively represent the post-yielding properties. Both the DBE and MCE seismic input levels were considered in the design, corresponding to life safety and collapse prevention performance levels respectively. The performance of the BRBF exceeded the desired performance levels and met the required ductility parameters. While the cumulative BRB ductility demand is well understood, the authors suggest further research regarding the maximum ductility demands of BRBs.

A design procedure for a target displacement design in the framework of the capacity spectrum method was developed by Kim and Choi (2004) based on the results of parametric study. In this study nonlinear static and dynamic time-history analyses were performed for comparison with the seismic response of model structures with BRBs. The authors suggested an equation for the equivalent damping of a structure with BRBs by initially defining the overall stiffness of the system as the combination of the stiffness of the main frame and the brace as seen in Figure 2.9. 


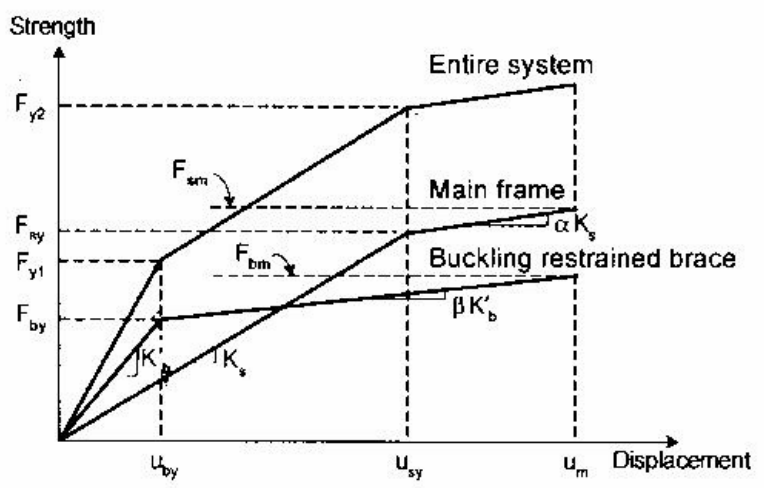

Figure 2.9 Load-displacement relationship of structure with BRB (Kim and Choi, 2004).

Through the presentation of several derivations and definitions, including an expression for equivalent damping of the system, the authors report an expression for optimizing the yield stress of the BRB. The parametric study concerning equivalent damping aided in several conclusions for optimal brace behavior. First, a larger brace sectional area results in higher equivalent damping. Likewise, a larger brace cross sectional area results in higher damping under small lateral displacements while a brace having a smaller cross sectional area sees higher damping under large lateral displacements. Finally, if a larger BRB is to be employed, the steel must have a lower yield stress to maximize equivalent damping. Given the limited available variance in steel strength, a designer can only practically affect the stiffness of the braces by varying the cross-sectional areas.

Kim and Choi modeled 5-story and 10-story structures to investigate their seismic responses with BRBs. Nonlinear time-history analyses were performed using scaled El Centro and Mexico City earthquakes. The same number of BRBs with yield stresses of 14.5 and $35 \mathrm{ksi}$ (100 and $240 \mathrm{MPa})$ were distributed throughout the structures using four different methods: distribution proportional to story stiffness, same size BRB in every story, distribution 
proportional to inter-story drift resulting from pushover analysis, and distributed proportional to story shear. Results indicated that distribution of BRBs in proportion to story drifts and story shears produced better structural performance. A design procedure was also proposed based on the assumption that required equivalent damping is supplied by plastic deformation of the BRBs. A model structure designed in accordance with the proposed method exhibited maximum displacements that corresponded well with target displacements.

In a similar study, Kim and Seo (2004) present a performance-based seismic design procedure for a single degree of freedom (SDOF) model structure employing BRBs and eventually a multiple degree of freedom (MDOF) model structure. A time-history analysis was carried out for this procedure, noting that despite the inherent limitations in nonlinear static procedures, they are a powerful alternative to a nonlinear dynamic approach for preliminary analysis and design of low-rise structures in particular. Both 3- and 5-story model structures were built according to the direct displacement design method. The models exhibited maximum displacements that corresponded well with target displacements and the BRBs dissipated energy inelastically while the rest of the structural members remained elastic.

Tremblay et al. (1999) studied the results of quasi-static load testing and nonlinear dynamic analysis of a BRBF. This system was suggested for the seismic upgrade of an unreinforced masonry building in Quebec. The authors utilized a BRB having a dog-bone shaped core to force and confine the inelastic behavior within the encased region of the brace. The cyclic load testing performed on one chevron BRBF demonstrated stable and symmetrical hysteretic behavior and significant strain hardening was observed. A nonlinear dynamic analysis of one of the 14 vertical braced frames proposed for the structure's upgrade demonstrated an adequate seismic response by only slightly exceeding the $1 \%$ story height limit for inter-story drift. Also, 
the analysis computed maximum forces within the braces of 1.14 to 1.25 the yield resistance, dependent upon the floor.

An alternate application of BRBs was approached by Carden et al. In the first of two companion papers, Carden et al. (2006a) report on the seismic performance of single angle X braces employed as end cross frames between steel girder bridges. The study included cyclic testing of single angle braces, as well as reverse static loading and shake table experiments on a large-scale, two girder bridge model loaded transversely. The shear force within the diagonal members of the cross frame was maximized through the reduction of the girder transverse stiffness by way of elastomeric bearings that allowed the girders to "rock". Results indicated that the single angle, when provided good connection details, performed well with cyclic deformations greater than $6 \%$ axial strain before failure. The static load and shake-table experiments performed on the bridge model resulted in drifts up to $5.3 \%$ when subjected to the 1940 El Centro earthquake scaled up by a factor of two. Noting that this drift results in brace axial strains of about $1.6 \%$, well below the calculated displacement capacity of the $\mathrm{X}$ brace cross frames $(6 \%)$, the system also exhibited no strength degradation and had a comparatively low post yield stiffness, effectively behaving as a structural fuse for the bridge. Ultimately, the X brace system reduced the elastic base shear seen in the bridge by $40-50 \%$.

In response to the poor energy dissipation characteristics of single $\mathrm{X}$ braces in steel girder bridges, Carden et al. (2006b) investigated the behavior of BRBs in the same model bridge of the companion study (Carden et al. 2006a). Nippon Steel provided "unbonded" BRBs designed to have a yield force similar to the previously tested $\mathrm{X}$ braces. Four BRBs were tested alone to determine their axial properties when subjected to cyclic loading. As expected, the braces showed excellent energy dissipation with a compressive strength 10-15\% higher than their 
tensile strength. The bridge model was tested with the BRBs having either pin connections or fixed connections. Both connection scenarios resulted in similar displacements of the bridge model, however the fixed-end connected BRBs increased the post-yield stiffness. Additionally, the fixed-end connections induced flexural behavior within the brace, which is not well understood, and therefore the authors recommend connections with lower flexural resistance. The BRB cross frames dissipated more energy and displaced less than "equivalent" $\mathrm{X}$ brace frames and are less likely to require replacement after a seismic event.

In a recent study, Tremblay et al. (2006) seeks to answer several issues that have been identified through considerable research regarding BRBFs. These issues include whether inplane bending impairs BRB performance, examining a reduced brace core length's performance and fracture life, and assessing an all-steel buckling-restraining mechanism. The authors also compared BRBs to conventional HSS section braces under identical quasi-static cyclic and dynamic loading conditions. The all-steel buckling-restraining mechanism was composed of two hollow steel tubes bolted together effectively sandwiching the steel plate brace core. The authors concluded again that the BRB exhibited a stable, ductile inelastic response without fracture. The brace core was dog-bone shaped with a reduced cross-sectional area at its midlength within the encasing tube. The length of the reduced brace core cross-sectional area was decreased to obtain a stiffer brace. An illustration of this concept is presented in Figure 2.10 (Tremblay et al. 2006)

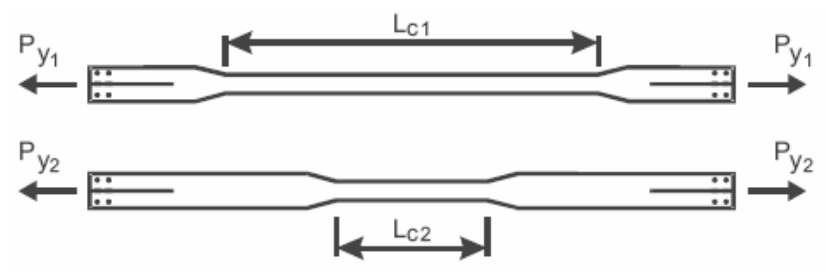

Figure 2.10 Reduced Core Brace Length (Tremblay et al. 2006). 
The BRB with a reduced core length developed larger strains, however, at large deformations both developed large axial forces due to strain hardening and friction between the core and the concrete restraining mechanism. The authors reported a $25 \%-30 \%$ reduction in flexural stiffness in the concrete filled tubes of the BRB upon axial yielding of the brace, which was determined to not affect the axial response of the braces. The all-steel buckling restraining mechanism proved to be a viable alternative to the concrete $\mathrm{BRB}$, however future work is necessary to address local core buckling and strain uniformity. The conventional HSS brace withstood an identical loading protocol without fracture, however it exhibited a poor energy dissipation capacity of about $13 \%$ of that reported for the concrete BRB.

Tremblay et al. (2006) succeeded in their attempt to present an alternative BRB configuration. The authors note in their report that the conventional concrete filled tube BRB does present several difficulties in their application; the fabrication of these braces is difficult and expensive. An alternative design using steel tubes as the buckling-restraining mechanism avoids the need for careful placement of debonding materials and the pouring and curing of concrete. Despite the fact that the authors ultimately suggest that the use of debonding materials would enhance the steel $\mathrm{BRB}$ behavior, this concept opens the door for alternative BRB configurations that present greater ease of application.

\subsection{RELATIONSHIP TO PRESENT WORK}

The present work proposes the use of bonded FRP materials to affect a level of buckling restraint to axially loaded braces. It is not intended to develop a brace as robust as existing 
BRBs. Nonetheless, it is suggested that through the use of PBD, a spectrum of behavior falling between that of OCBFs and BRBFs is possible and has applications in practice. 


\subsection{EXPERIMENTAL PROGRAM}

This chapter reports the details of the experimental program including specimen descriptions, retrofit application procedures, test set-up, instrumentation and procedure.

\subsection{WT-SECTION BRACE SPECIMENS}

A total of six A992 Grade 50 WT 6x7 (U.S. designation) steel brace specimens were included in the experimental program. Of these, one was encased in a circular steel HSS $7 \mathrm{x}$ 0.125 (U.S. designation) pipe section filled with grout creating a buckling restrained brace, four were retrofitted with FRP pultruded strips, and one was tested as an unretrofit control specimen. Of the four FRP-retrofit braces, CFRP strips were applied to two and GFRP strips were employed for the remaining two. The width and number of layers of FRP were varied for each retrofit specimen: in one case a single layer of 2" $(50.8 \mathrm{~mm})$ wide strip was used and in the other two 1 " $(25.4 \mathrm{~mm})$ wide strips were stacked on top of each other. Figure 3.1 gives a summary of the six specimens tested. Manufacturer reported material properties for the steel, FRP and adhesive materials used are presented in Table 3.1. 
Table 3.1 Manufacturer's Reported Material Properties

\begin{tabular}{|l|c|c|c|c|}
\hline Material & $\begin{array}{c}\text { Tensile } \\
\text { Strength, } \\
\text { ksi }\end{array}$ & $\begin{array}{c}\text { Tensile } \\
\text { Modulus, } \\
\text { ksi }\end{array}$ & $\begin{array}{c}\text { Elongation } \\
\text { at Rupture }\end{array}$ & $\begin{array}{c}\text { Tangent } \\
\text { Modulus of } \\
\text { Elasticity, ksi }\end{array}$ \\
\hline A992 Steel & 50 & 29000 & - & - \\
\hline HS Carbon FRP & 405 & 22500 & 0.018 & - \\
\hline UHM Glass FRP & 130 & 6000 & 0.022 & - \\
\hline FX 776 Adhesive & 4.5 & - & 0.025 & 575 \\
\hline
\end{tabular}

*NOTE $-1 \mathrm{ksi}=6.895 \mathrm{MPa}$

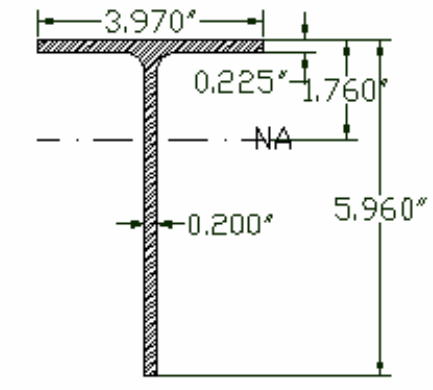

Control Specimen C

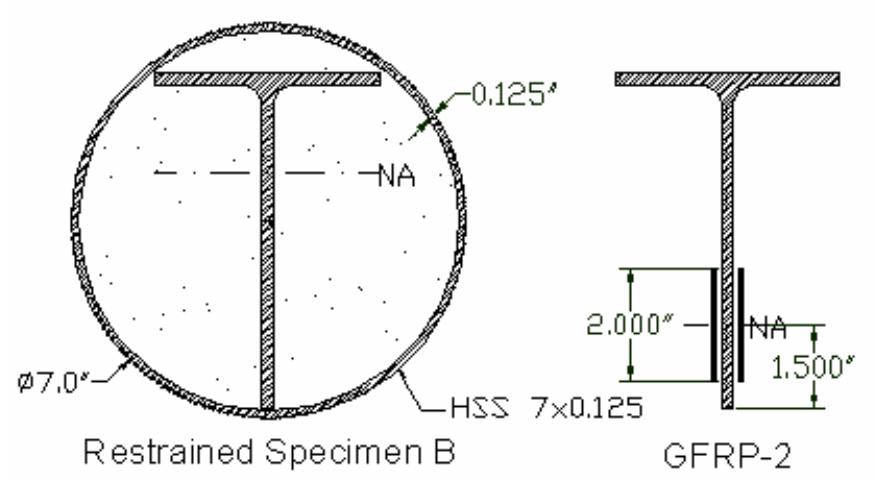

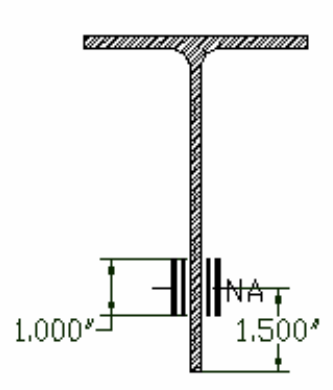

CFRP-1

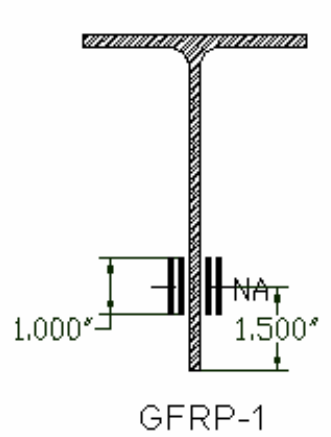

Figure 3.1 Specimen Summary

The prefabricated WT $6 \times 7$ sections were ordered cut to a length of $651 / 2 "(1664 \mathrm{~mm})$. The connection detail was designed to a) reflect an AISC-compliant brace connection in an attempt to better approximate the conceptual application; and b) result in a transfer of forces coincident with the neutral axis location (designated NA in Figure 3.1). Three 7/8" (22 mm diameter) A325 bolts were used to connect the brace to $8 \times 4 \times 7 / 16$ (U.S. designation) double- 
angle clip connection at both ends. The bolted connection was aligned with the theoretical centroid of the section to ensure concentric loading. Each angle was connected to the base plates using two 7/8" (22 mm) A325 bolts. The connection detail is shown in Figure 3.2. Detailed calculations for the connection design can be found in Appendix A.
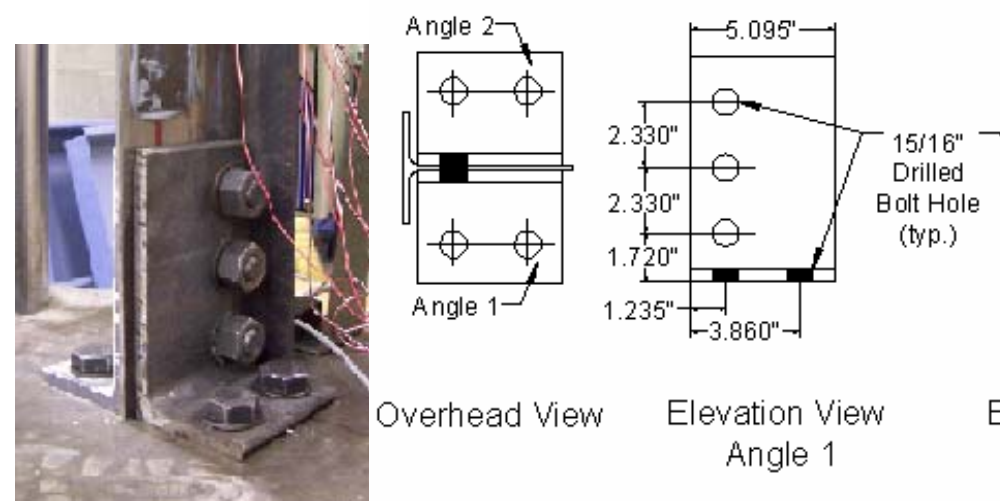

Overhead View
Elevation View Angle 1
Elevation View Angle 2

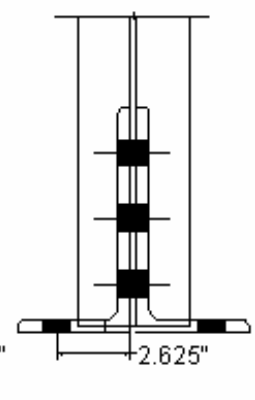

Figure 3.2 Details of brace connection used for testing.

\subsection{RETROFIT MEASURES}

Four different retrofit measures using FRP materials were tested in this study. A fifth specimen employed a buckling-restrained brace for the purpose of comparison with the FRP retrofit options. The buckling-restrained brace retrofit was not the primary focus of this investigation.

\subsubsection{FRP Retrofit Braces}

The adhesive system used for all of the FRP retrofit measures was FX 776. The two different FRP materials used were Fyfe Tyfo UC high strength (HS) carbon FRP and Fyfe Tyfo 
UG ultra high modulus (UHM) glass FRP. FRP and adhesive materials properties can be found in Table 3.1. The CFRP was available in 4" $(102 \mathrm{~mm})$ wide, 0.055 " $(1.4 \mathrm{~mm})$ thick strips which can easily be cut longitudinally using a razor and transversely using aviation shears. The GFRP was available in $4 "(102 \mathrm{~mm})$ wide, $0.075 "(1.9 \mathrm{~mm})$ thick strips that were cut in the same manner. All of the strips were cut 48 " $(1219 \mathrm{~mm})$ long and either 1" $(25.4 \mathrm{~mm})$ or 2" $(50.8 \mathrm{~mm})$ wide. The FRP strips were applied to each side of the stem of the WT $6 \times 7$ brace centered $1 \frac{1 / 2}{2}$ $(38.1 \mathrm{~mm})$ from the tip as shown in Figure 3.1. Two configurations were tested; a single 2" wide strip on each side of the stem, or two 1" wide strips located on top of one another on each side of the stem. The two 1" strips were preassembled and allowed to cure prior to installation on the WT section; this was done to ensure a uniform installation. The two FRP configurations used result in the same amount of FRP materials having the same centroid applied to the steel section in an attempt to optimize the retrofit application. The retrofit schemes are shown in Figure 3.1.

\subsubsection{Application of FRP to Test Specimens}

The practice of bonding FRP materials to steel is still in its infancy and requires several steps to ensure bond integrity. The steel substrate must be properly prepared in order to provide an adequate bond surface - addressing both chemical and mechanical properties of the surface. An appropriate epoxy resin system must be properly applied during the designated pot life, and the FRP material and steel substrate must be clean and dry. The steps taken to provide a sound steel-FRP bond for this study are presented in the following subsections. 


\subsubsection{Steel Substrate Preparation}

In order to ensure an adequate mechanical bond for the FRP application, the steel substrate had to be properly prepared. The area of the WT stems where FRP was to be applied was ground using a 40 grit zirconia alumina sanding belt to remove rust and to achieve a uniform roughened surface area of bare (white) steel. Figure 3.3 shows a photograph of a typical prepared steel brace surface (a GFRP strip is shown on the right of this photo). Following sanding and again prior to FRP application, the steel surface was cleaned with a degreasing/corrosion inhibiting agent and allowed to dry. In this manner, it is believed that no corrosion product formed between the time of surface preparation and FRP application.

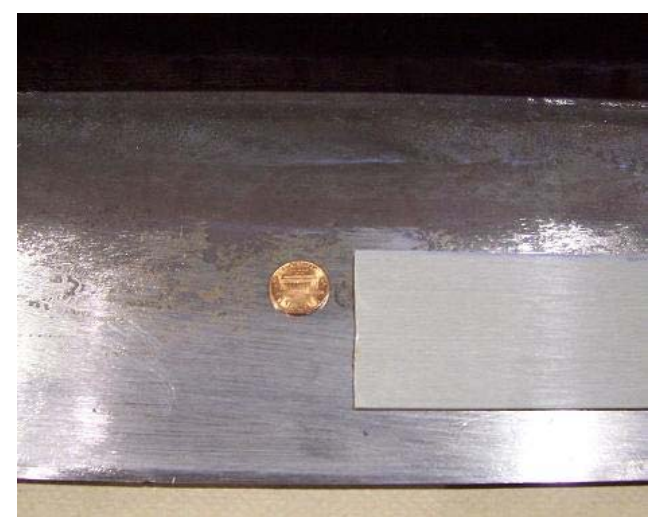

Figure 3.3 Photograph of steel surface preparation.

\subsubsection{Preparation of the FRP Material}

The glass and carbon FRP strips were cut to 48 " (1219 mm) lengths using a variable speed Dremel tool. The length was chosen to span nearly the entire clear distance of the brace between connection angles so as to mitigate any development length issues associated with bond of the FRP. After the strips were cut to the prescribed width (2" or 1") and length they were stored in a clean dry place to avoid any dirt or damage until application. Immediately prior to placement the FRP was wiped down to remove any excess dust or dirt from its surface. 
As mentioned previously, the number of FRP layers was either a single 2" wide strip on each side of the WT stem or two 1" wide strips on each side of the stem. The two 1" wide strip pairs were bonded together before being applied to the steel. The two-part epoxy system was combined and applied to both sides of the joining FRP strips. The two strips were sandwiched together and subjected to uniform pressure over their length to alleviate any air bubbles within the epoxy layer and ensure a constant thin width. The strip pairs were kept in a clean, dry space protected from dirt or mechanical damage and allowed to cure for over 24 hours.

\subsubsection{Application of the FRP to the Steel}

After the steel and FRP strips were prepared, the system was ready to be joined. The WT sections were oriented so that one side of the stem received the FRP application first and after curing for approximately 24 hours were flipped over to apply FRP to the opposite side. In this manner the FRP was applied in the "downhand" direction and sagging due to gravity was not an issue in the application. The two-part adhesive system was mixed according to the manufacturer's specifications and applied within the system's designated pot life. The epoxy resin was applied with plastic spatulas over the length of the FRP strips and the section of the brace where the FRP would lay ensuring that both surface areas had a full, uniform layer of epoxy. Once both the steel and FRP were covered in epoxy, the FRP strip was laid longitudinally onto the stem of the WT brace, aligning the strip centerline $1 \frac{1 / 2 "}{}$ ( $\left.38.1 \mathrm{~mm}\right)$ from the tip of the stem. Uniform pressure was applied to the strips by hand from the midpoint of the brace out to the ends to expel any air bubbles within the bond and promote uniformity of the adhesive layer. The resulting adhesive layer was measured to be an average of $0.023 "(0.58 \mathrm{~mm})$ thick. 


\subsubsection{Buckling Restrained Brace Retrofit}

One additional specimen was constructed by placing the brace inside a steel HSS $7 \mathrm{x}$ 0.125 pipe section and filling it with grout, creating a buckling-restrained brace (BRB) as described in Section 2.6. To ensure that the brace could move freely within the grout-filled tube, it was covered with $0.005 "(0.127 \mathrm{~mm})$ thick polytetrafluoroethylene (PTFE) tape. The taped brace was inserted into the 49" (1245 mm) long HSS7 x 0.125 tube as shown in Figure 3.1. Wood forming capped off the end of the tube around the brace and helped to maintain the position of the brace in the tube, and grout was placed within the tube. The grout was rodded to promote uniformity and compaction. Several 4" x 8" (102mm x $203 \mathrm{~mm})$ grout cylinders were cast to be broken at the time of BRB testing. The grout within the BRB was allowed to cure for 16 days before the brace was tested. The grout cylinders reported an average compressive strength at the time of BRB testing of 5,127 psi (35.35 MPa).

\subsection{SPECIMEN DESIGNATION}

The six different braces considered within the scope of this thesis are designated as follows. The four different FRP retroffited braces are labeled according to their FRP material first and the width of the strip second. The last two specimens were both considered control

specimens to add perspective to the behavior of the retrofit braces and are designated $\mathrm{C}$ for control or B for buckling-restrained, respectively. The two options for the FRP material are:

CFRP $=$ Carbon Fiber Reinforced Polymer, and

GFRP $=$ Glass Fiber Reinforced Polymer 
Where the strip width can be either of the following:

$$
\begin{aligned}
& 1=\text { two } 1 "(25.4 \mathrm{~mm}) \text { wide strips, or } \\
& 2=\text { single } 2 "(50.8 \mathrm{~mm}) \text { wide strip. }
\end{aligned}
$$

\subsection{TEST SETUP}

All of the brace specimens were tested under cyclic compressive loading. The braces were positioned so as to be loaded concentrically through their theoretical cross-section centroids using a 200 kip $(890 \mathrm{kN})$ capacity Baldwin Universal Testing Machine (UTM). The 65 1/2” (1664 $\mathrm{mm}$ ) long braces were connected to the base plates using pairs of $8 \times 4 \times 7 / 16$ angles and three 7/8" A325 bolts as described in Section 3.1 and shown in Figure 3.2. The angles were connected to the 2" $(50.4 \mathrm{~mm})$ thick base plates by two $7 / 8$ " A325 bolts. The bottom base plate was connected to the lower platten of the UTM with four $3 / 4$ " A325 bolts. The top base plate was fit into the upper crosshead of the UTM using four $3 / 4$ " studs bearing against the perimeter of a circular opening within the crosshead. Thus a positive shear connection was made at both ends of the specimen ensuring no unintentional lateral deflections of the connection regions. A photograph and drawing of the brace set-up is shown in Figure 3.4. Detailed drawings of the test setup components are provided in Appendix B. 

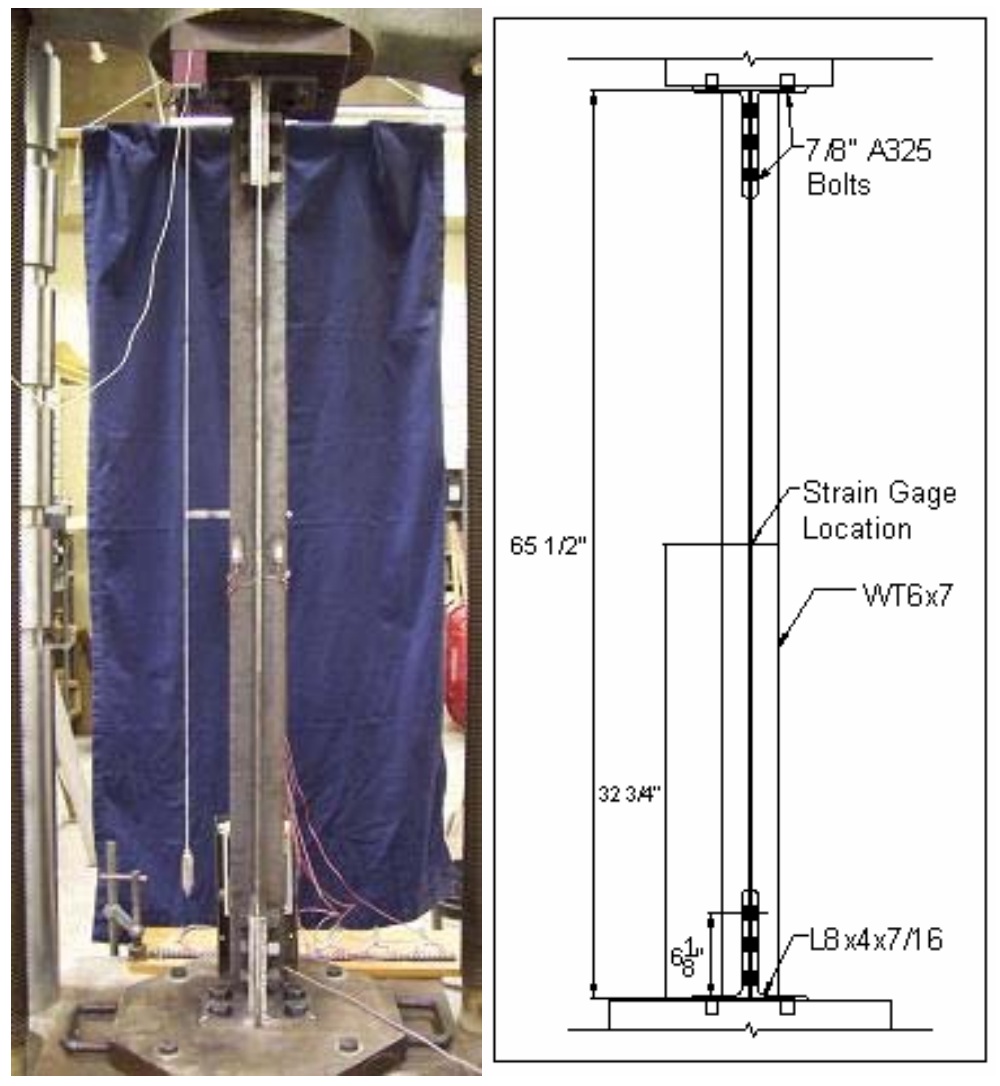

Figure 3.4 Brace Set-Up

\subsection{INSTRUMENTATION}

All six of the brace specimens utilized the same basic instrumentation scheme. Each brace was instrumented with six longitudinally oriented electrical resistance strain gages located on the tips of the WT flange and stem. The gages were placed 1/2" $(12.7 \mathrm{~mm})$ from the tips of the stem and flange at brace midheight. Two additional strain gages were utilized for the FRP retrofit specimens to monitor the FRP behavior located at the middle of each strip, also located at brace mid-height. Note that the CFRP-2 and GFRP-2 specimens were instrumented with strain gages about $3 / 8$ " $(9.52 \mathrm{~mm})$ from the tip of the stem in order to provide space for the FRP strip. Draw 
wire transducers measured the longitudinal (axial) displacement of the brace (DWT1), the horizontal (lateral) displacement of the stem at the cross-sectional centroid at brace mid-height (DWT2), and the horizontal (lateral) displacement of the flange-stem intersection of the cross section at brace mid-height (DWT3). For specimen B (the BRB), lateral deflection was measured from the exterior of the confining tube in the directions coincident with the WT brace principal orthogonal axes. Figure 3.5 shows the instrumentation scheme used.

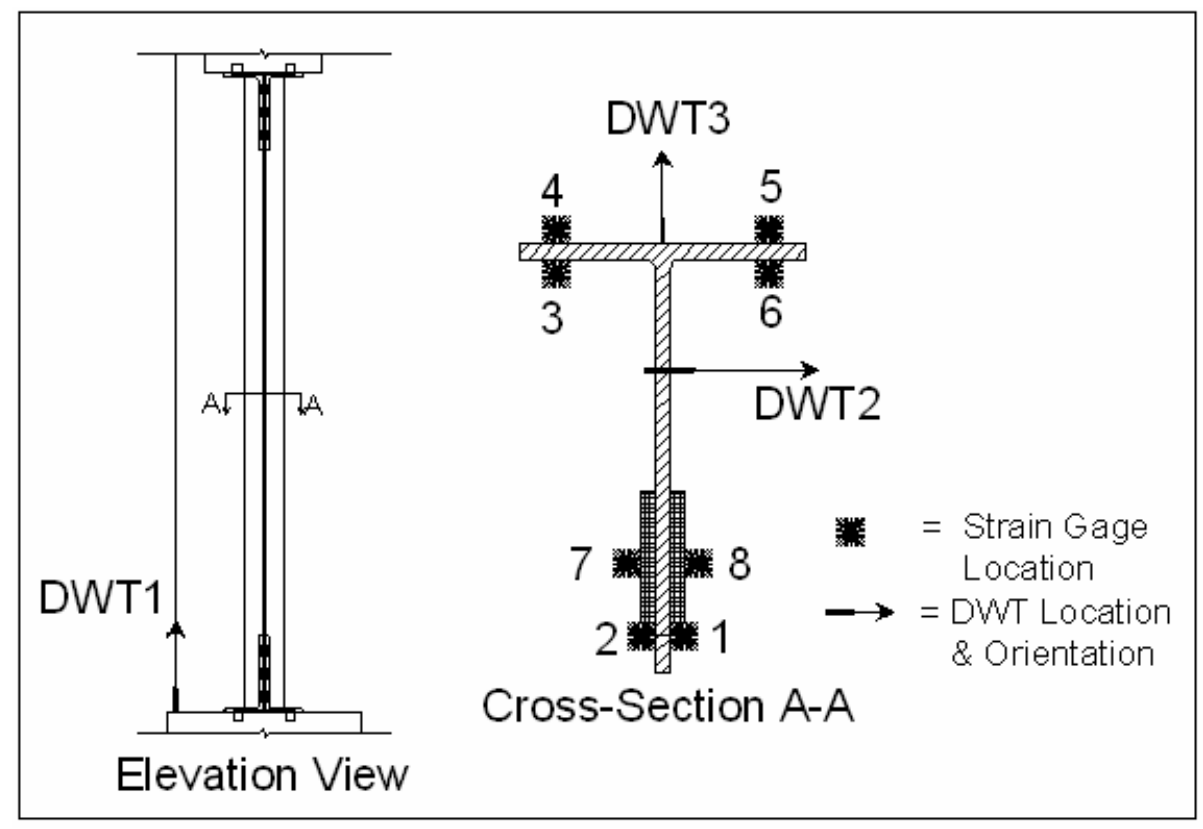

Figure 3.5 Instrumentation Diagram

The UTM used was equipped with an internal 200 kip $(890 \mathrm{kN})$ load cell. That load cell, along with the strain gages and draw wire transducers were connected into a Vishay System 5100 data acquisition system. The loading rate was controlled manually using the UTM hydraulic load controls. 


\subsection{TEST PROCEDURE}

Six steel brace specimens were tested under cyclic compressive loading up to failure. One of the braces was tested as an unretrofit control specimen (Specimen C). A buckling-restrained brace (Specimen B) was also tested to identify optimal brace performance in contrast with the control and FRP-retrofitted braces. The remaining four braces were retrofitted with either CFRP or GFRP strips and tested to failure. All of the cyclic compressive tests were run under manual load control. Each brace was initially subjected to a small tensile force of approximately $2000 \mathrm{lbs}$ $(8.9 \mathrm{kN})$ to allow the loading sequence to pass through zero in each cycle. For all braces, with the exception of the $\mathrm{BRB}$, the first loading cycle imposed a maximum 5 kip $(22.2 \mathrm{kN})$ compressive load and then returned to the initial 2 kip $(8.9 \mathrm{kN})$ tensile load. The following cycles incrementally increased the maximum compressive load by 5 kips $(22.2 \mathrm{kNs})$ each cycle and each returned to the initial $2 \mathrm{kip}(8.9 \mathrm{kN})$ tensile load upon cycle completion. Each brace specimen reached at least 45 kips $(200 \mathrm{kN})$ in this manner and cyclic loading was continued until failure occurred as defined by either excessive lateral deflection or FRP strip debonding. Caution was taken to prevent extreme lateral deflection in order to preserve the connection elements for subsequent tests. The BRB, expected to achieve a higher load capacity, was cycled in increments of 10 kips $(44.5 \mathrm{kN})$. 


\subsection{PREDICTED SPECIMEN BEHAVIOR}

\subsubsection{Predicted WT 6x7 Brace Behavior}

The AISC Manual of Steel Construction (AISC 2005a) classifies steel sections as compact, noncompact, or slender-element sections based on their limiting width-thickness ratio, $\lambda$. The stem and flange properties of the WT $6 \times 7$ section considered in this work are presented in Table 3.2.

Table 3.2 WT 6x7 Stem and Flange Properties

\begin{tabular}{|c|c|c|c|c|c|}
\hline \multirow[b]{2}{*}{$\begin{array}{l}\text { Description of } \\
\text { Element }\end{array}$} & \multirow[b]{2}{*}{$\begin{array}{l}\text { Width- } \\
\text { thickness } \\
\text { Ratio }\end{array}$} & \multicolumn{3}{|c|}{ AISC Limiting Width-Thickness Ratios } & \multirow[b]{2}{*}{ WT $6 \times 7$} \\
\hline & & $\begin{array}{c}\lambda_{\mathrm{p}} \\
\text { Compact }\end{array}$ & $\begin{array}{c}\lambda_{\mathrm{r}} \\
\text { Noncompact }\end{array}$ & $\begin{array}{c}\text { Slender Element } \\
\text { Compression } \\
\text { Member }\end{array}$ & \\
\hline $\begin{array}{l}\text { Uniform } \\
\text { compression in } \\
\text { stems of tees }\end{array}$ & $\mathrm{d} / \mathrm{t}_{\mathrm{w}}$ & na & $\begin{array}{c}0.75 \sqrt{ }\left(\mathrm{E} / \mathrm{F}_{\mathrm{y}}\right) \\
\mathbf{1 8}\end{array}$ & $\begin{array}{c}1.03 \sqrt{ }\left(\mathrm{E} / \mathrm{F}_{\mathrm{y}}\right) \\
\mathbf{2 4 . 8}\end{array}$ & 29.8 \\
\hline $\begin{array}{l}\text { Flexure in } \\
\text { flanges of tees }\end{array}$ & $\mathrm{b} / \mathrm{t}_{\mathrm{f}}$ & $\begin{array}{c}0.38 \sqrt{ }\left(\mathrm{E} / \mathrm{F}_{\mathrm{y}}\right) \\
\mathbf{9 . 2}\end{array}$ & $\begin{array}{c}0.56 \sqrt{ }\left(\mathrm{E} / \mathrm{F}_{\mathrm{y}}\right) \\
\mathbf{1 3 . 5}\end{array}$ & $\begin{array}{c}1.03 \sqrt{ }\left(\mathrm{E} / \mathrm{F}_{\mathrm{y}}\right) \\
\mathbf{2 4 . 8}\end{array}$ & 8.8 \\
\hline
\end{tabular}

The limiting ratio for the stem of a WT section to be classified as non-compact is (note that all equations are presented in standard English units format):

$$
\lambda_{r}<0.75 \sqrt{E / F_{y}}
$$

The $\mathrm{d} / \mathrm{t}_{\mathrm{w}}$ ratio for the WT $6 \mathrm{x} 7$ section tested, equal to $1.21 \sqrt{E / F_{y}}=29.8$ does not meet this limitation and is therefore classified as a slender-element section. The critical sectional stress determined from an Euler buckling analysis is therefore subject to a further reduction factor, $\mathrm{Q}_{\mathrm{s}}$. The calculation of the critical stress for the cross section becomes:

$$
F_{c r}=Q\left(0.658 Q^{\lambda_{c}^{2}}\right) F_{y}
$$


Where $\lambda_{c}$ is the column slenderness parameter determined in Chapter E of the AISC manual (AISC 2005a):

$$
\lambda_{c}=\frac{k L}{\pi r_{y}} \sqrt{\frac{F_{y}}{E}}
$$

And $\mathrm{Q}=\mathrm{Q}_{\mathrm{s}}$ because the cross section is comprised of only unstiffened elements. The value of $\mathrm{Q}_{\mathrm{s}}$ determined for unstiffened stems of tees in compression having $\lambda_{p}>1.03 \sqrt{E / F_{y}}$ is (AISC 2005a):

$$
Q_{s}=\frac{0.69 E}{F_{y}\left(d / t_{w}\right)^{2}}
$$

The resulting local critical stem buckling load for a WT $6 \times 7$ section is approximately 44 kips. Detailed calculations are presented in a mathcad document in Appendix C.

The flexural-torsional buckling capacity of the cross section is determined according to Chapter E3 of the AISC Manual (AISC 2005a). The critical stress is defined by equation E3-2 as:

$$
F_{c r f t}=\left(\frac{F_{c r y}+F_{c r z}}{2 H}\right)\left[1-\sqrt{1-\frac{4 F_{c r y} F_{c r z} H}{\left(F_{c r y}+F_{c r z}\right)^{2}}}\right]
$$

Where $\mathrm{F}_{\text {cry }}$ is the critical local buckling stress calculated previously (Eqn 3.2), and $\mathrm{F}_{\mathrm{crz}}$ and $\mathrm{H}$ are functions of torsional properties of the cross section. This stress results in a critical flexuraltorsional buckling load of about 30 kips. Thus the brace behavior is expected to be dominated by lateral-torsional response.

The brace behavior is therefore expected to be characterized by large lateral translations of the stem tip, twist about the centroid and nominal strong axis translation. This behavior can 
be clearly seen in Figure 4.30. For the very slender stem WT tested, plastic "kinking" of the stem is expected with increased axial (and thus lateral) displacement.

\subsubsection{Predicted BRB Behavior}

Several attempts have been made to quantify the expected capacity of BRBs. Detail calculations following a modified method presented by Black et al. (2004) are presented in Appendix C. This method identifies the four distinct buckling modes including global flexural buckling of the entire brace, buckling of the inner core in higher modes, plastic torsional buckling of the projection of the steel core outside of the confining tube, and the compressive squash load of the inner core section. Ultimately, it was anticipated, and referenced in reviewed literature, that the limiting component for the BRB will be the connection region. Current specifications place strict demands on the capacity of the connection in order mitigate an out-ofplane flexural (buckling) response in that region. For consistency within the study, the same connection detail was used for each brace. This connection, as described earlier, was designed for a bare steel brace and therefore was presumed to be the limiting factor upon the ultimate capacity of the BRB. The predicted capacity of the BRB Specimen B was determined to be 104 kips and the critical response was predicted to be governed by the squash load of the WT 6x7 brace. 


\subsection{EXPERIMENTAL RESULTS}

This chapter presents the results of the brace experimental testing and discusses the behavior of each test specimen.

\subsection{TEST RESULTS}

Table 4.1 summarizes the maximum applied compressive loading, maximum longitudinal (axial) and mid-height lateral displacements, as well as the number of loading cycles imposed for each brace specimen tested. Each specimen was cycled in increments of 5,000 lbs $(22.2 \mathrm{kN})$ with the exception of Specimen B, which was cycled in $10,000 \mathrm{lb}(44.5 \mathrm{kN})$ increments due to its greater expected capacity. Table 4.2 provides the maximum strains in the stem tip, flange tips and FRP (when applicable), measured at mid-height for each of the brace specimens. Figure 4.1 through Figure 4.5 show the load vs. axial deformation (measured with DWT 1) for each of the retrofitted brace specimens tested in comparison to the control specimen C. Figure 4.6 through Figure 4.10 show the load vs. midspan lateral displacement of the stem (DWT 2; measuring lateral displacement in the weak-axis direction of the tee) for each of the retrofitted brace specimens as well as the control specimen C. Figure 4.11 through Figure 4.15 show the load vs. midspan lateral displacement at the intersection of the stem and flange (DWT 3; strong axis lateral displacement) for each of the retrofitted specimens in contrast with the control specimen 
C. These graphs present the actual data recorded during the cyclic loading and illustrate any residual displacement and accumulated damage through subsequent cycles. Figure 4.16 through Figure 4.20 show the load vs. strain at the stem tip at brace mid-height, and FRP for each of the retrofitted specimens compared with the same steel strains from the control Specimen C. The strains for the retrofit specimen of Figures 4.16 through 4.20 are offset by $+/-5,000$ microstrain $(+/-10,000$ microstrain for Specimen B) for clarity. Figure 4.21 through Figure 4.25 show the load vs. strain in the flange tips at brace mid-height for each of the retrofitted specimens contrasted against the strain in the flange tips of the control specimen, Specimen C. The strains for the retrofit specimen are offset by $+/-10000$ microstrain for clarity in these figures.

Table 4.1 Summary of displacement results from brace cyclic loading.

\begin{tabular}{|l|c|c|c|c|c|c|}
\hline & C & B & CFRP-2 & CFRP-1 & GFRP-2 & GFRP-1 \\
\hline Maximum Compressive Load, lbs & 49255 & 93835 & 48712 & 47833 & 52191 & 53772 \\
\hline Maximum Axial Displacement, in. & -0.570 & -0.587 & -0.640 & -0.447 & -0.572 & -1.581 \\
\hline $\begin{array}{l}\text { Maximum Weak-Axis Lateral } \\
\text { Displacement (DWT 2), in. }\end{array}$ & 2.260 & -0.360 & 3.593 & 3.156 & 2.432 & 6.528 \\
\hline $\begin{array}{l}\text { Maximum Strong-Axis Lateral } \\
\text { Displacement (DWT 3), in. }\end{array}$ & -0.045 & 0.246 & -0.159 & 0.122 & -0.292 & 0.702 \\
\hline $\begin{array}{l}\text { Number of Cycles } \\
\text { (Load Increment, lbs) }\end{array}$ & $\begin{array}{c}9 \\
(5000)\end{array}$ & $\begin{array}{c}8 \\
(10000)\end{array}$ & $\begin{array}{c}10 \\
(5000)\end{array}$ & $\begin{array}{c}10 \\
(5000)\end{array}$ & $\begin{array}{c}10^{1} \\
(5000)\end{array}$ & $\begin{array}{c}11 \\
(5000)\end{array}$ \\
\hline
\end{tabular}

${ }^{1}$ Specimen GFRP-2 passed through the cycle to 30,000 lbs due to error in load control, thus reducing the total number of cycles.

$*$ NOTE $-1 \mathrm{lb}=4.45 \mathrm{~N}, 1 \mathrm{in}=0.0254 \mathrm{~m}$

Table 4.2 Summary of strain readings from brace cyclic loading

\begin{tabular}{|l|c|c|c|c|c|c|}
\hline & C & B & CFRP-2 & CFRP-1 & GFRP-2 & GFRP-1 \\
\hline Maximum Compressive Load, lbs & 49255 & 93835 & 48712 & 47833 & 52191 & 53772 \\
\hline Maximum Strain (1), $\mu$ e & 1314 & -1173 & -3710 & -7545 & 7597 & -2365 \\
\hline Maximum Strain (2), $\mu$ e & -1325 & -14803 & 8394 & 12815 & 1791 & 3824 \\
\hline Maximum Strain (3), $\mu$ e & -4845 & -1338 & 14624 & 15724 & 4397 & 14186 \\
\hline Maximum Strain (4), $\mu$ e & -5295 & $l$ & 14856 & 6873 & 3994 & 15967 \\
\hline Maximum Strain (5), $\mu$ e & 1976 & -1350 & -13565 & -15365 & -11863 & -15276 \\
\hline Maximum Strain (6), $\mu$ Meximum Strain (7), $\mu$ ee & 1701 & -1360 & -14979 & -15098 & -10143 & -6719 \\
\hline Maximum Strain (8), $\mu e$ & & & 7126 & 7532 & -975 & 6581 \\
\hline
\end{tabular}

${ }^{1}$ Strain gage 4 for Specimen B failed.

$* \mathrm{NOTE}-1 \mathrm{lb}=4.45 \mathrm{~N}$ 


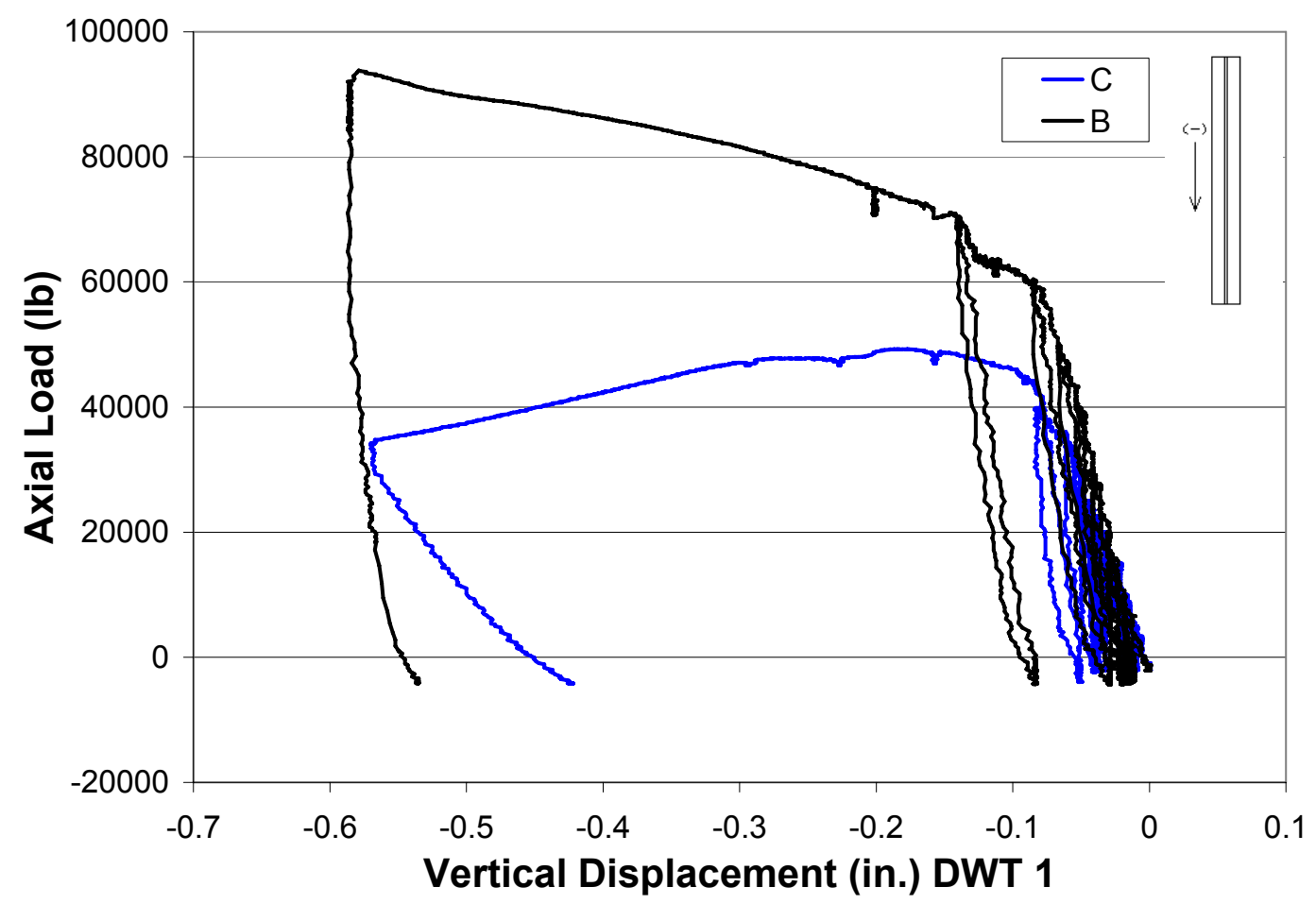

Figure 4.1 Load vs. axial displacement of Specimens B and C.

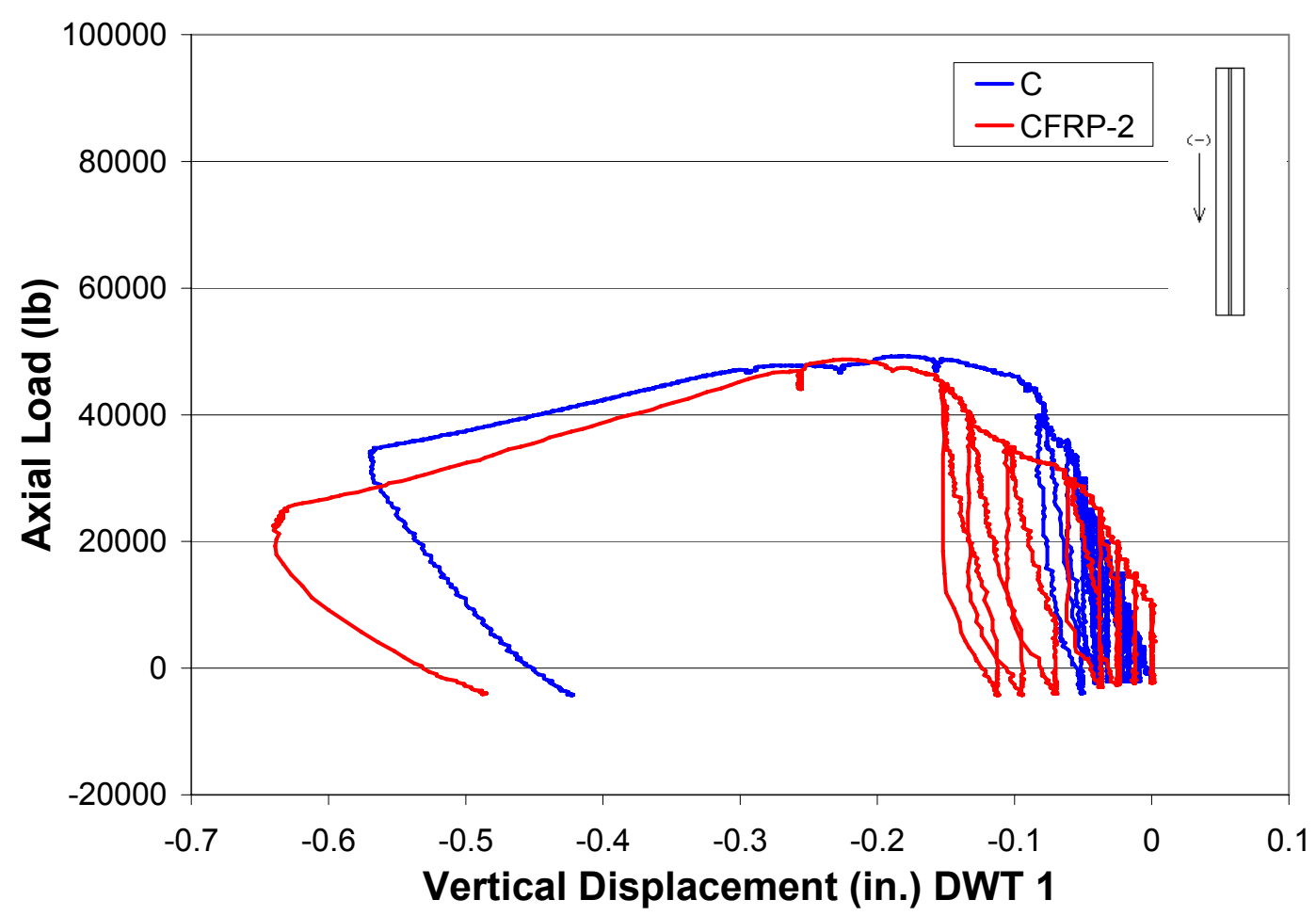

Figure 4.2 Load vs. axial displacement of Specimens CFRP-2 and C. 


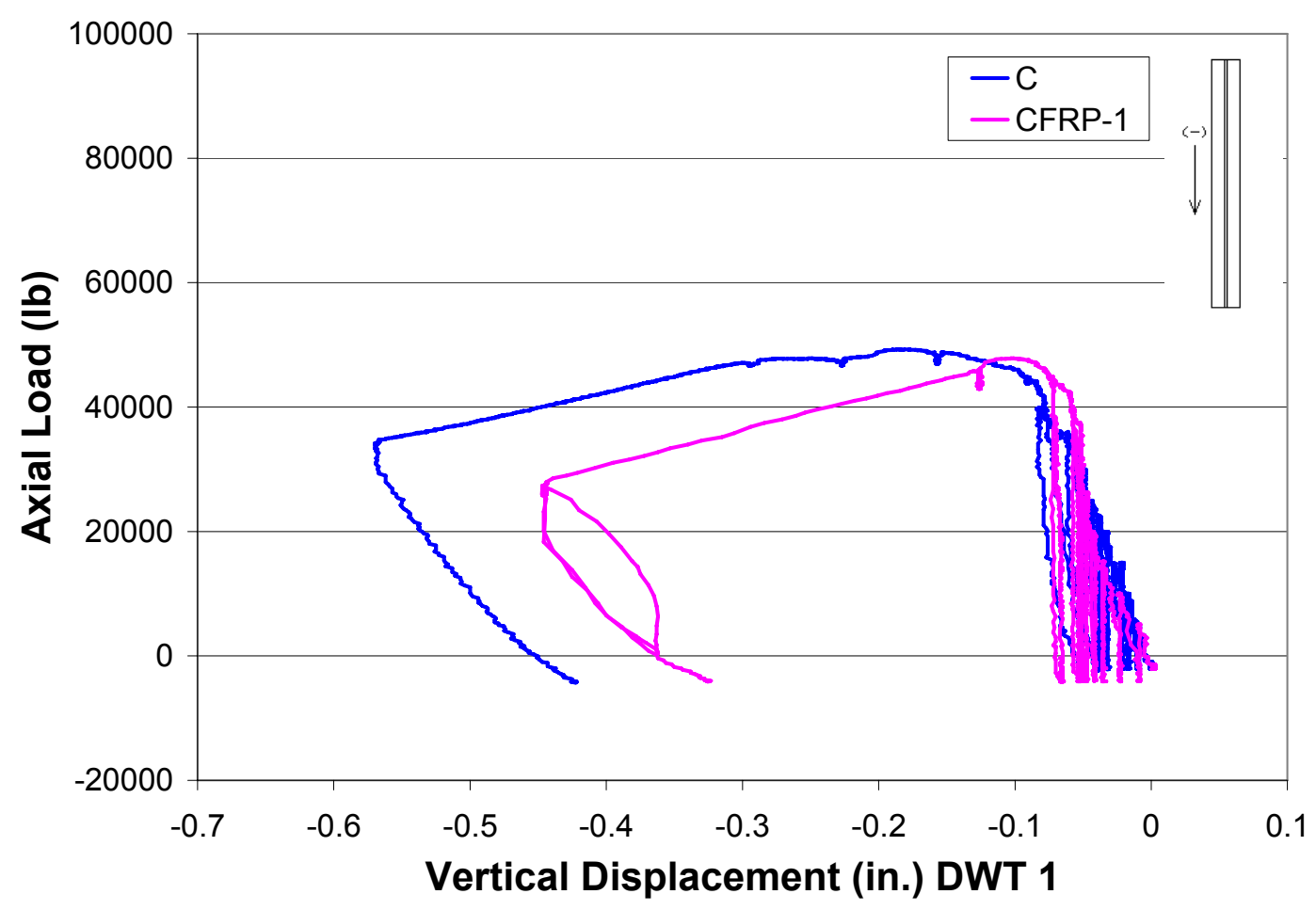

Figure 4.3 Load vs. axial displacement of Specimens CFRP-1 and C.

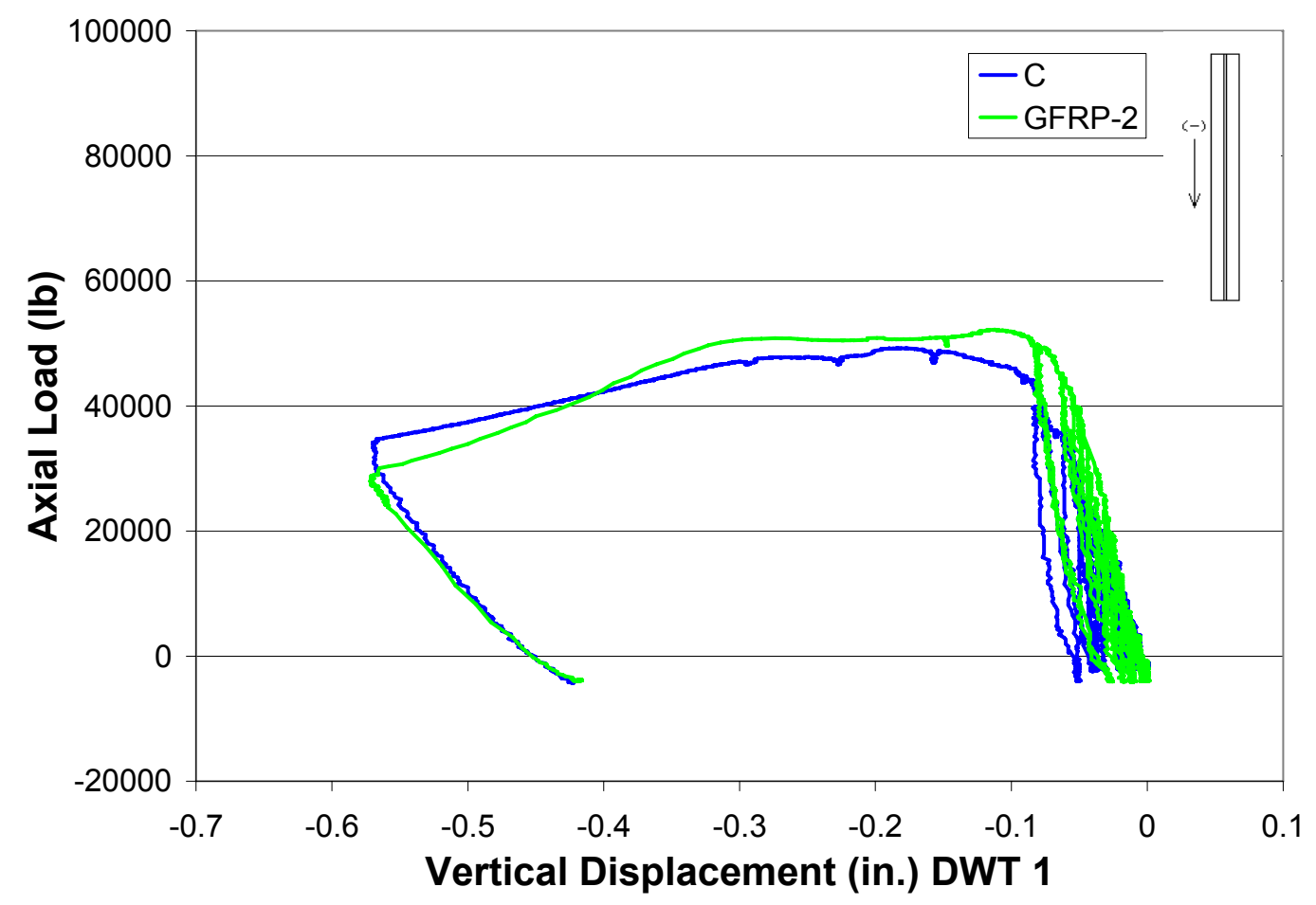

Figure 4.4 Load vs. axial displacement of Specimens GFRP-2 and C. 


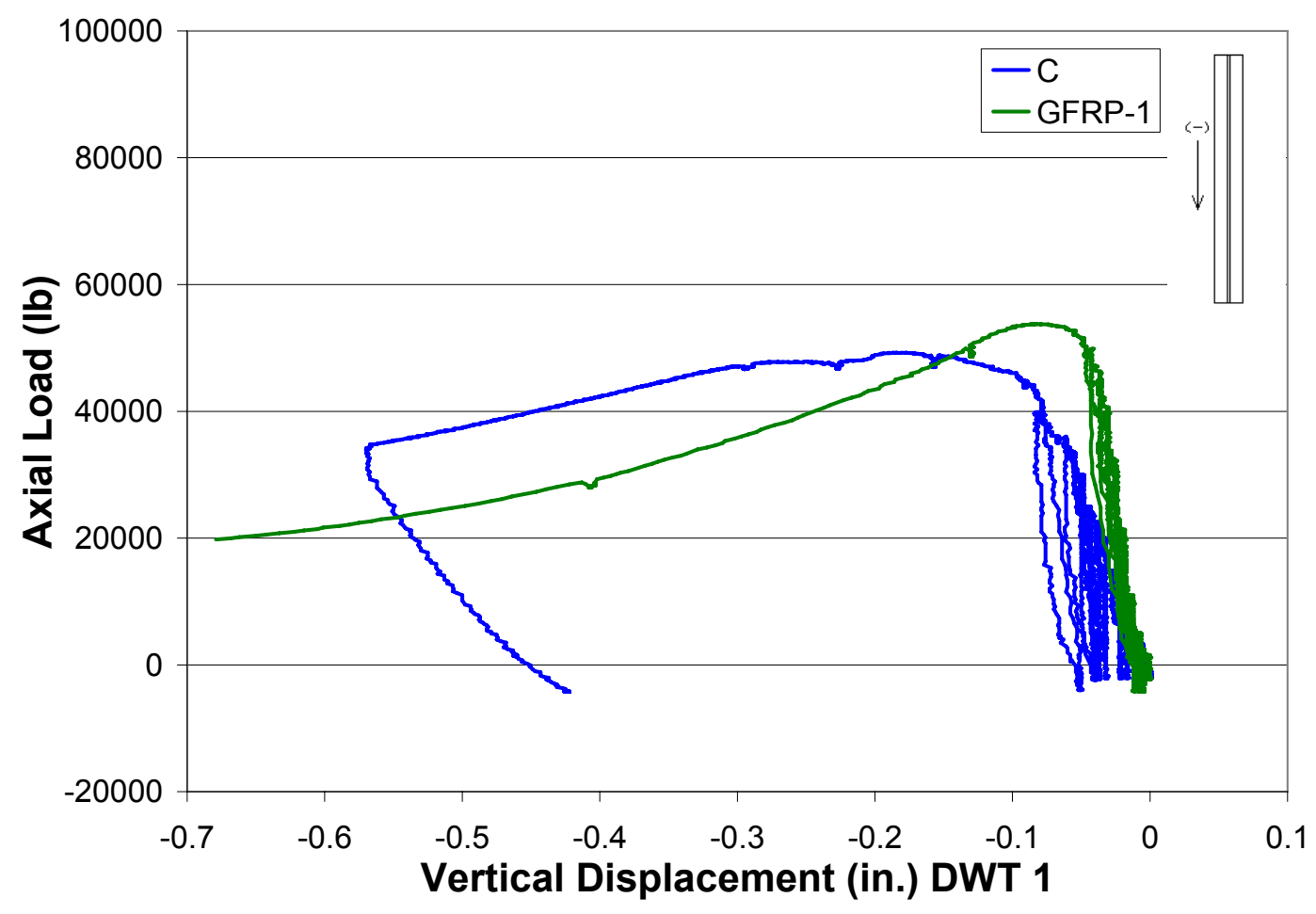

Figure 4.5 Load vs. axial displacement of Specimens GFRP-1 and C.

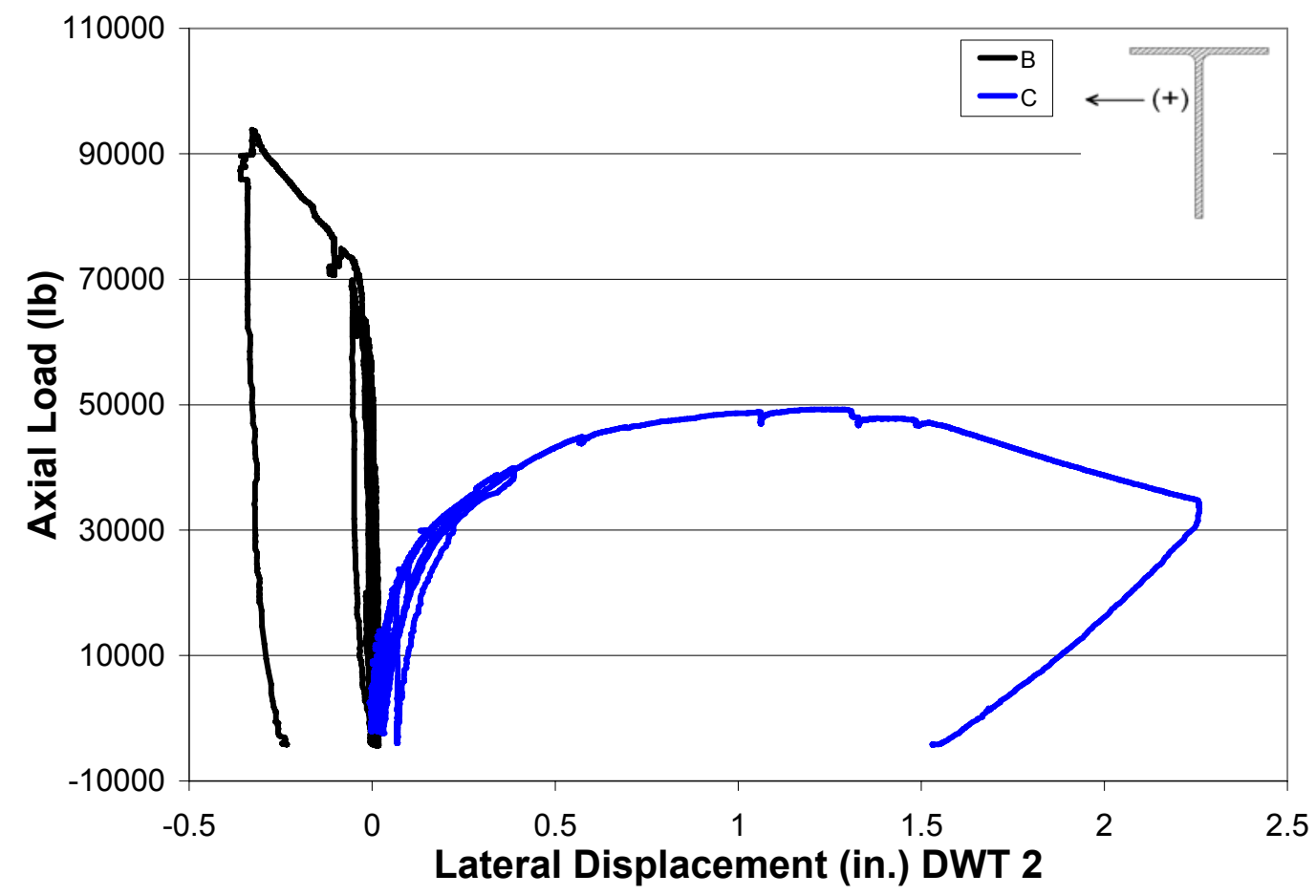

Figure 4.6 Load vs. weak-axis lateral displacement of Specimens B and C. 


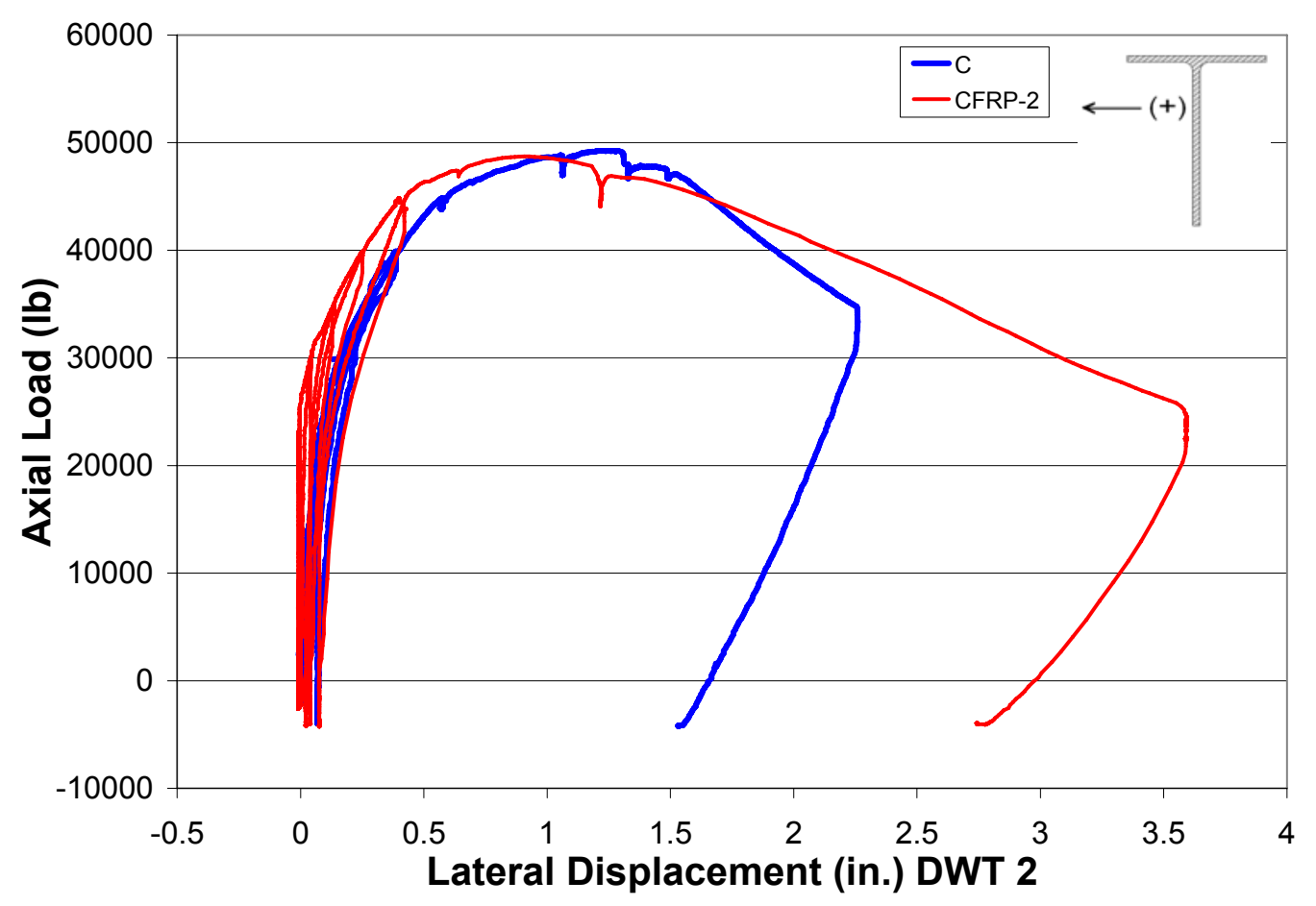

Figure 4.7 Load vs. weak-axis lateral displacement of Specimens CFRP-2 and C.

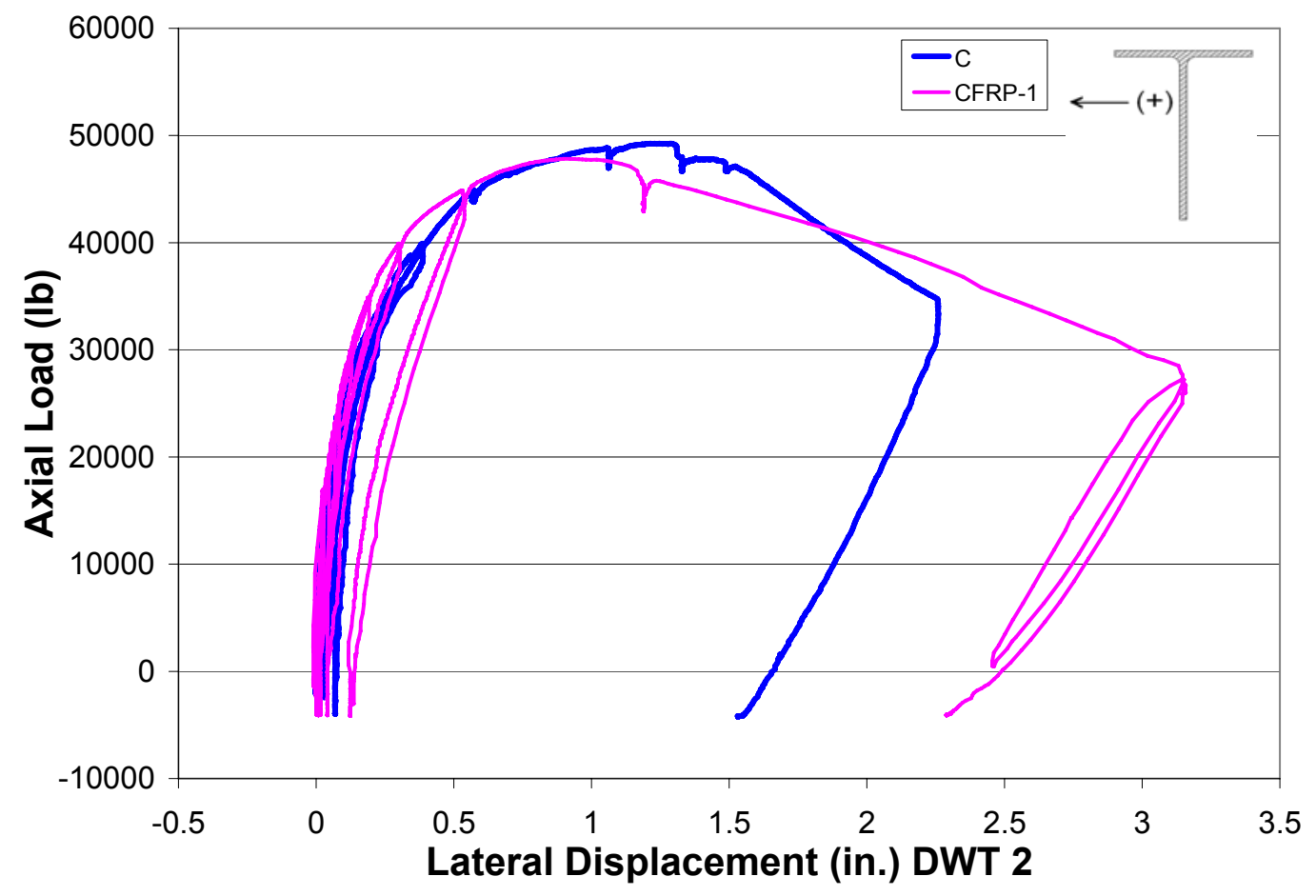

Figure 4.8 Load vs. weak-axis lateral displacement of Specimens CFRP-1 and C. 


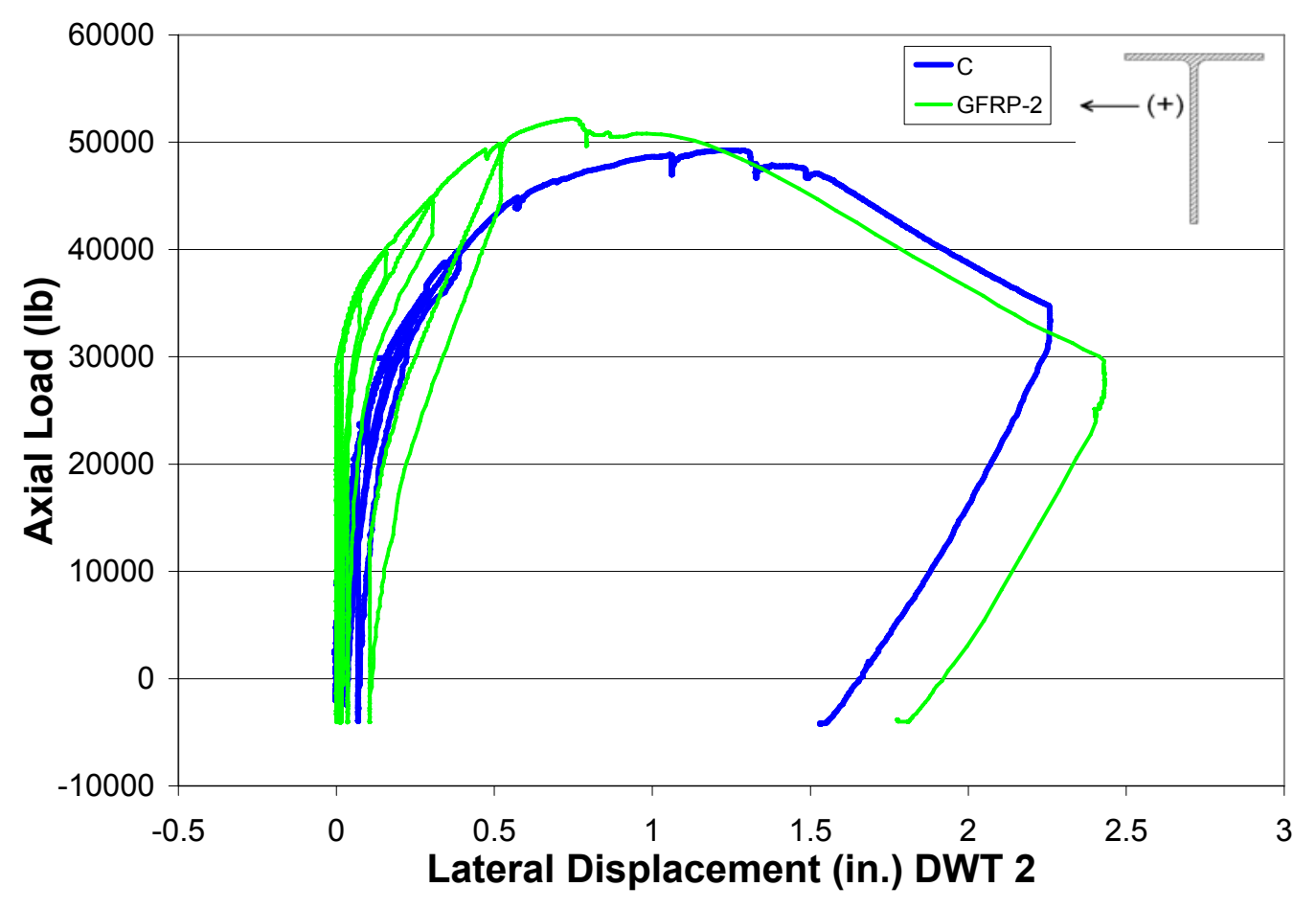

Figure 4.9 Load vs. weak-axis lateral displacement of Specimens GFRP-2 and C.

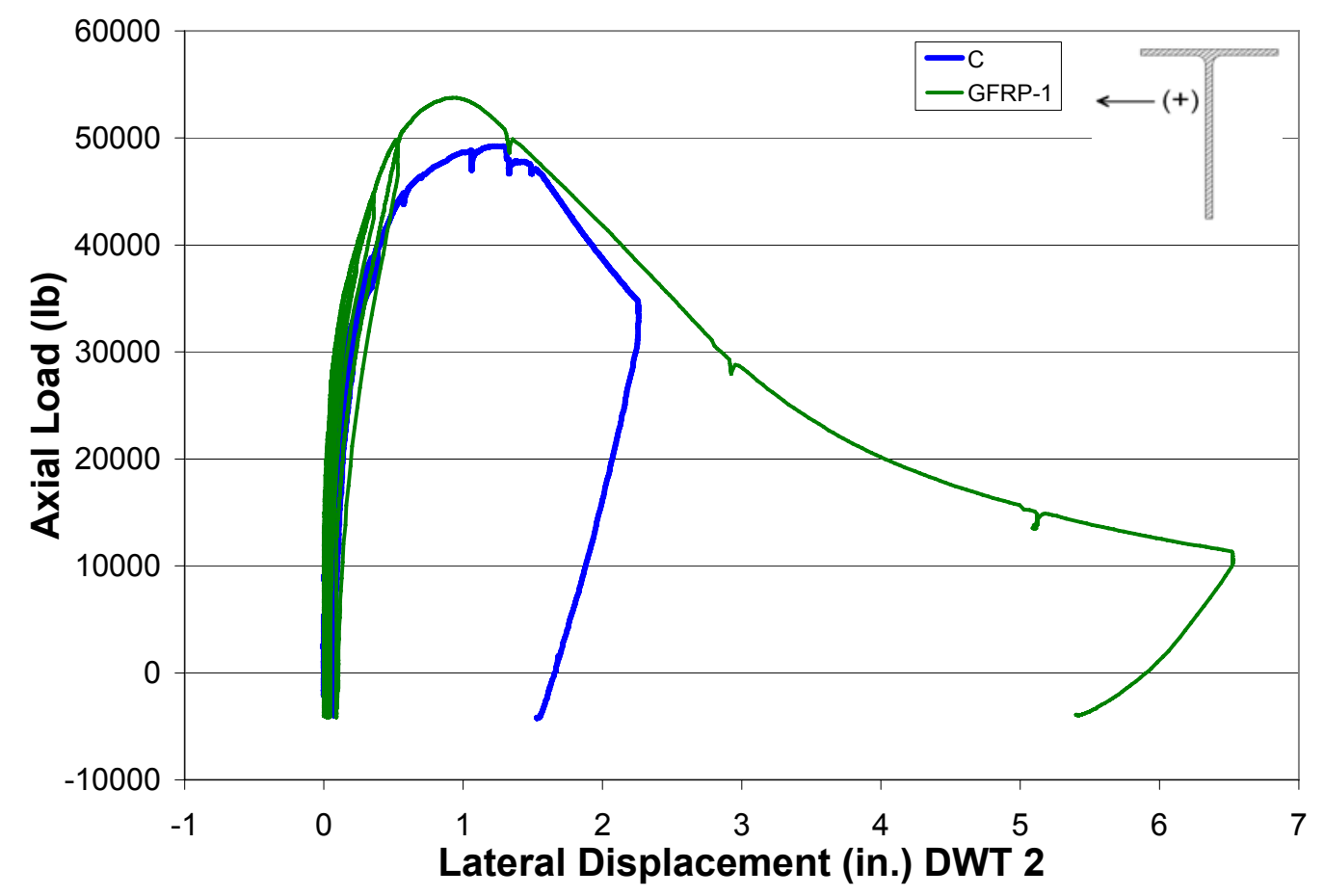

Figure 4.10 Load vs. weak-axis lateral displacement of Specimens GFRP-1 and C. 


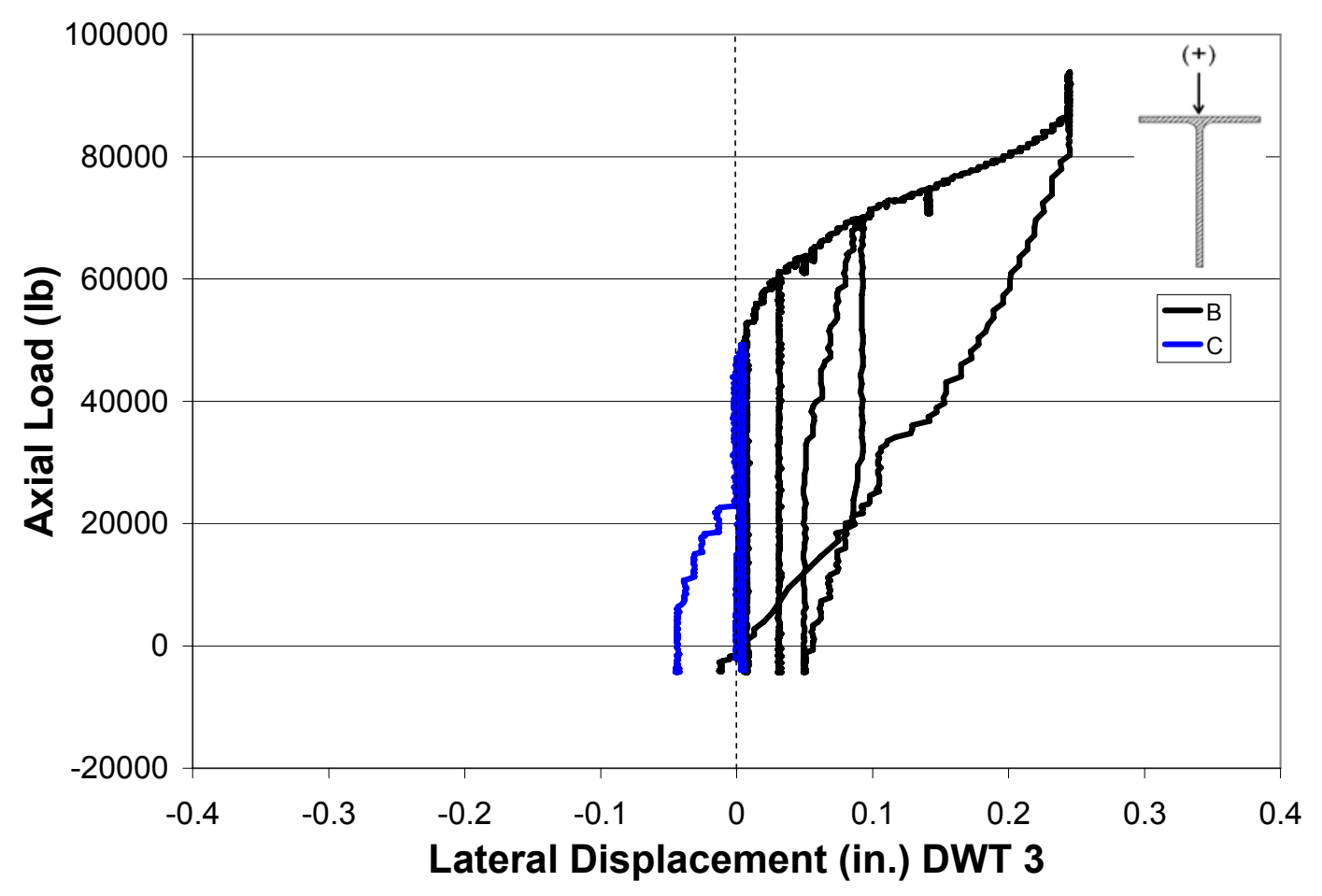

Figure 4.11 Load vs. strong-axis lateral displacement of Specimens B and C.

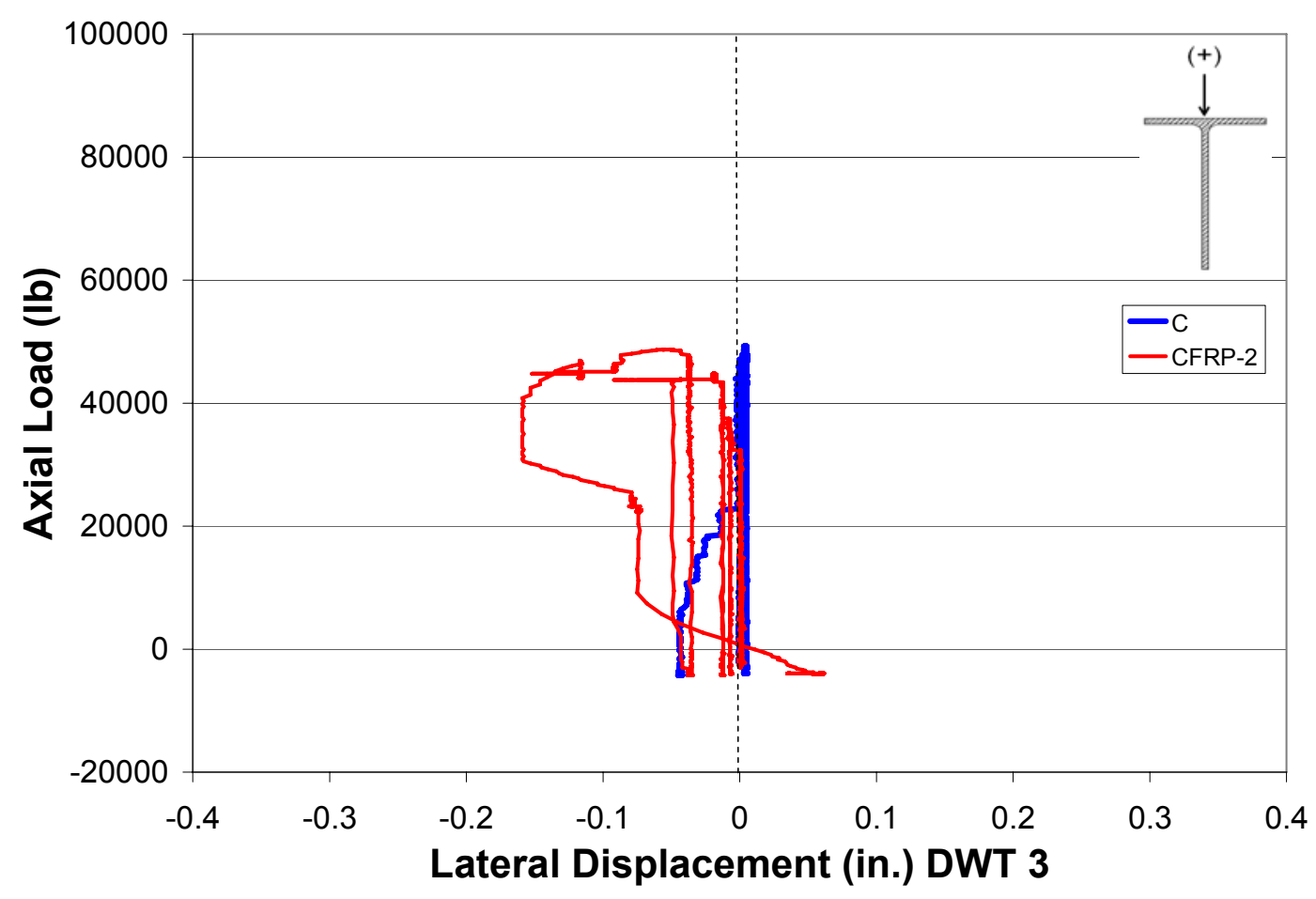

Figure 4.12 Load vs. strong-axis lateral displacement of Specimens CFRP-2 and C. 


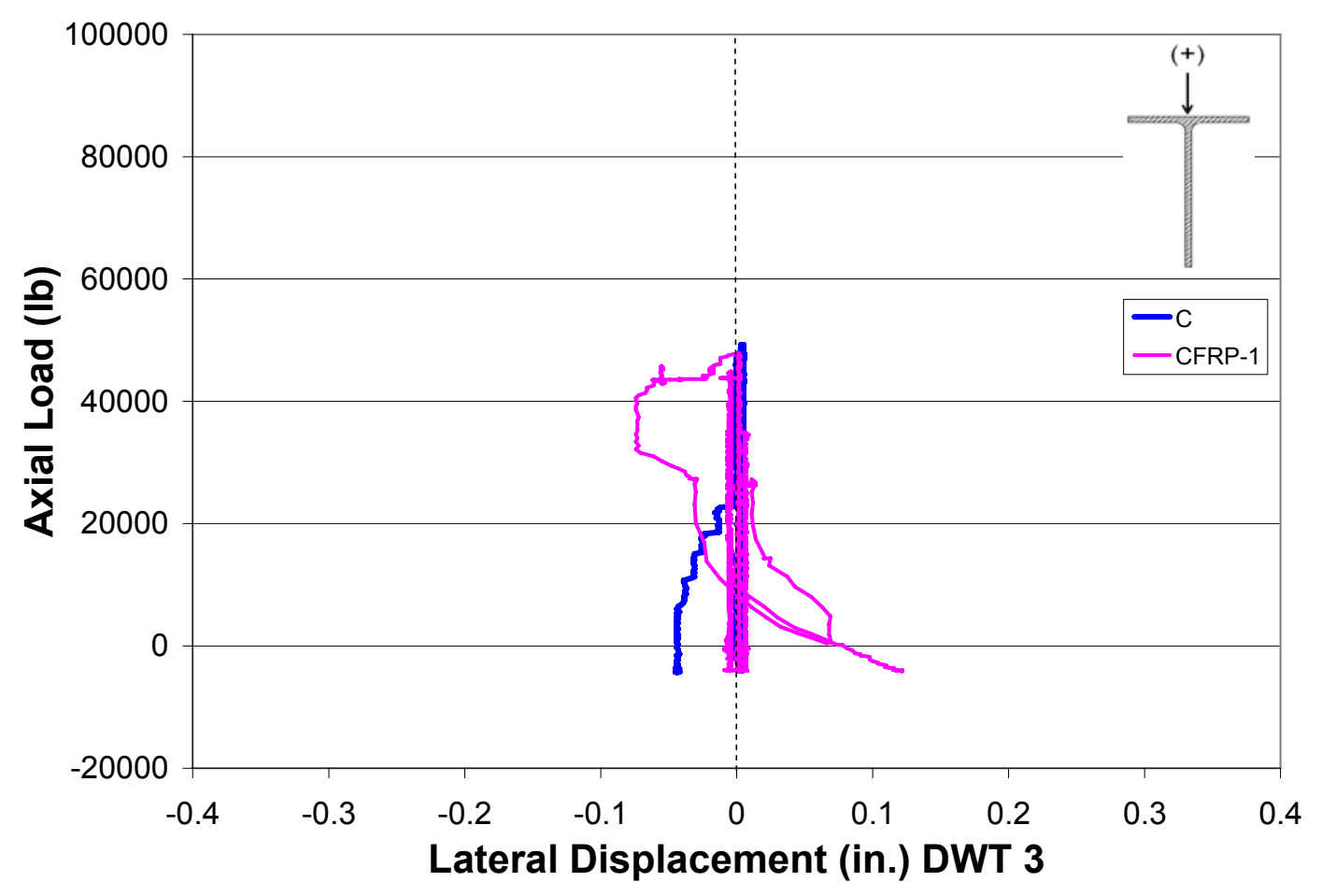

Figure 4.13 Load vs. strong-axis lateral displacement of Specimens CFRP-1 and C.

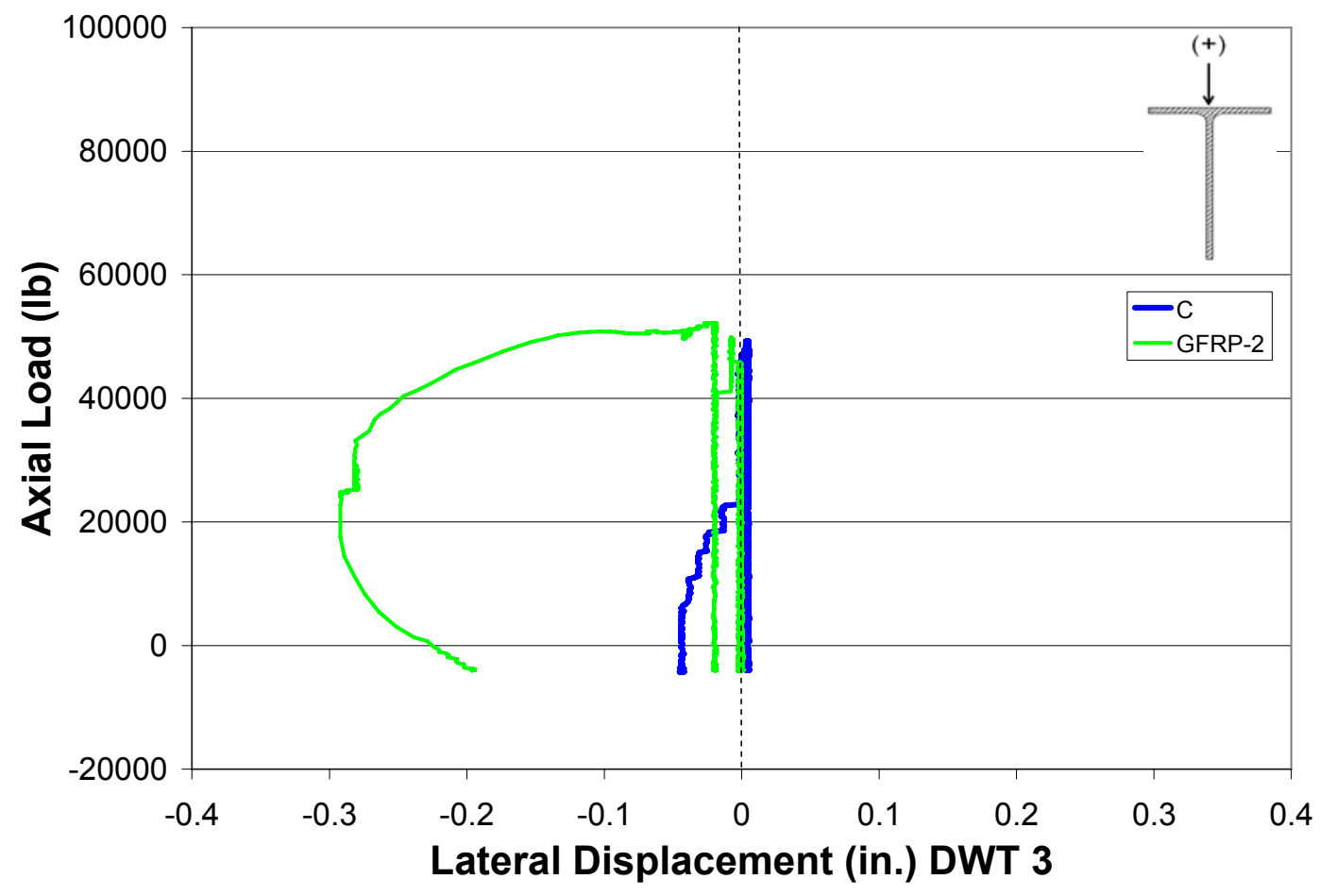

Figure 4.14 Load vs. strong axis lateral displacement of Specimens GFRP-2 and C. 


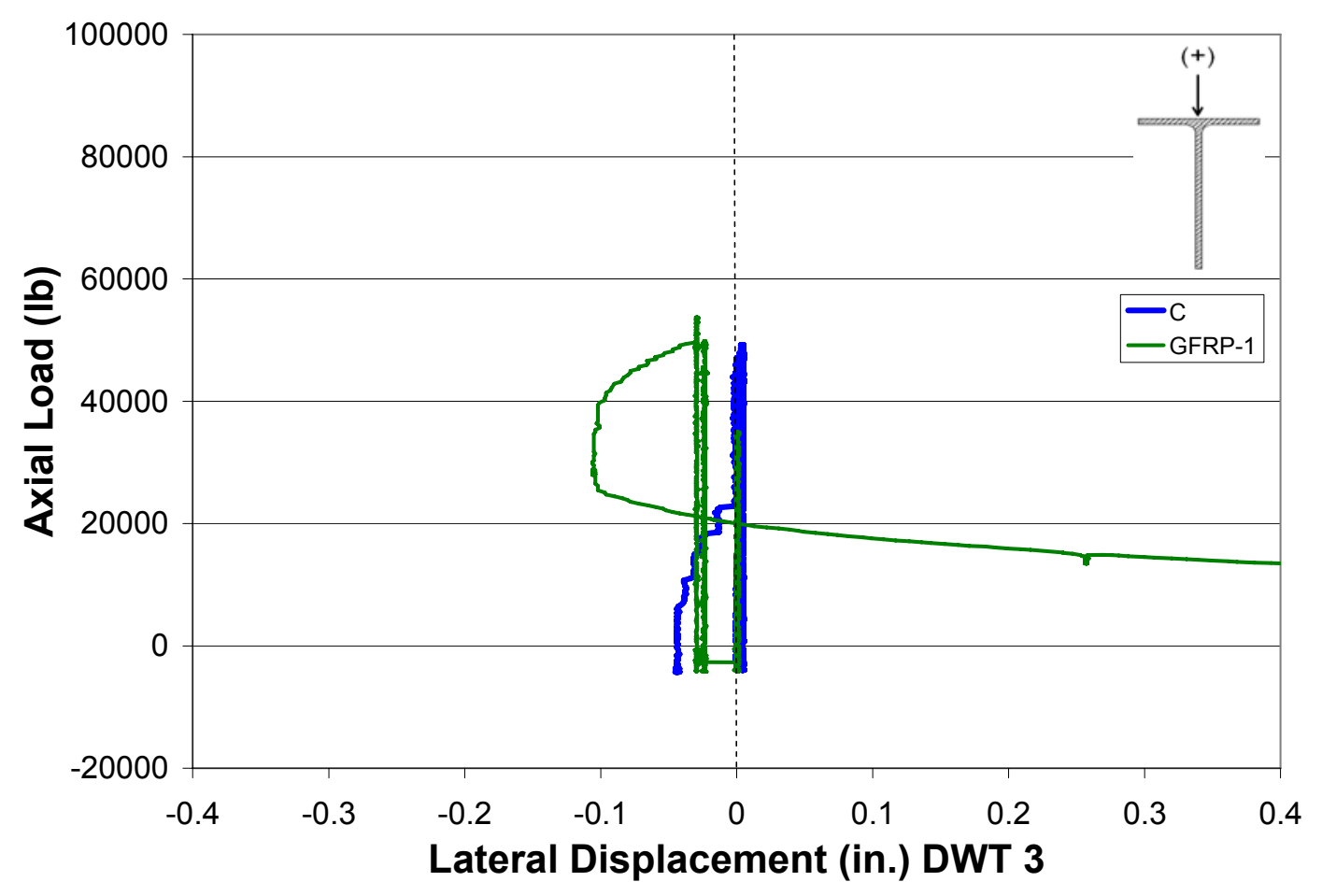

Figure 4.15 Load vs. strong-axis lateral displacement of Specimens GFRP-1 and C.

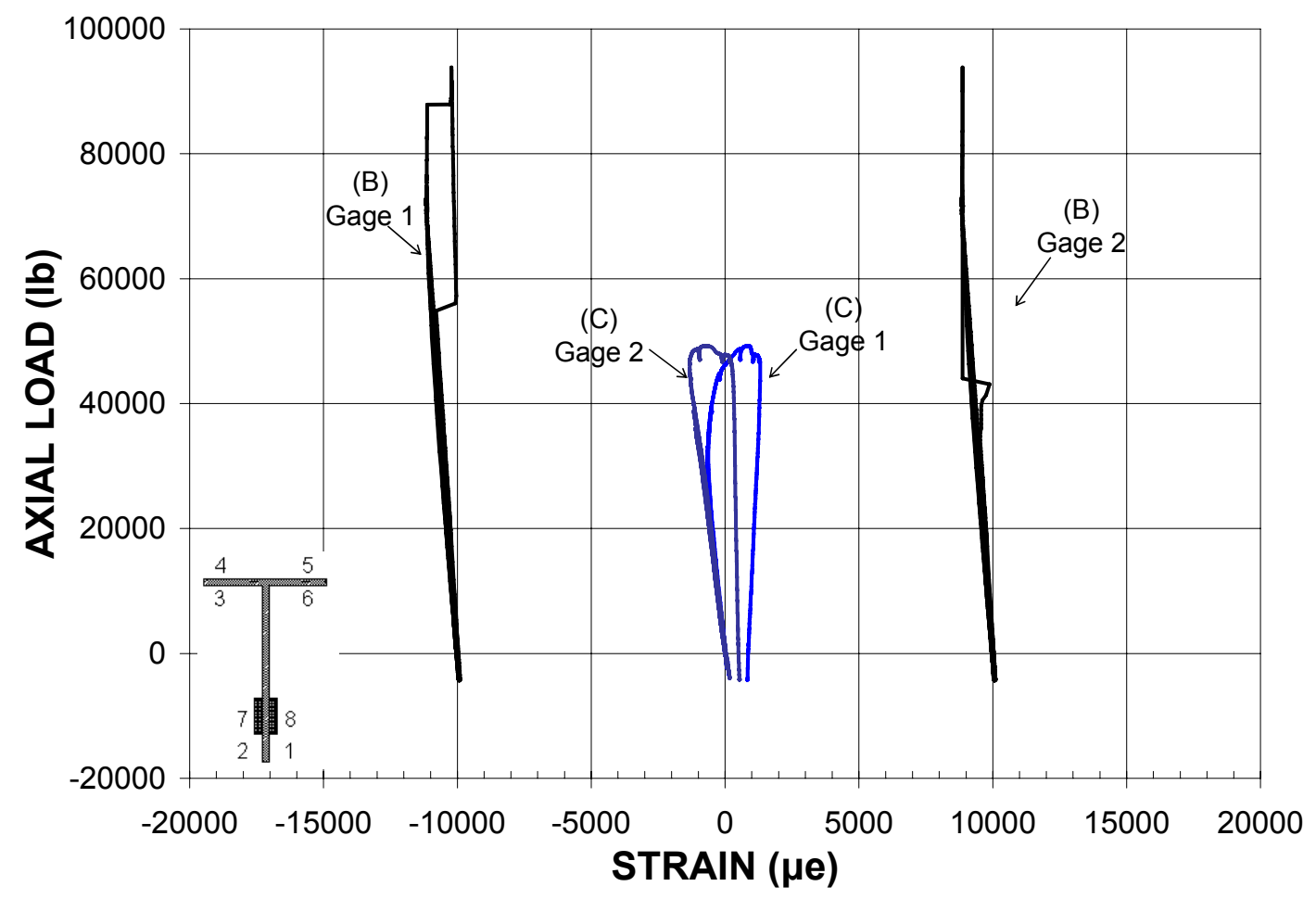

Figure 4.16 Load vs. steel strain in the stem tip for Specimens B and C. 


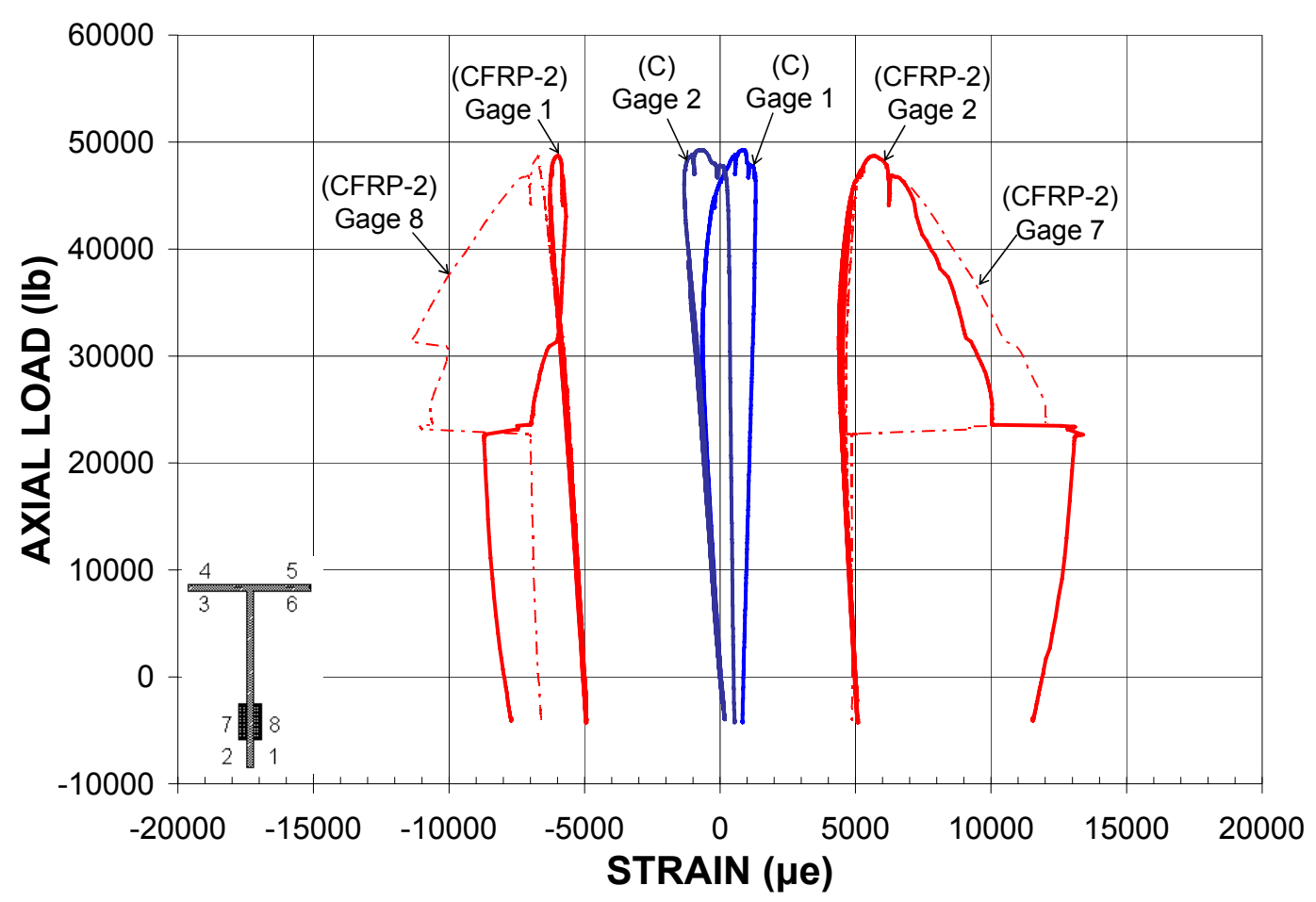

Figure 4.17 Load vs. strain in the stem tip and FRP for Specimens CFRP-2 and C.

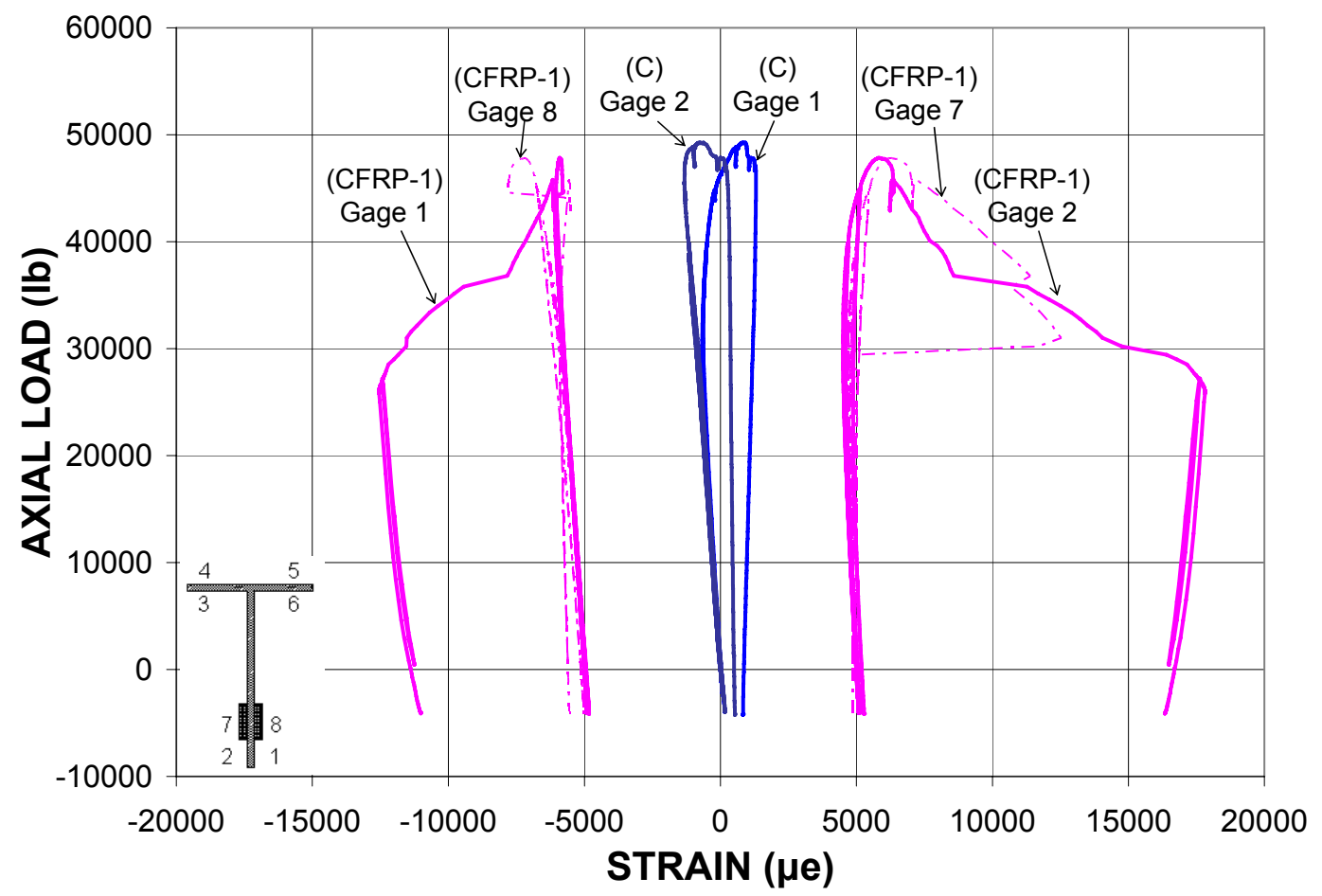

Figure 4.18 Load vs. strain in the stem tip and FRP for Specimens CFRP-1 and C. 


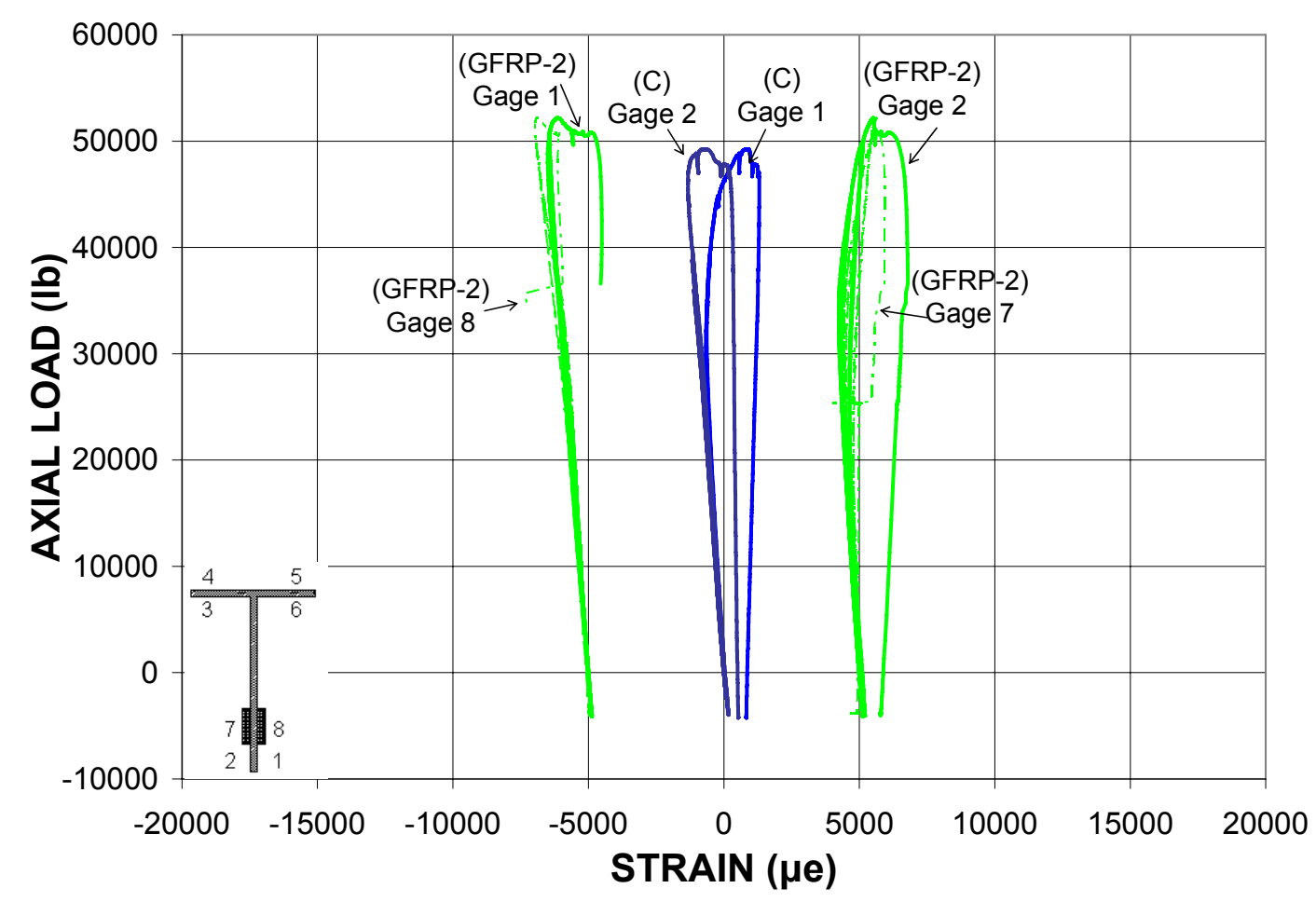

Figure 4.19 Load vs. strain in the stem tip and FRP for Specimens GFRP-2 and C.

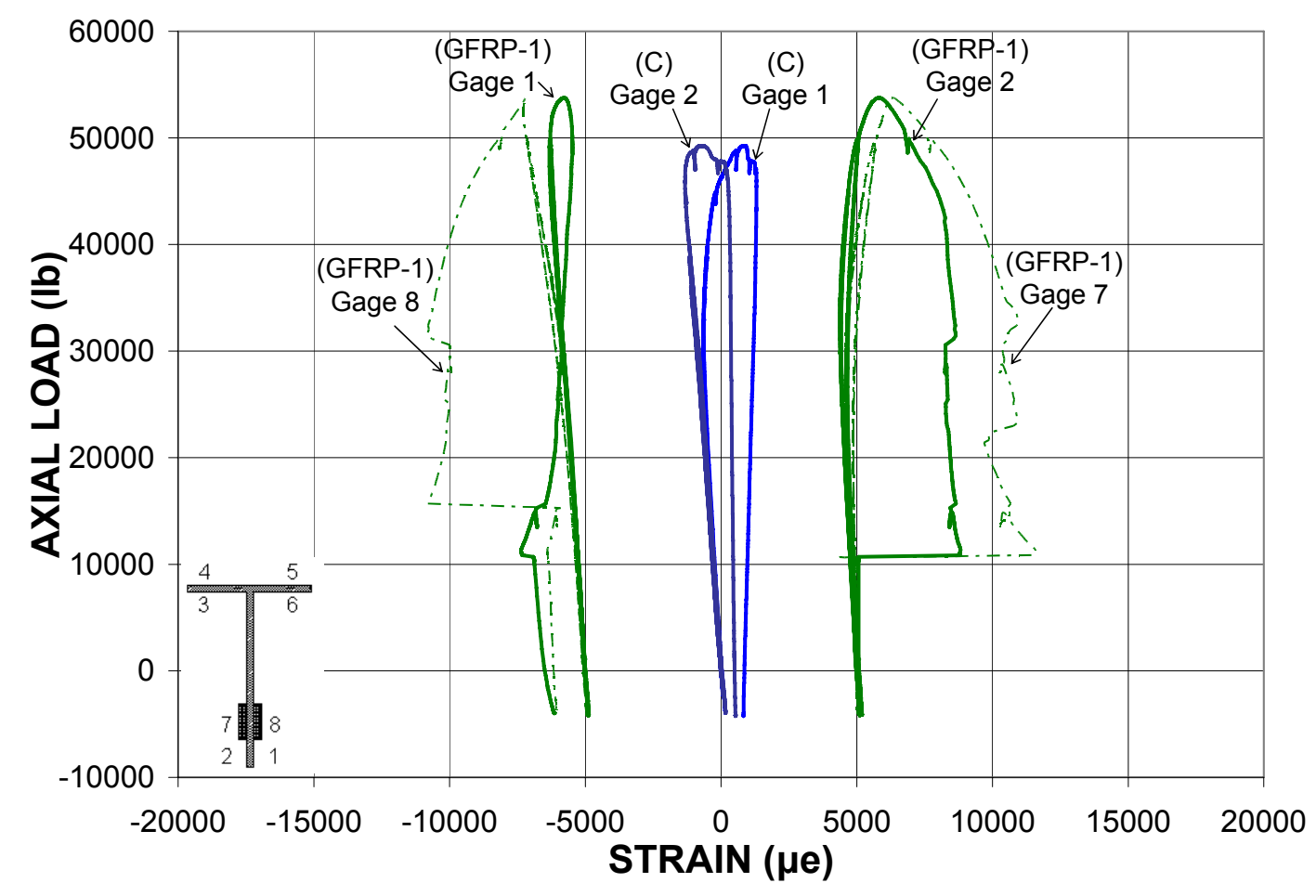

Figure 4.20 Load vs. strain in the stem tip and FRP for Specimens GFRP-1 and C. 


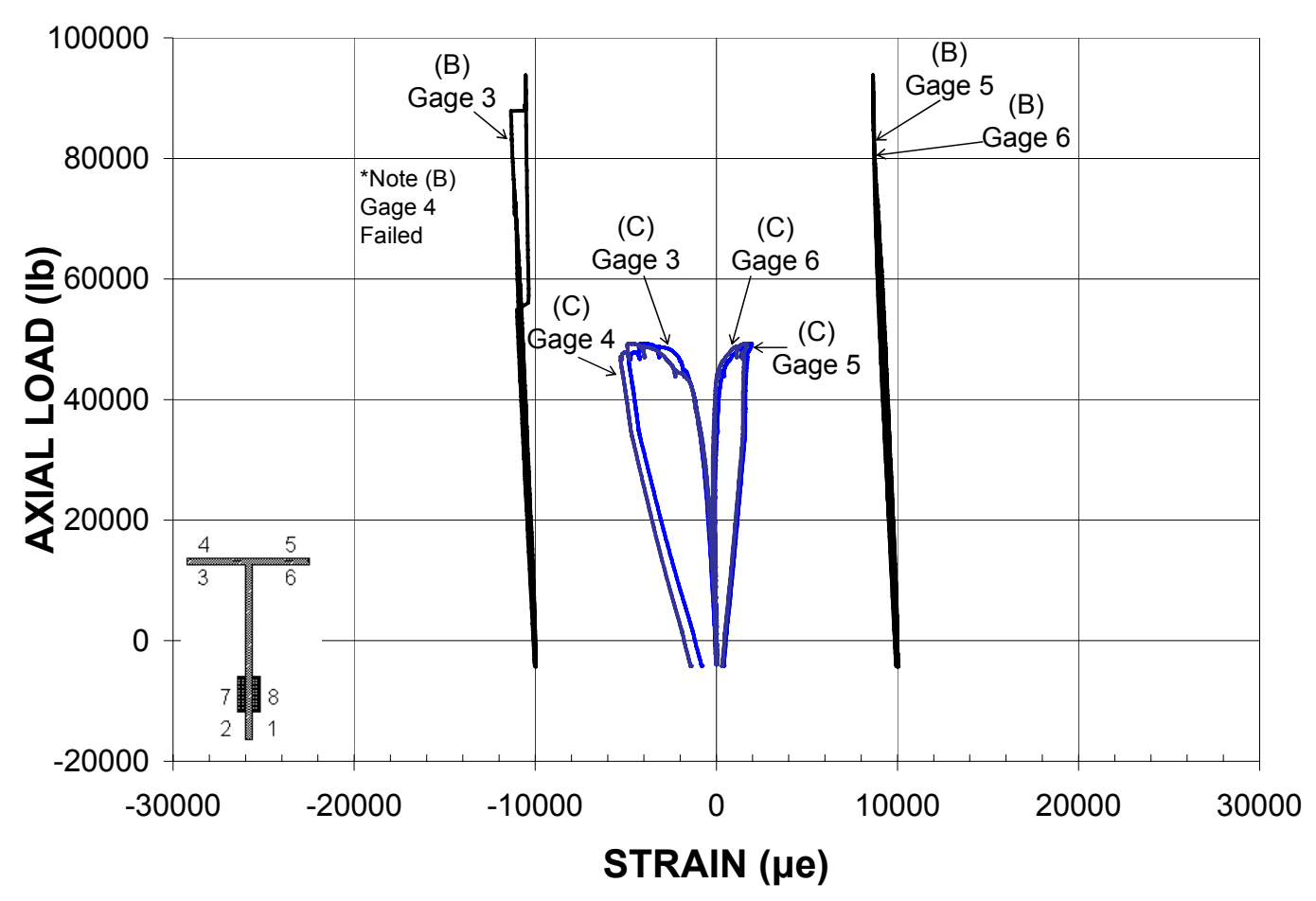

Figure 4.21 Load vs. strain in flange tips of Specimens B and C.

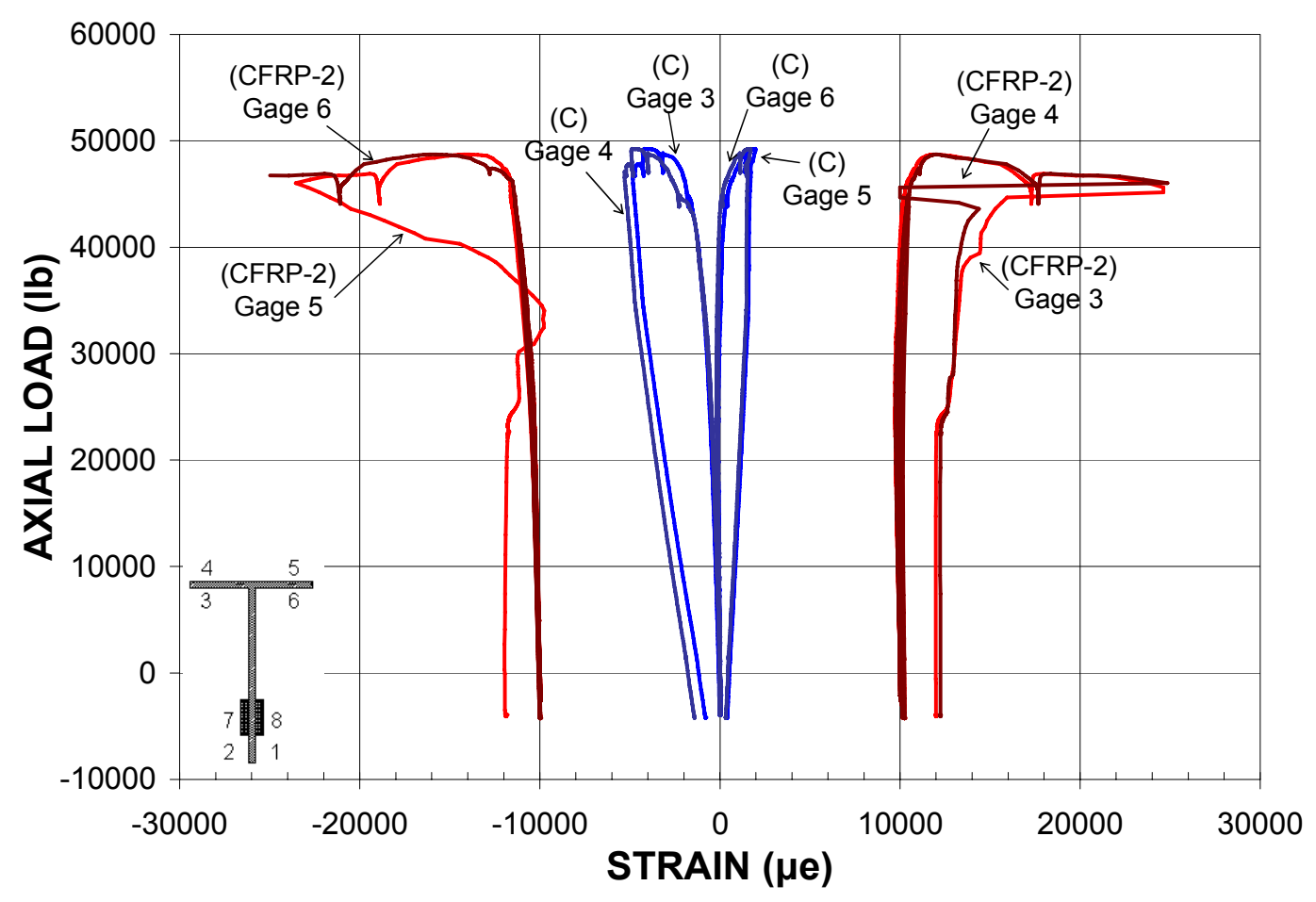

Figure 4.22 Load vs. strain in flange tips of Specimens CFRP-2 and C. 


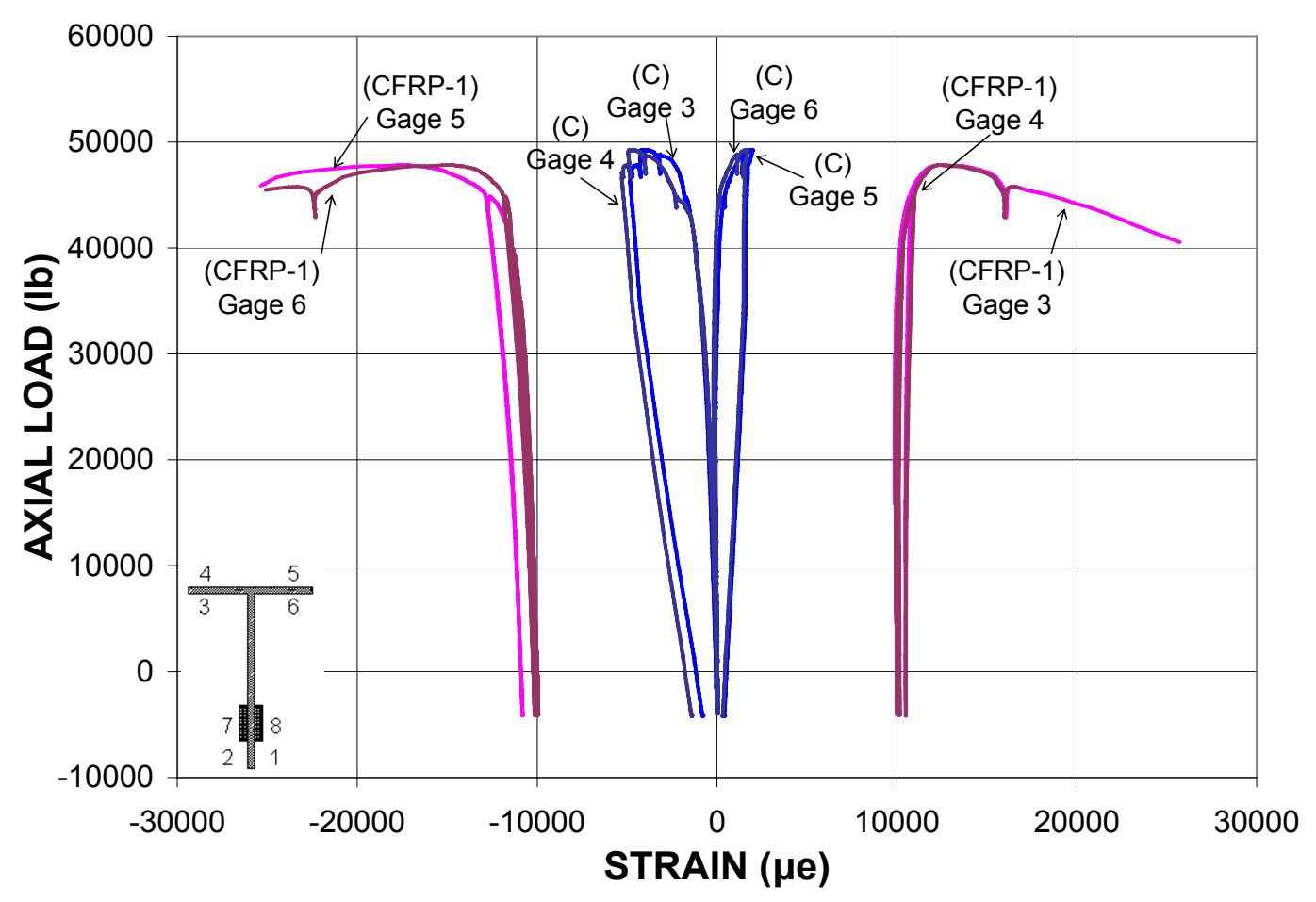

Figure 4.23 Load vs. strain in flange tips of Specimens CFRP-1 and C.

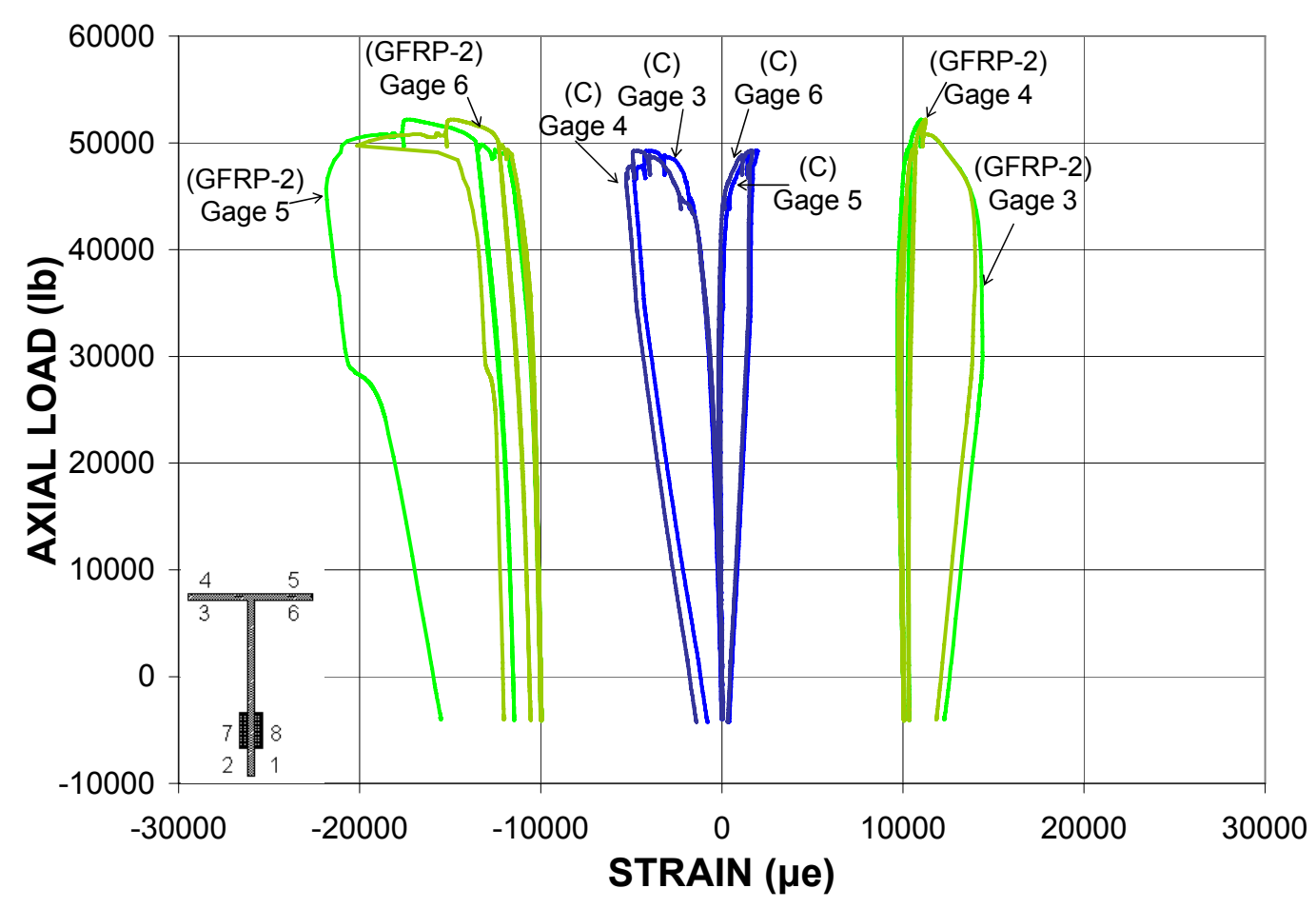

Figure 4.24 Load vs. strain in flange tips of Specimens GFRP-2 and C. 


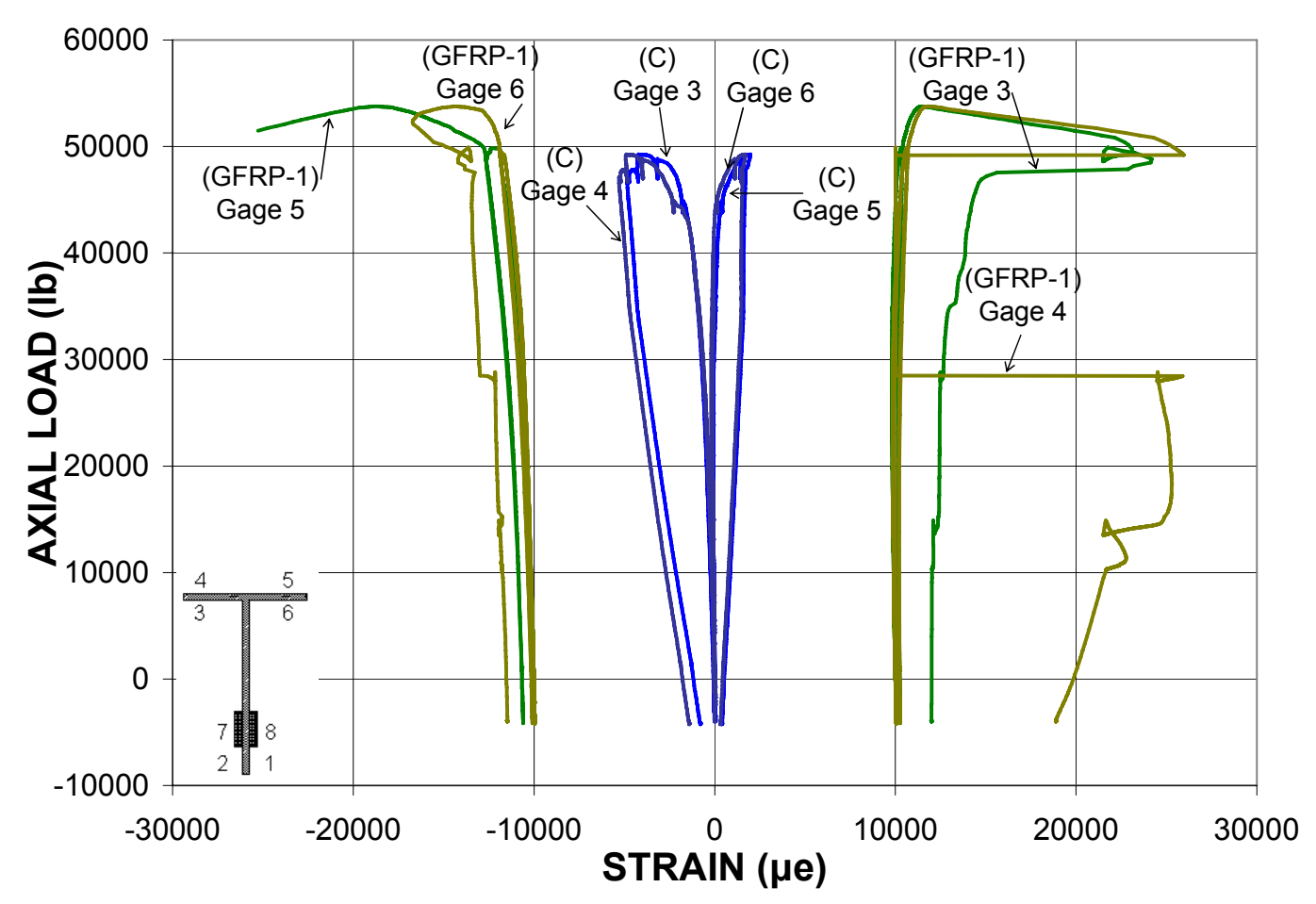

Figure 4.25 Load vs. strain in flange tips of Specimens GFRP-1 and C.

\subsection{SPECIMEN BEHAVIOR}

This section presents the behavior of each specimen.

\subsubsection{Specimen C}

The cyclic testing of the control brace, Specimen $\mathrm{C}$, induced a buckling failure characterized by excessive lateral deflections. Specimen $\mathrm{C}$ was subjected to 9 cycles of increasing compressive loading with a maximum load of 49,255 lbs (219 kN). A peak axial displacement along the length of Specimen C of -0.57 ' $(-14.5 \mathrm{~mm})$ was recorded. The maximum measured mid-height lateral displacement in the weak and strong directions was 2.26 " (57.4 mm) 
and $-0.045 "(-1.14 \mathrm{~mm})$ (see Figure 3.4 for a definition of the positive and negative lateral deflections), respectively. These deflections were measure at mid-height of the brace; however maximum lateral displacement of the stem and local buckling were observed at a location 20" $(508 \mathrm{~mm})$ from the lower end of the brace. Visible buckling was first observed during the $6^{\text {th }}$ cycle reaching a maximum compressive load of $30,000 \mathrm{lbs}(133 \mathrm{kN})$. During the $8^{\text {th }}$ loading cycle, at an approximate load of $38,900 \mathrm{lbs}(173 \mathrm{kN})$, the friction connection at the bottom end of the brace slipped and the bolts transitioned into bearing. Specimen $\mathrm{C}$ was the first brace to be tested, therefore the loading was slowly increased after completing the $9^{\text {th }}$ cycle to $45,000 \mathrm{lbs}$ $(200 \mathrm{kN})$, until excessive deflections were seen. Significant lateral torsional buckling was observed at higher loads and was apparent in residual displacements. Figure 4.26 presents pictures of Specimen $\mathrm{C}$ at three different loading stages. In this figure (and subsequent figures) a plumb bob to the left of each specimen indicates the original vertical orientation.

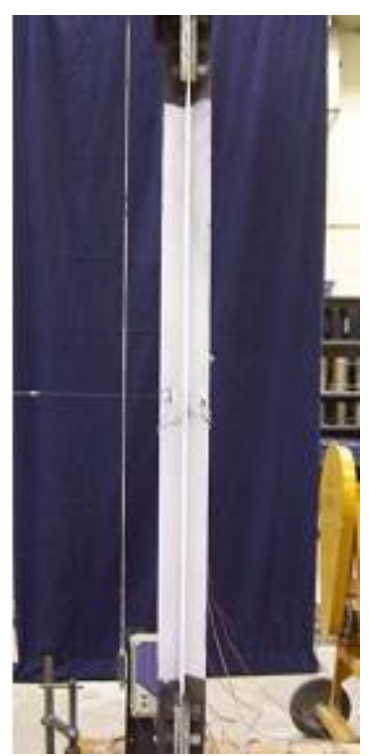

(a)

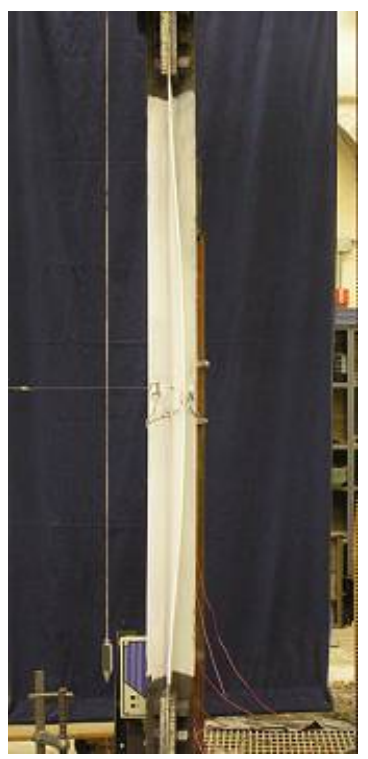

(b)

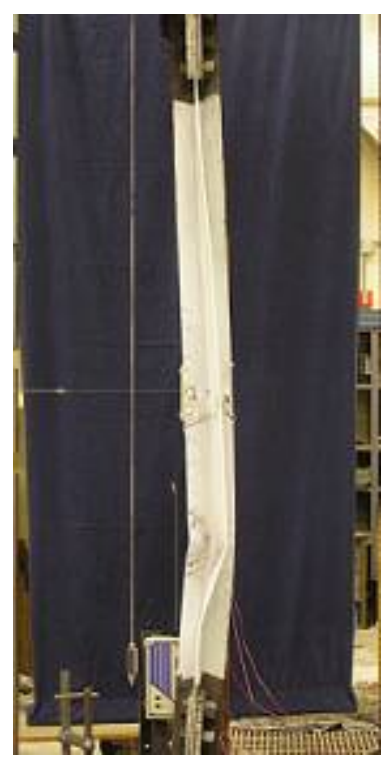

(c)

Figure 4.26 Specimen C

(a) prior to loading, (b) stem buckling after cycle 9 to 45,000 lbs. (200 kN), and (c) at maximum displacement following 9 cycles of loading. 


\subsubsection{Specimen B}

Specimen B was subject to cyclic compressive loading increasing in 10,000 lbs (44.5 kN) increments. During the $7^{\text {th }}$ cycle to $70,000 \mathrm{lbs}(311.4 \mathrm{kN})$ significant local buckling of the exposed brace above the lower connecting angles was noted. Specimen B was loaded with a total of 8 cycles of compressive loading increasing in increments of $10,000 \mathrm{lbs}(44.5 \mathrm{kN})$. After the 8 cycles and holding at a load of $80,000 \mathrm{lbs}(355.9 \mathrm{kN})$, the load was increased to a maximum of 93,835 lbs $(417.4 \mathrm{kN})$. The maximum axial displacement was -0.587 " $(-14.9 \mathrm{~mm})$ and the maximum weak and strong axis lateral displacement was $0.36 "(9.14 \mathrm{~mm})$ and $0.246 "(6.25$ $\mathrm{mm}$ ), respectively. The strain differential between gages 1 and 2 as well as gages 5 and 6 were minimal signifying the absence of local buckling within the restrained portion of the brace throughout the loading program. Figure 4.27 shows pictures of Specimen B prior to loading, at maximum displacement, and a close-up view of the exposed brace region and local buckling above the lower connection. 


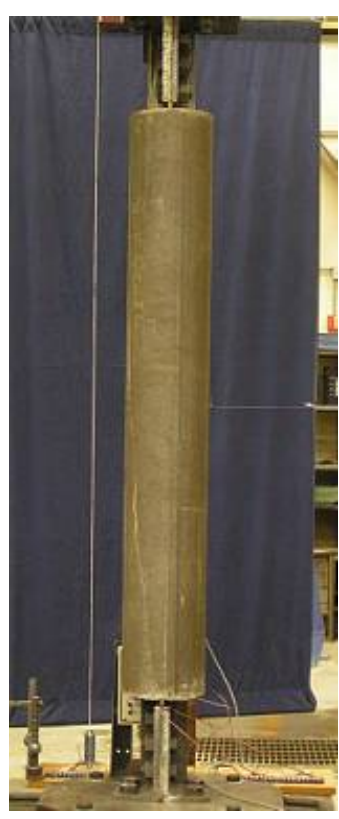

(a)

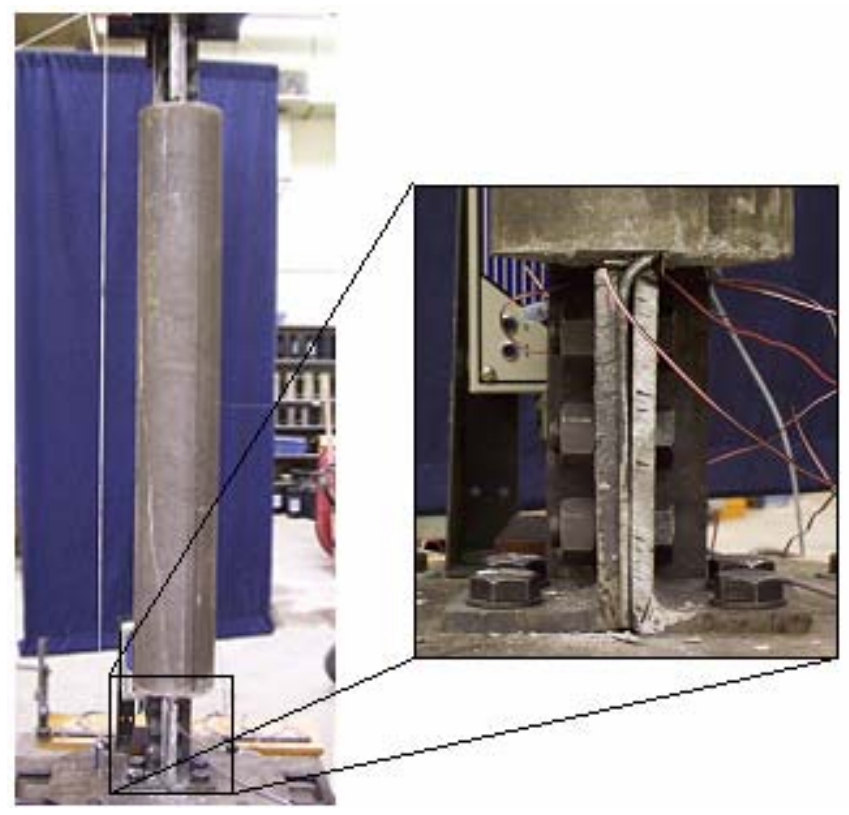

(b) (c)

Figure 4.27 Specimen B

(a) prior to loading, (b) at maximum displacement after 8 cycles of loading, (c) close-up of buckling near the connection.

\subsubsection{Specimen CFRP-2}

Incrementally increased cyclic compressive loading of Specimen CFRP-2 induced a buckling failure characterized by excessive lateral deflections, and eventual CFRP debonding. Specimen CFRP-2 was subjected to 10 cycles of compressive loading with a maximum load of 48,712 lbs $(216.7 \mathrm{kN})$. A peak axial displacement along the length of Specimen CFRP-2 of 0.64" (-16.3 mm) was recorded. The maximum measured weak and strong axis mid-height lateral displacement was 3.593" (91.3 mm) and -0.159" (-4.04 mm), respectively. Slight visible buckling was first observed during the $6^{\text {th }}$ cycle corresponding to a maximum compressive load of $30,000 \mathrm{lbs}(133.4 \mathrm{kN})$. Recorded strain values in the stem show the onset of local buckling to have occurred around 32,000 lbs $(142.3 \mathrm{kN})$. CFRP debonding was observed at the maximum 
imposed load. The CFRP strip on the tension side of the brace stem debonded from the steel initiating near the region of greatest curvature and propagating to the end of the application. The CFRP strip on the compression side of the stem debonded only near mid-height of the brace, remaining bonded to the brace toward the termination of the CFRP strip. Figure 4.28 presents pictures of Specimen CFRP-2 at different loading stages and final debonding of the CFRP.

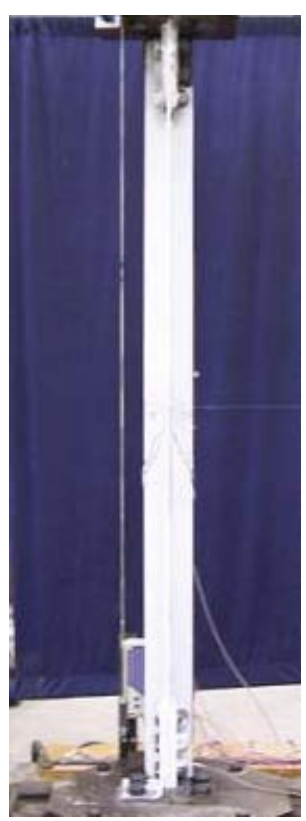

(a)

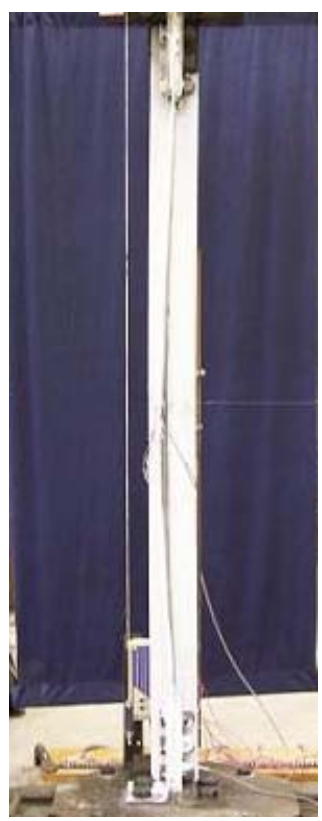

(b)

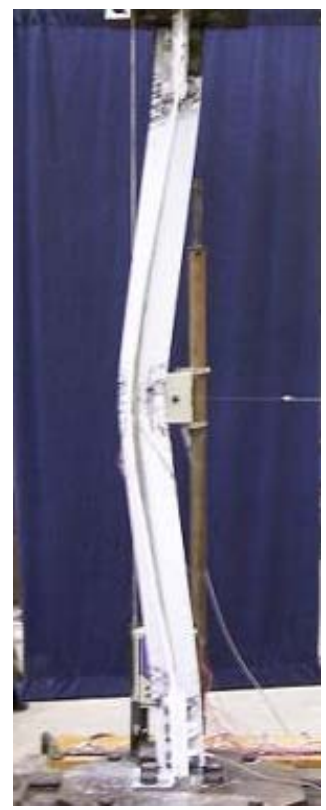

(c)

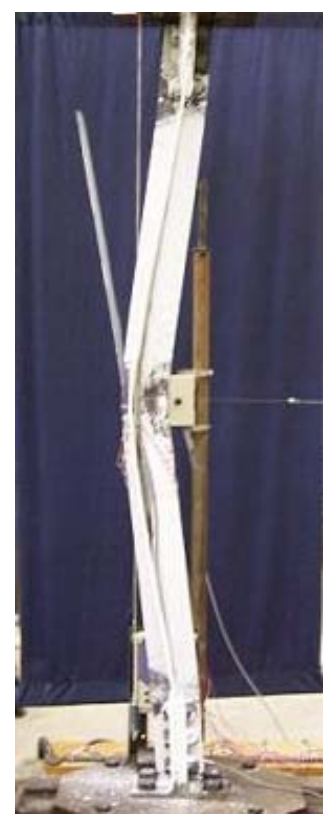

(d)

Figure 4.28 Specimen CFRP-2

(a) prior to loading, (b) stem buckling after cycle 9 to $45,000 \mathrm{lbs}$. (200 kN), (c) at maximum displacement after 10 cycles of loading prior to CFRP debonding, and (d) at maximum displacement with CFRP debonded.

\subsubsection{Specimen CFRP-1}

Specimen CFRP-1 failed under increased cyclic compressive loading by buckling characterized by excessive lateral deflections, and eventual CFRP debonding. Specimen CFRP-1 was subjected to 10 cycles of compressive loading with a maximum load of 47,833 lbs (212.8 $\mathrm{kN})$. A peak axial displacement along the length of Specimen CFRP-1 of -0.457 " (11.6 mm) was 
recorded. The maximum measured weak and strong-axis mid-height lateral displacement was $3.156 "(80.2 \mathrm{~mm})$ and $0.122 "(3.1 \mathrm{~mm})$, respectively. Slight visible buckling was first observed during the $6^{\text {th }}$ cycle corresponding to a maximum compressive load of $30,000 \mathrm{lbs}(133.4 \mathrm{kN})$. Similar to specimen CFRP-2, recorded strain values in the stem show the onset of local buckling to have occurred around 32,000 lbs $(142.3 \mathrm{kN})$. CFRP debonding was observed at the maximum imposed load. The CFRP strip on the tension side of the brace stem debonded from the steel initiating near the region of greatest curvature and propagating to the bottom end of the application. The CFRP strip on the compression side of the stem debonded only at mid-height of the brace, remaining bonded to the brace toward the termination of the CFRP strip. Figure 4.29 presents pictures of Specimen CFRP-1 at different loading stages and final debonding of the CFRP.

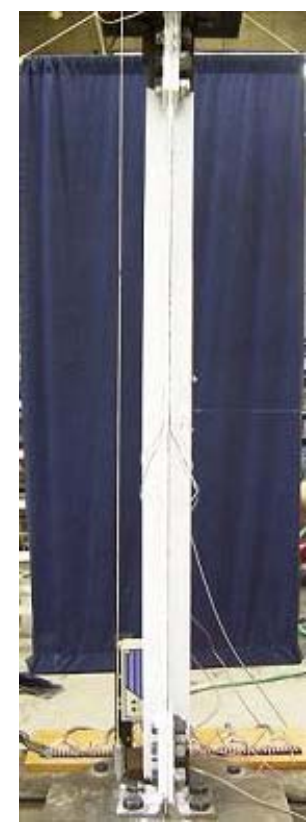

(a)

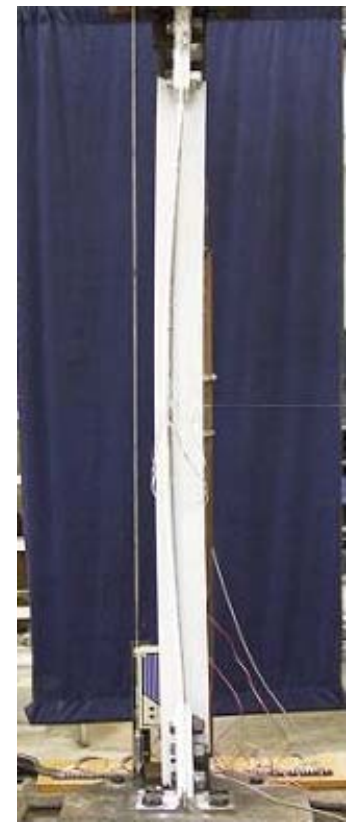

(b)

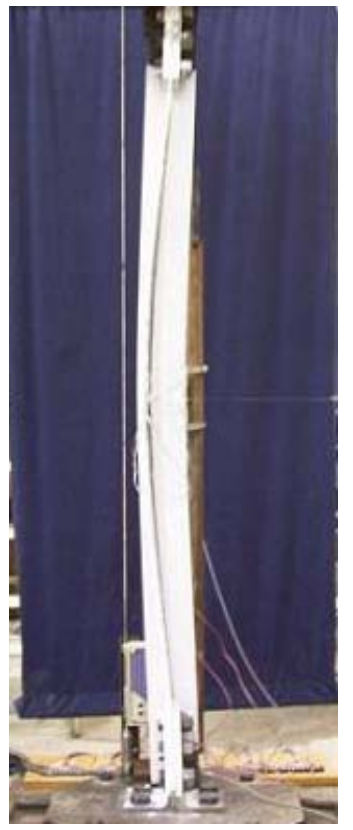

(c)

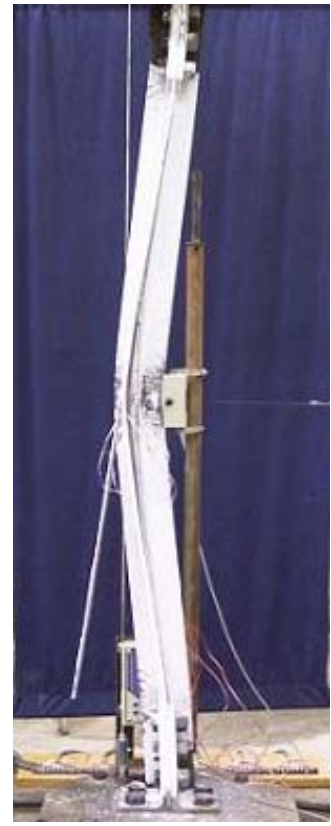

(d)

Figure 4.29 Specimen CFRP-1

(a) prior to loading, (b) stem buckling after cycle 9 to 45,000 lbs. (200 kN), (c) at maximum displacement after 10 cycles of loading prior to CFRP debonding, and (d) at maximum displacement with CFRP debonded. 


\subsubsection{Specimen GFRP-2}

Specimen GFRP-2 was loaded cyclically in compression and failed by buckling characterized by excessive lateral deflections, and eventual GFRP debonding. Specimen GFRP-2 was subjected to 10 cycles of compressive loading with a maximum load of 52,191 lbs (232.2 $\mathrm{kN})$. A peak axial displacement along the length of Specimen GFRP-2 of -0.572 " (-14.5 mm) was recorded. The maximum measured weak and strong-axis mid-height lateral displacement was $2.432 "(61.8 \mathrm{~mm})$ and $0.292 "(7.4 \mathrm{~mm})$, respectively. These deflections were measure at mid-height of the brace; however maximum lateral displacement of the stem and was observed at a location 17" (432 mm) from the top end of the brace with local buckling occurring around 28" $(711 \mathrm{~mm})$ from the top. Slight visible buckling was first observed during the $6^{\text {th }}$ cycle corresponding to a maximum compressive load of $35,000 \mathrm{lbs}(155.7 \mathrm{kN})$. (The $6^{\text {th }}$ cycle was loaded to a maximum load of $36,000 \mathrm{lbs}(160.1 \mathrm{kN})$ due to an error in load control, effectively skipping the cycle to $30,000 \mathrm{lbs}$. $(133.4 \mathrm{kN}))$ Recorded strain values in the stem show the onset of local buckling to have occurred around 34,500 lbs (153.5 kN). GFRP debonding was observed at the maximum imposed load. Both GFRP strips debonded from the steel at their top ends. Significant lateral torsional buckling was observed at higher loads and was apparent in residual displacements. Figure 4.30 presents pictures of Specimen GFRP-2 at different loading stages and final debonding of the GFRP. 


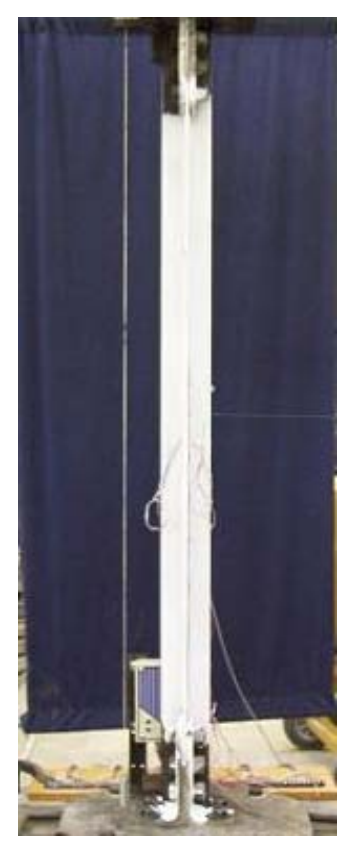

(a)

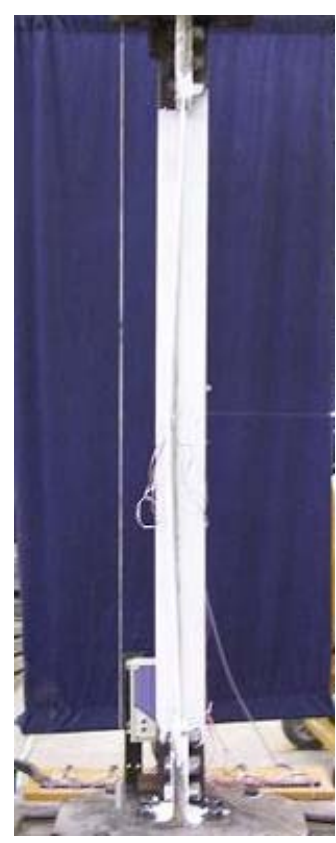

(b)

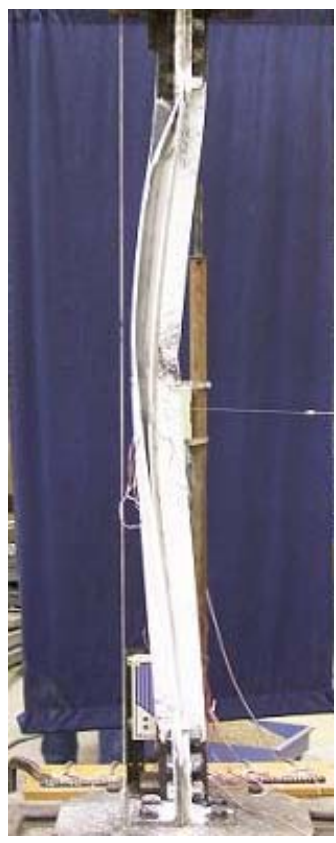

(c)

Figure 4.30 Specimen GFRP-2

(a) prior to loading, (b) stem buckling after cycle 9 to 45,000 lbs. (200 kN), and (c) at maximum displacement after 10 cycles of loading with GFRP debonded.

\subsubsection{Specimen GFRP-2}

Specimen GFRP-1 was loaded cyclically in compression and failed by buckling characterized by excessive lateral deflections, and eventual GFRP debonding. Specimen GFRP-1 was subjected to 11 cycles of compressive loading with a maximum load of 53,772 lbs (239.2 $\mathrm{kN})$. A peak axial displacement along the length of Specimen GFRP-1 of -1.581 ” (-40.2 mm) was recorded. The maximum measured weak and strong-axis mid-height lateral displacement was 6.528” (166 mm) and 0.702” (17.8 mm), respectively. Displacements for specimen GFRP-1 were significantly larger than previous specimens as the displacements were increased following the peak load cycle in order to affect debonding of the GFRP strips from the steel. Significant local buckling was observed just below strain gages 5 and 6 as well as directly above and below 
the connection region. Slight visible buckling was first observed during the $7^{\text {th }}$ cycle corresponding to a maximum compressive load of about 35,000 lbs $(155.7 \mathrm{kN})$. Recorded strain values in the stem show the onset of local buckling to have occurred around 34,898 $\mathrm{lbs}$ (155.2 $\mathrm{kN})$. GFRP debonding was observed at the maximum displacement attained but at a load lower than the maximum observed load (i.e in the post-peak response). The GFRP strips on the tension side of the stem debonded from the steel initiating at their top end, while the GFRP on the compression side of the stem debonded from the bottom end. Significant lateral torsional buckling was observed at higher loads and was apparent in residual displacements. Figure 4.31 presents pictures of Specimen GFRP-1 at different loading stages and final debonding of the GFRP.

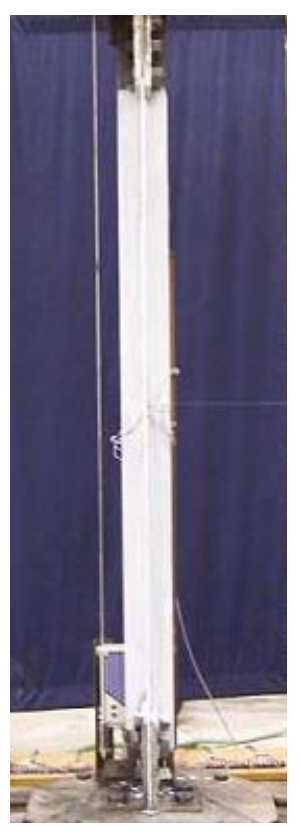

(a)

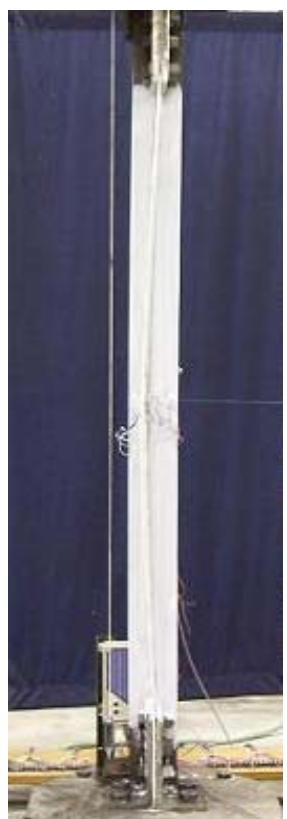

(b)

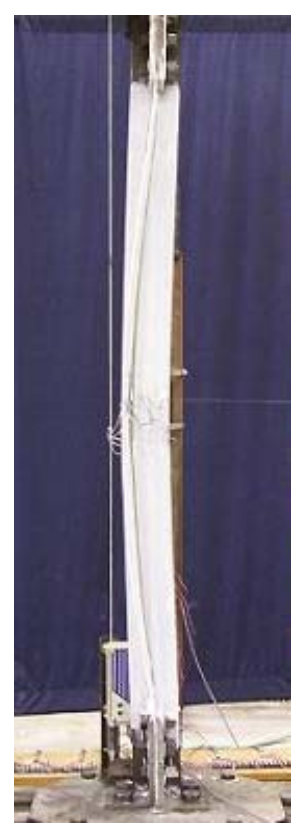

(c)

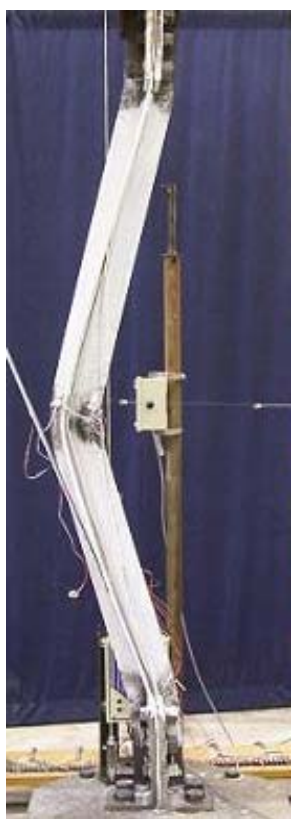

(d)

Figure 4.31 Specimen GFRP-1

(a) prior to loading, (b) stem buckling after cycle 9 to $45,000 \mathrm{lbs}$. (200 kN), (c) at maximum displacement after 11 cycles of loading prior to GFRP debonding, and (d) at maximum displacement with CFRP debonded. 


\subsection{EXPERIMENTAL DISCUSSION}

This chapter reports interpretation and discussion of results derived from the experimental data presented in Chapter 4.

\subsection{SPECIMEN AXIAL BEHAVIOR}

Figure 5.1 shows the load vs. axial displacement backbone curves for all of the specimens tested. 


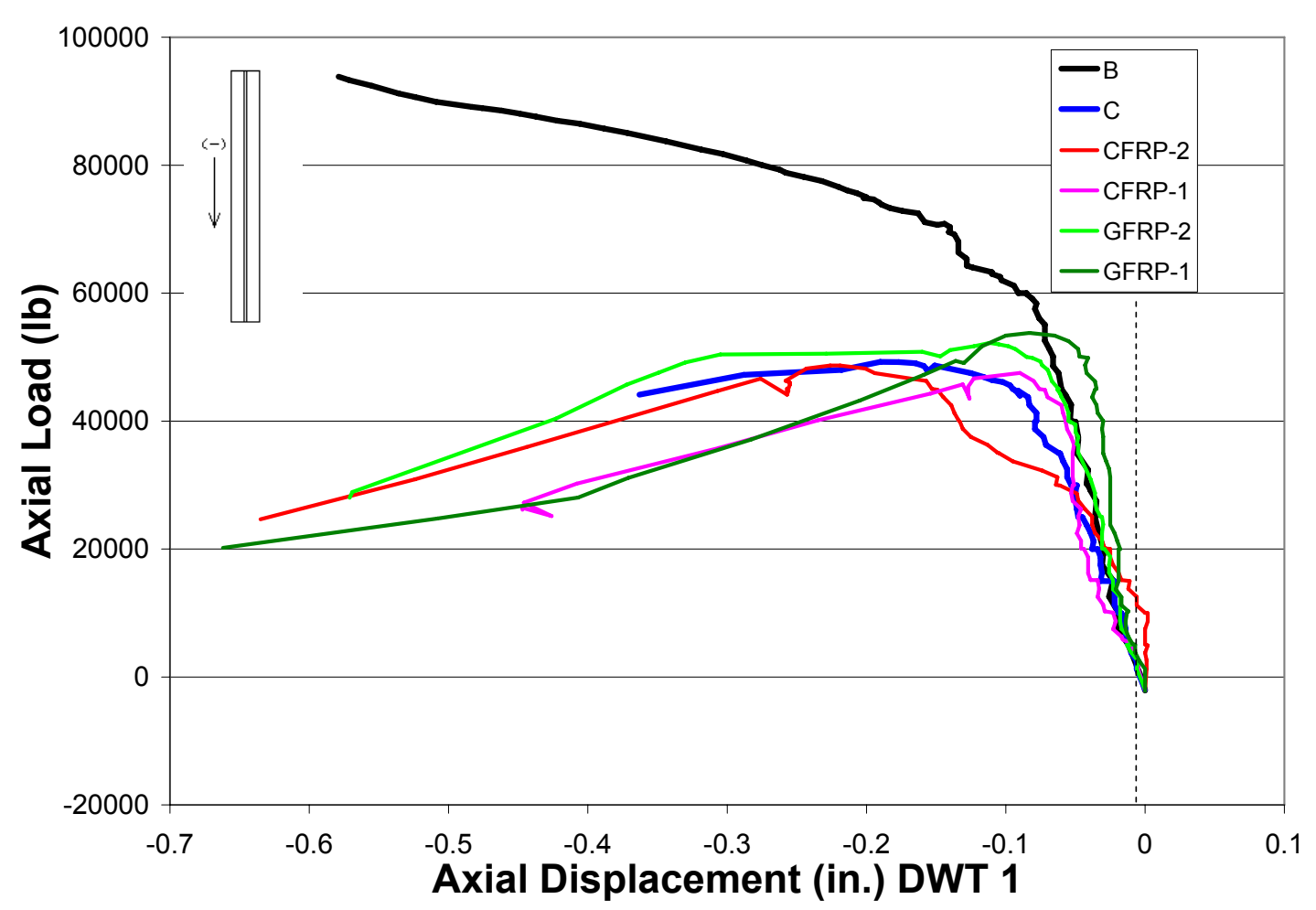

Figure 5.1 Load vs. axial displacement backbone curve for all specimens

As seen in Figure 5.1, the FRP retrofit specimens did not provide a significant increase in axial capacity compared to the control specimen C. The GFRP-2 and GFRP-1 retrofit specimens gained $6 \%$ and $9 \%$ axial capacity, respectively, which is modest compared to the $91 \%$ gain in axial capacity demonstrated by specimen B. Specimens CFRP-2 and CFRP-1 showed a slight decrease in axial capacity as compared with the control specimen $\mathrm{C}$. The variation in observed capacity may largely be attributed initial imperfections in the specimens and an eccentric loading condition as described in the following section. 


\subsection{APPARENT LOADING ECCENTRICITY}

At low force levels where elastic behavior is expected, applied axial forces should result in uniform strains in the cross section. Any initial imperfection and/or eccentricity of the load will result in non-uniform, flexure-induced behavior. This initial imperfection results in an eccentricity in the compressive loading which undermines the member's resistance to buckling. This imperfection can be the result of several factors including slight out-of-straightness of the specimens, misalignments within the test set-up, inconsistent stem length imposed during member fabrication, or any combination of these. By assessing this behavior, an equivalent initial loading eccentricity may be determined. This equivalent eccentricity therefore includes the cumulative effects of real load eccentricity and initial imperfections in the section. Inspection of the strains at low load levels across all specimen cross sections indicated that the flanges and stem of each cross section were not equally strained. To quantify the apparent imperfections in each specimen, the initial equivalent eccentricities were calculated from the strain gradients across the specimen cross sections at $5000 \mathrm{lb}(22.2 \mathrm{kN})$ compressive loading during the first cycle. This calculation was made by averaging the strains in gages 1 and 2, 3 and 4, 5 and 6 , and, 7 and 8 (when applicable) (see Figure 3.5 for an illustration of gage locations). Assuming the average strain values varied linearly across the stem and flanges, linear interpolation allowed approximate strain values to be calculated at the cross section tips. Strain values were converted to stresses and the resultant force magnitude and location were found by summing moments about one point. Figure 5.2 and Table 5.1 summarize the apparent locations of the axial resultant load and equivalent eccentricity for each specimen. The theoretical centroid, based on the expected geometry of a WT6x7 (AISC 2005) is located at the middle of the stem $(\mathrm{y}=1.985 \mathrm{in}$. 
$(50.4 \mathrm{~mm}))$ and $1.760 \mathrm{in} .(44.7 \mathrm{~mm})$ from the outside of the flange as shown in Figure 5.2. Representative calculations for the loading locations are presented in Appendix D.

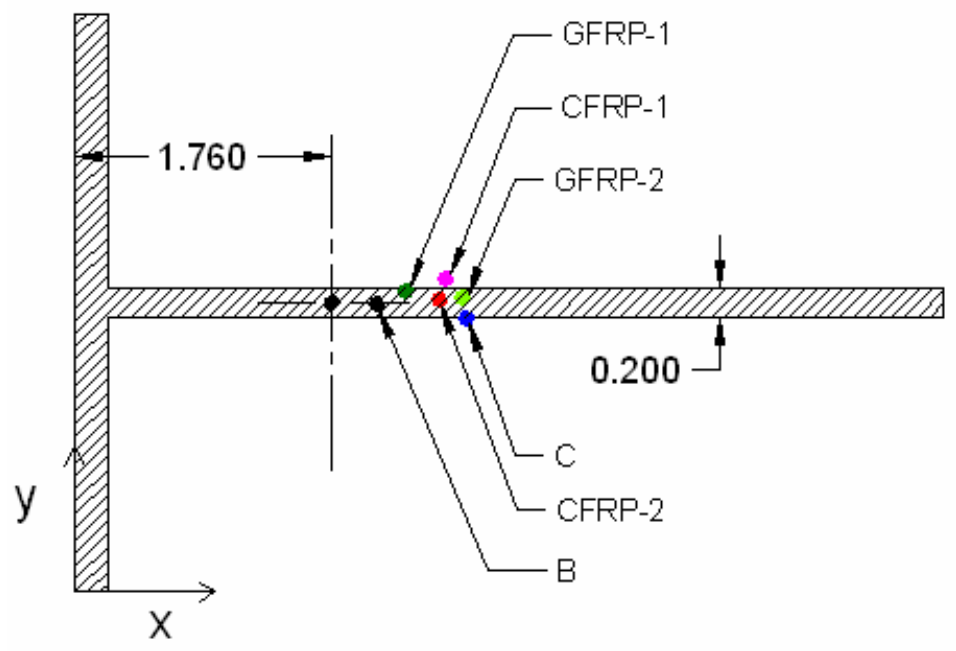

Figure 5.2 Load centroid location for each specimen

Table 5.1 Coordinates of equivalent load eccentricity

\begin{tabular}{|l|c|c|c|c|c|}
\hline & $\begin{array}{c}\mathbf{x} \\
\text { [in.] }\end{array}$ & $\begin{array}{c}\Delta \mathbf{x}\left(\mathbf{e}_{\mathbf{x}}\right) \\
\text { [in.] }\end{array}$ & $\begin{array}{c}\mathbf{y} \\
\text { [in.] }\end{array}$ & $\begin{array}{c}\Delta \mathbf{y}\left(\mathbf{e}_{\mathbf{y}}\right) \\
\text { [in.] }\end{array}$ & $\begin{array}{c}\text { Peak Observed } \\
\text { Load (lb) }\end{array}$ \\
\hline Theoretical Centroid & $\mathbf{1 . 7 6 0}$ & - & $\mathbf{1 . 9 8 5}$ & - & - \\
\hline Control Specimen C & 2.683 & 0.932 & 1.882 & -0.103 & 49255 \\
\hline Specimen B & 2.072 & 0.312 & 1.972 & -0.013 & 93835 \\
\hline Specimen CFRP-2 & 2.504 & 0.744 & 2.00 & 0.015 & 48712 \\
\hline Specimen CFRP-1 & 2.547 & 0.787 & 2.149 & 0.164 & 47833 \\
\hline Specimen GFRP-2 & 2.659 & 0.899 & 2.016 & 0.031 & 52191 \\
\hline Specimen GFRP-1 & 2.269 & 0.509 & 2.066 & 0.081 & 53772 \\
\hline
\end{tabular}

\subsection{SPECIMEN RESPONSE INCLUDING APPARENT LOADING EQUIVALENT ECCENTRICITY}

Figure 5.3 through Figure 5.5 present the load vs. lateral displacement graphs for each specimen offset to account for the initial equivalent loading eccentricities $\left(\mathrm{e}_{\mathrm{x}}\right.$ and $\left.\mathrm{e}_{\mathrm{y}}\right)$. Figure 5.3 
presents the load vs. weak-axis lateral displacement for all specimens. The weak-axis lateral displacement is the sum of the initial load eccentricity, $e_{y}$, which is calculated at mid-height of the specimens and the readings from DWT 2. Figure 5.4 presents a close-up view of the load vs. total weak-axis lateral displacement truncated at 0.5 in. to better illustrate the difference in eccentricity between each specimen and the effect on weak-axis lateral displacement behavior. The bifurcation load, that is the load at which the lateral displacement begins to increase at a reduced apparent stiffness indicating the onset of elastic buckling, is reduced with an increasing equivalent eccentricity. This behavior is expected and predicted by conventional elastic buckling theory (Timoshenko, 1936).

Figure 5.5 presents the load vs. strong-axis lateral displacement for all specimens. Again, the strong-axis lateral displacement is the sum of the initial equivalent eccentricity, $\mathrm{e}_{\mathrm{x}}$, and the readings from DWT 3. As might be expected for the WT elements tested, little strong-axis buckling was evident. This reflects the significant difference between the strong and weak axis radii of gyration which have a ratio of $r_{x} / r_{y}=2.55$ (AISC, 2005a). In these sections, weak-axis behavior should be expected to dominate. 


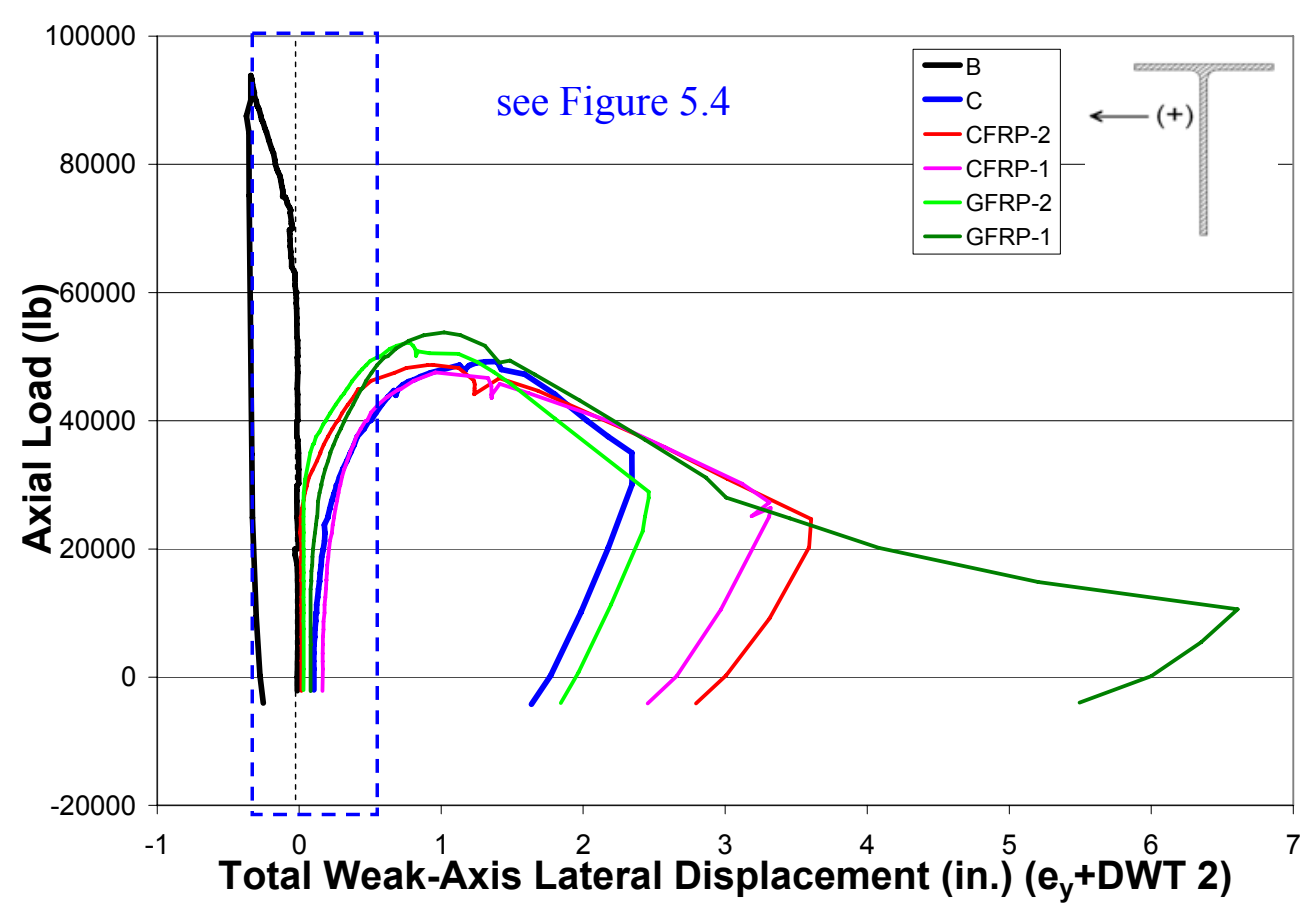

Figure 5.3 Load vs. weak-axis lateral displacement backbone curves including initial load eccentricity for all specimens

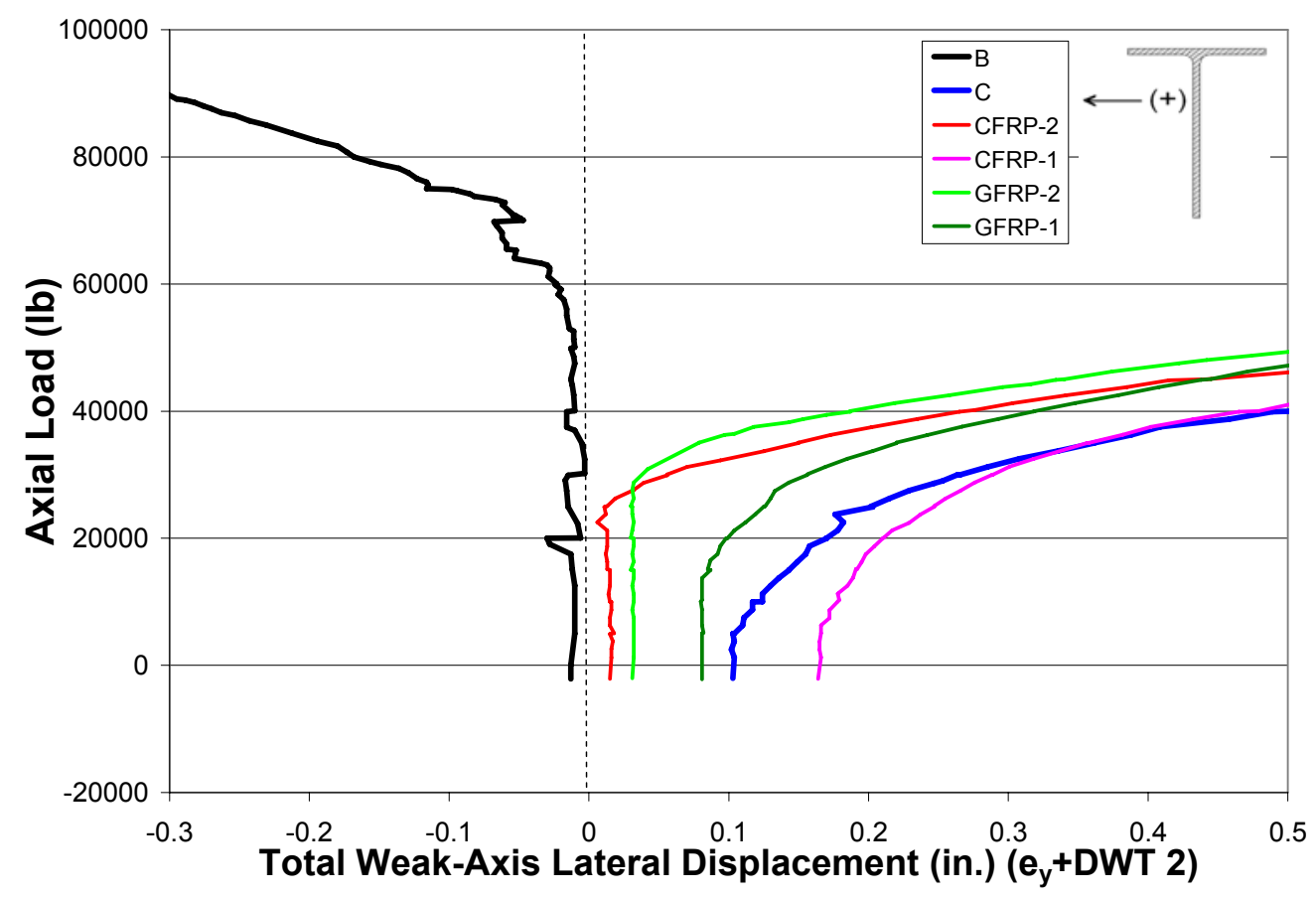

Figure 5.4 Load vs. weak-axis lateral displacement backbone curves including initial load eccentricity for all specimens truncated at $0.5 \mathrm{in.}$ 


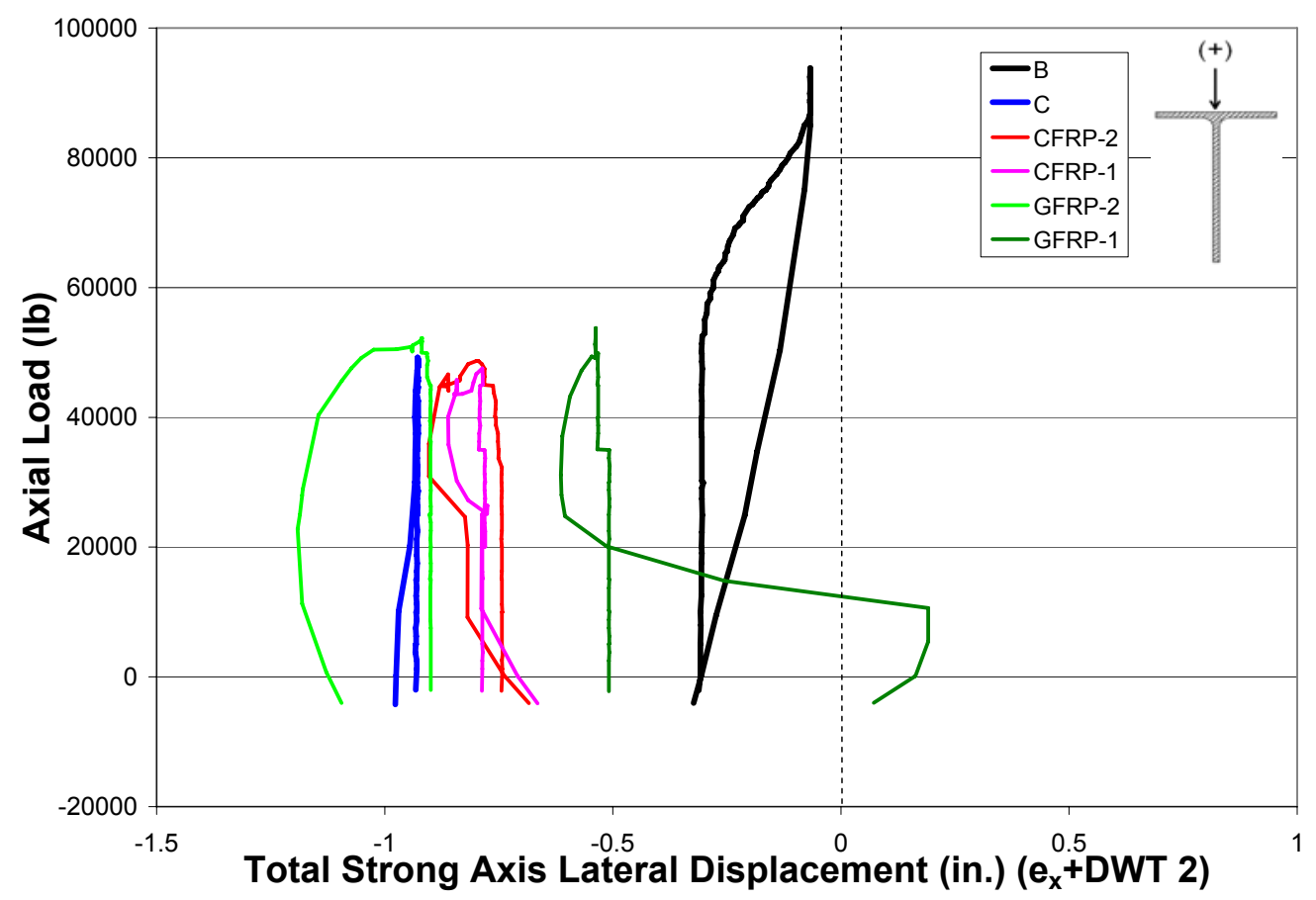

Figure 5.5 Load vs. strong-axis lateral displacement backbone curves including initial load eccentricity for all specimens.

Figure 5.3 shows that the behavior of the FRP-retrofitted specimens exhibit a higher initial slope when compared to the control specimen, indicating improved member stability against lateral deflections. Specimens CFRP-2, GFRP-2 and GFRP-1 showed significantly greater initial stiffness. GFRP-2 and GFRP-1 both showed a higher peak load than the control specimen C.

Figure 5.4 gives better insight to the initial behavior of each specimen, and indicates that a larger initial load eccentricity results in a lower bifurcation load indicating earlier onset of elastic buckling. This ultimately results in a lower peak load. Specimens CFRP-2 and GFRP-2 demonstrate more definitive bifurcation points due to their minimal initial loading eccentricity as 
indicated in Figure 5.2. Specimens $\mathrm{C}$ and CFRP-1 had greater initial load eccentricities and lower bifurcation points ultimately compromising the member's buckling capacity.

Despite a lack of axial capacity increase, the retrofit specimens did exhibit greater control over the weak-axis lateral displacement response as well as the weak and strong-axis bifurcation points. Table 5.2 presents the displacement performance parameters and observed bifurcation points for all specimens. Figure 5.6 provides a definition for the entries of Table 5.2. The deflection values of $0.1 "(2.54 \mathrm{~mm})$ and $0.3 "(7.62 \mathrm{~mm})$ are selected arbitrarily to illustrate specimen behavior. They represent mid-height lateral deflections of L/655 and L/218 respectively. In Table 5.2, bifurcation loads are shown determined from both strain and DWT readings.

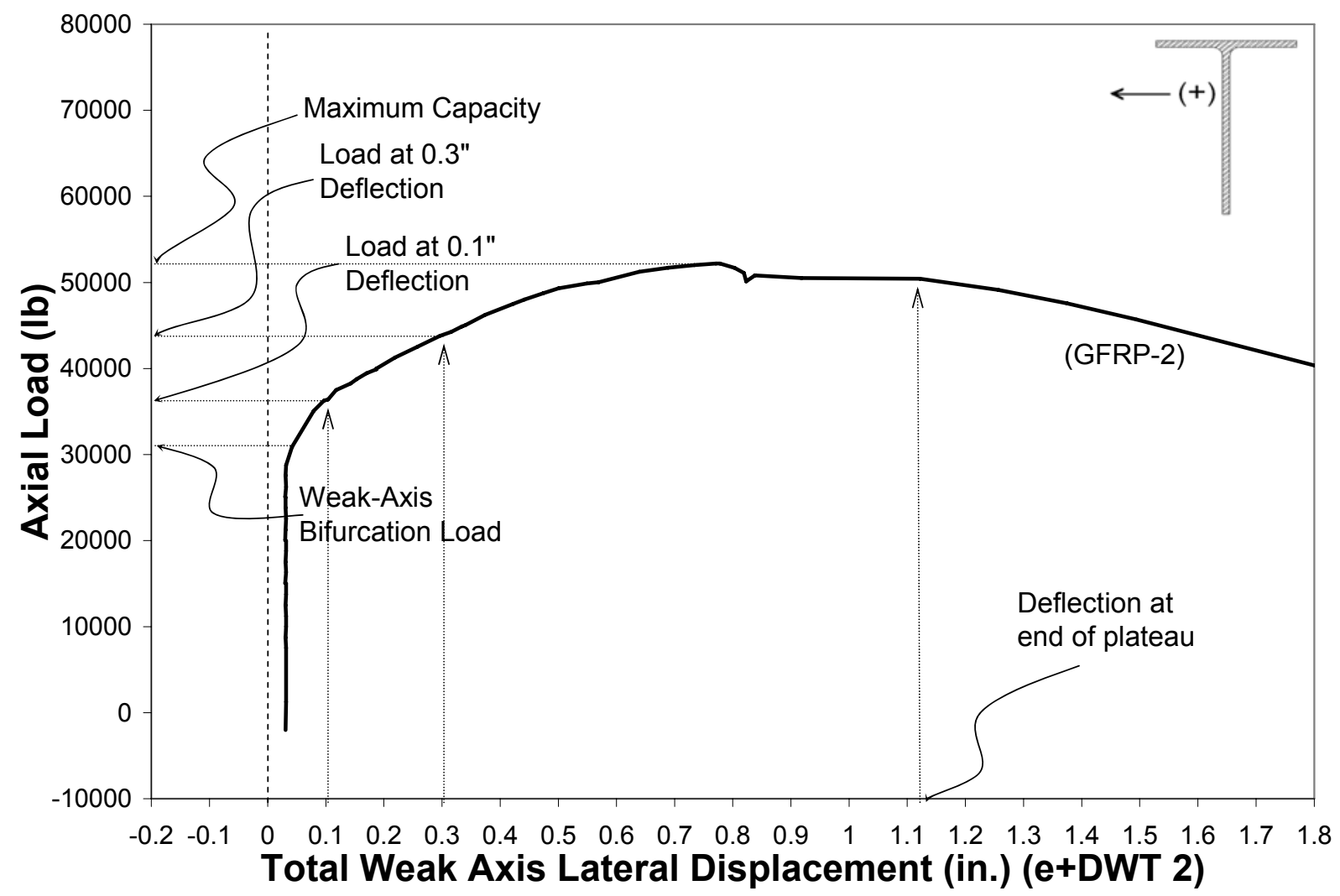

Figure 5.6 Definition of displacement performance parameters. 
Table 5.2 Displacement performance parameters and bifurcation load for all specimens.

\begin{tabular}{|c|c|c|c|c|c|c|c|}
\hline & $\mathbf{C}$ & B & CFRP-2 & CFRP-1 & GFRP-2 & GFRP-1 \\
\hline \multicolumn{2}{|l|}{ Maximum Capacity (lbs) } & 49255 & 93835 & 48712 & 47833 & 52191 & 53772 \\
\hline \multicolumn{2}{|c|}{ Load@0.1"Weak-Axis Deflection (lbs) } & 25086 & 72067 & 33225 & 27506 & 37969 & 32267 \\
\hline \multicolumn{2}{|c|}{ Load@0.3" Weak-Axis Deflection (lbs) } & 37310 & 90642 & 41570 & 39910 & 44811 & 42565 \\
\hline \multicolumn{2}{|c|}{ Weak-AxisDeflection@end of plateau (in.) } & 1.386 & $\mathrm{~N} / \mathrm{A}$ & 1.22 & 1.21 & 0.951 & 0.996 \\
\hline \multirow{2}{*}{$\begin{array}{l}\text { Weak-Axis Bifurcation } \\
\text { Load (lbs) }\end{array}$} & DWT 2 Readings & 8155 & 59828 & 26828 & 8033 & 30906 & 17092 \\
\hline & Strain Readings & 29755 & $\mathrm{~N} / \mathrm{A}$ & 31419 & 31028 & 33415 & 32530 \\
\hline \multirow{2}{*}{$\begin{array}{l}\text { Strong-Axis Bifurcation } \\
\text { Load (lbs) }\end{array}$} & DWT 3 Readings & $22630^{1}$ & 52973 & 43859 & 47113 & 45990 & 48877 \\
\hline & Strain Readings & 2 & 2 & 2 & 2 & 2 & 2 \\
\hline
\end{tabular}

${ }^{1}$ Strong-Axis bifurcation occurred during unloading after maximum cycle.

${ }^{2}$ Strain readings did not indicate any strong-axis bifurcation.

*NOTE $-1 \mathrm{lb}=4.45 \mathrm{~N}, 1$ in $=0.0254 \mathrm{~m}$

A weak-axis lateral deflection of $0.1 "(2.54 \mathrm{~mm})$ and 0.3 " $(7.62 \mathrm{~mm})$ occurred at higher loads for the FRP-retrofitted specimens than that of the control specimen C. At 0.1 " $(2.54 \mathrm{~mm})$ weak-axis lateral deflection, the corresponding load increase ranged from $9.6 \%$ to $51.4 \%$ for the FRP-retrofitted specimens, with GFRP-2 reaching the highest load. At 0.3 " (7.62 mm) weak-axis lateral deflection, the corresponding load increase varied between $7.0 \%$ and $20.1 \%$, with GFRP-2 and GFRP-1 reaching the two highest loads. The weak-axis lateral deflection at the end of the plateau, as defined by Figure 5.6, decreased compared to the control specimen, indicating a loss of ductility for the FRP-retrofitted specimens. This apparent loss of ductility is mostly an artifact of the behavior of Specimen C. As seen in Figure 4.26, a plastic "kink" formed away from midspan toward the lower end of the brace; thus the midspan deflection is better controlled. Nonetheless, a ductility loss may result from the additional stiffness the FRP provides to the system. It is also possible that the brittle nature of the FRP bond to the steel substrate would reduce the overall ductility of the system if the bond failed in the plateau region. Debonding strains will be discussed in greater detail later, however the strains at mid-height indicated debonding occurred at displacements greater than 1.386" $(35.2 \mathrm{~mm})$ (the end of the plateau for specimen C) for all specimens except for CFRP-1. Debonding occurred at a weak-axis lateral 
displacement of 1.190" (30.2 mm) for specimen CFRP-1 which may explain its loss of ductility. However, it is more likely that the high eccentric loading contributed more significantly to its marginal behavior.

The increase in weak-axis bifurcation load based on lateral displacement readings (DWT 2) ranged from $109 \%$ to $279 \%$ for specimens GFRP-2, CFRP-2 and GFRP-1 (listed in decreasing order). However, specimen CFRP-1 demonstrated a 1.5\% decrease in the bifurcation load which again reflects the effect of the larger initial loading eccentricity. The weak-axis bifurcation load was also measured using strain measurements. The point of bifurcation was apparent when strain readings on opposite sides of the stem (gages 1 and 2) stopped "tracking" one another with one gage continuing to register increasing compression and the other decreasing compression and eventually reading tensile strain. This behavior is indicative of stem bending associated with elastic buckling. Based on strain readings, the FRP-retrofitted weak-axis bifurcation load increase ranged from $4.3 \%$ to $12.3 \%$. The strain readings provide a more specific determination of bifurcation than the displacement readings due to the effect of initial load eccentricity. The initial eccentricity made determination of actual bifurcation difficult as may be inferred from Figure 5.4.

The strong-axis bifurcation load could only be measured using the displacement (DWT 3) readings. The strain measurements did not provide any definitive point of bifurcation, however the displacement readings did illustrate the point at which buckling about the strong-axis occurred. The increase in strong-axis bifurcation load based on lateral displacement readings for the FRP-retrofitted specimens varied from $94 \%$ to $116 \%$. This increase may suggest that the FRP provides stability to the unstable stem and ultimately diverts the onset of strong-axis buckling of the brace member. 


\subsection{RESIDUAL DISPLACEMENT RESPONSES}

Figure 5.7 through Figure 5.9 present the load vs. displacement graphs for the single cycle to $50,000 \mathrm{lbs}$. $(222.4 \mathrm{kN})$ for all specimens. These graphs illustrate the residual displacements for each specimen following this load cycle. Figure 5.7 shows the load vs. axial displacement, Figure 5.8 shows the load vs. weak-axis lateral displacement and Figure 5.9 shows the load vs. strong-axis lateral displacement after the 50,000 lbs. (222.4 kN) cycle for all specimens. Table 5.3 tabulates these residual displacements as well as residual strain readings following the $50,000 \mathrm{lbs}(222.4 \mathrm{kN})$ cycle.

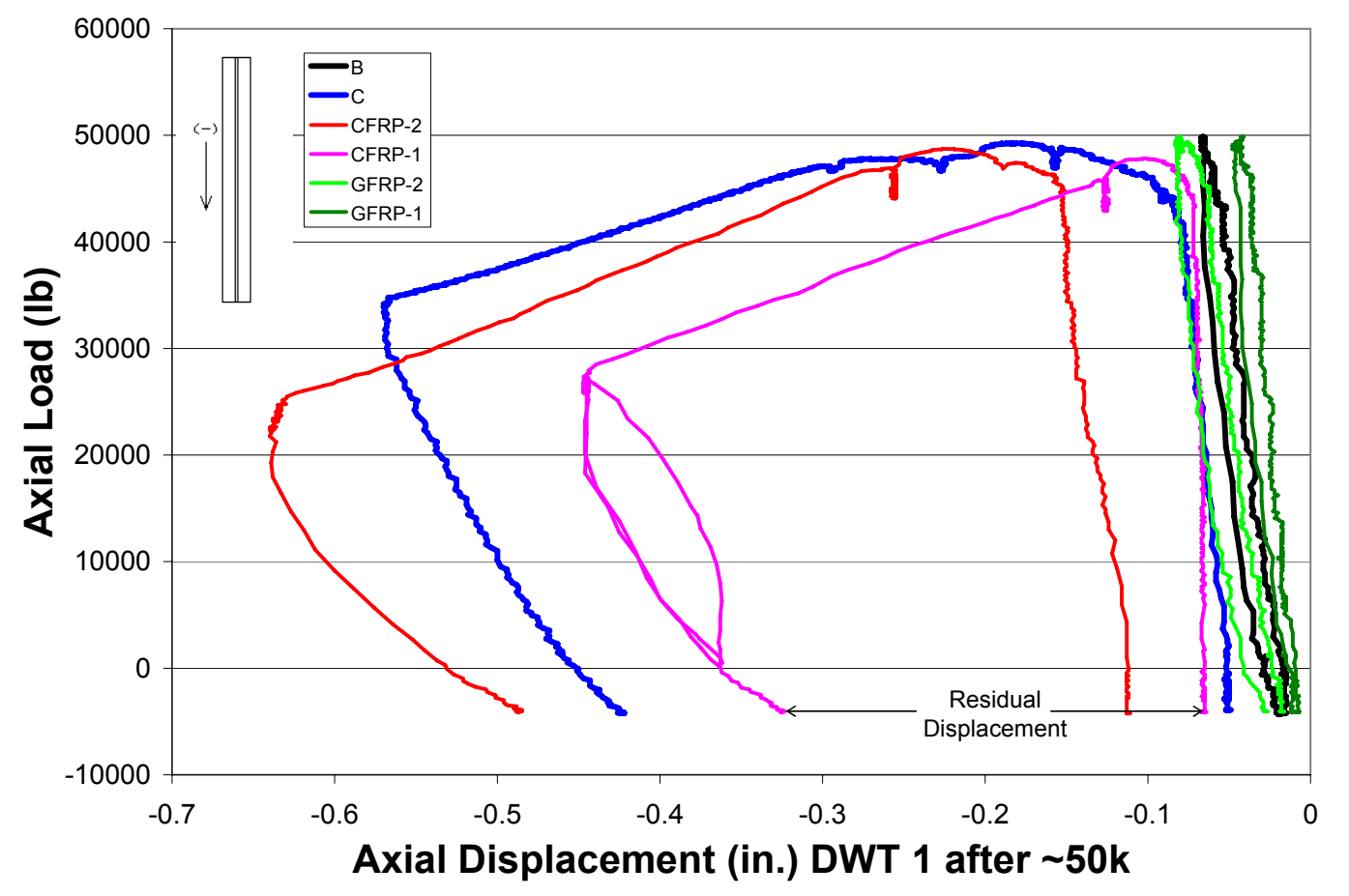

Figure 5.7 Cycle to 50,000 lbs illustrating residual axial displacement for all specimens 


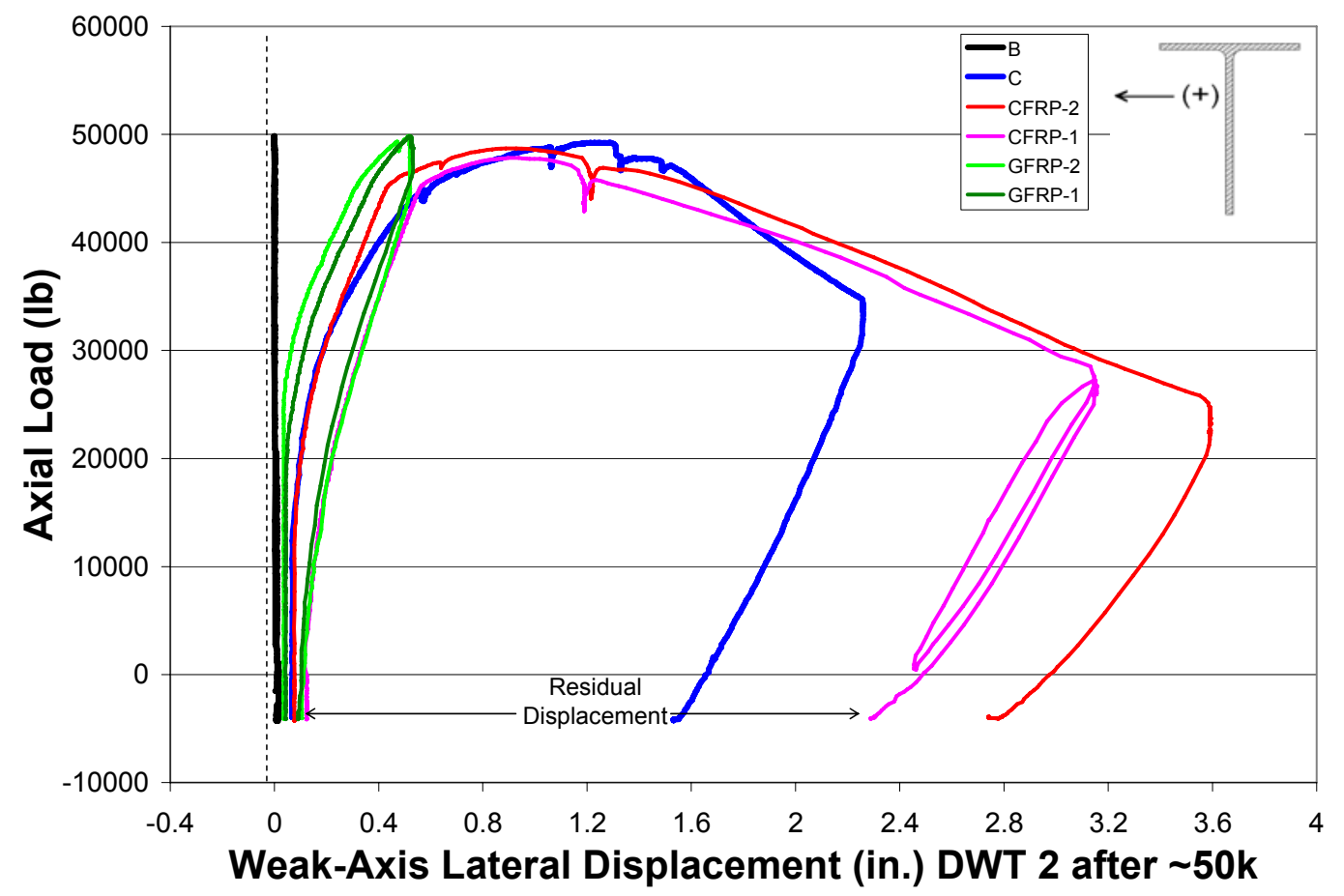

Figure 5.8 Cycle to 50,000 lbs illustrating residual weak-axis lateral displacement for all specimens

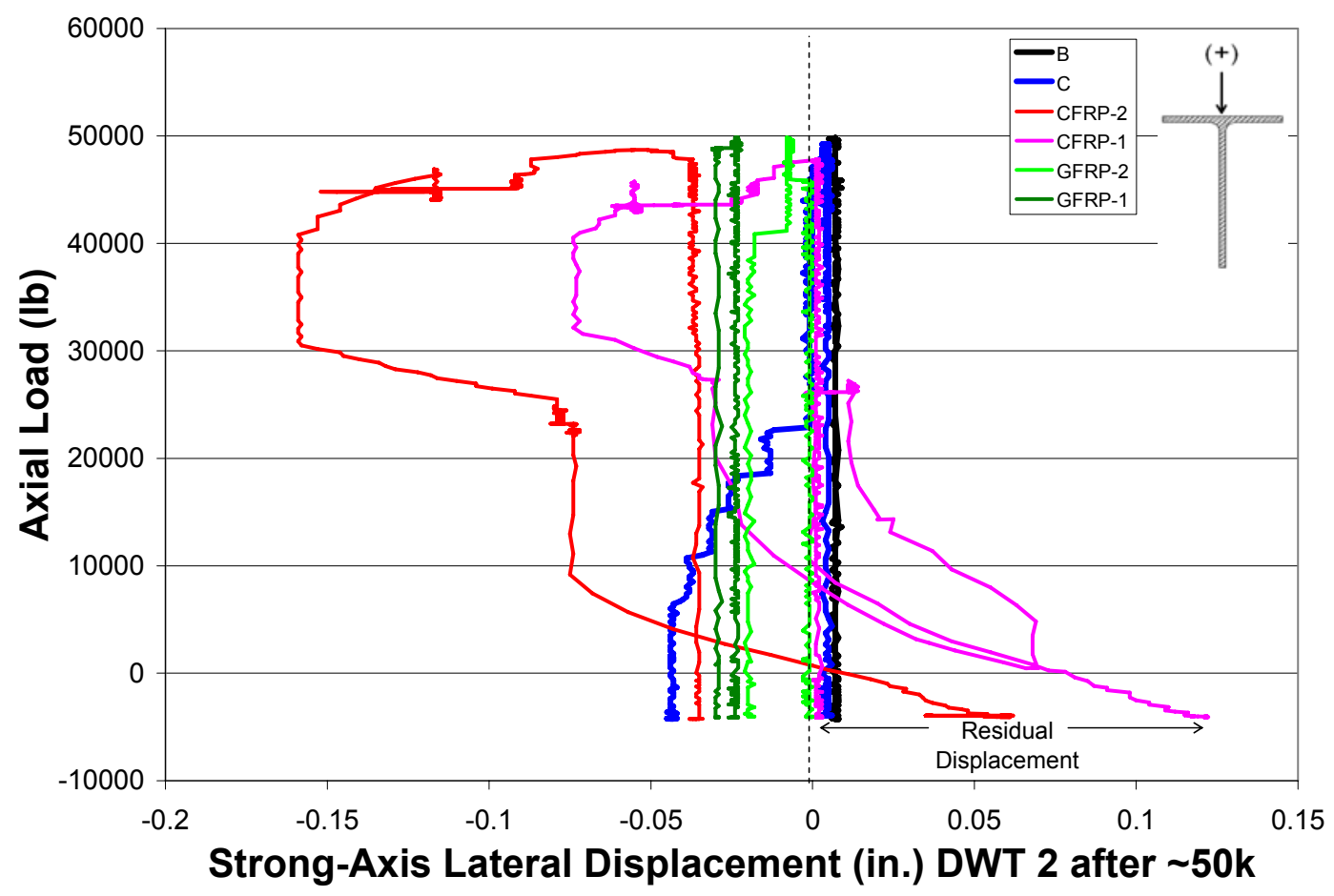

Figure 5.9 Cycle to 50,000 lbs illustrating residual strong-axis lateral displacement for all specimens 
Table 5.3 Residual displacement and strains following the cycle to 50,000 lbs.

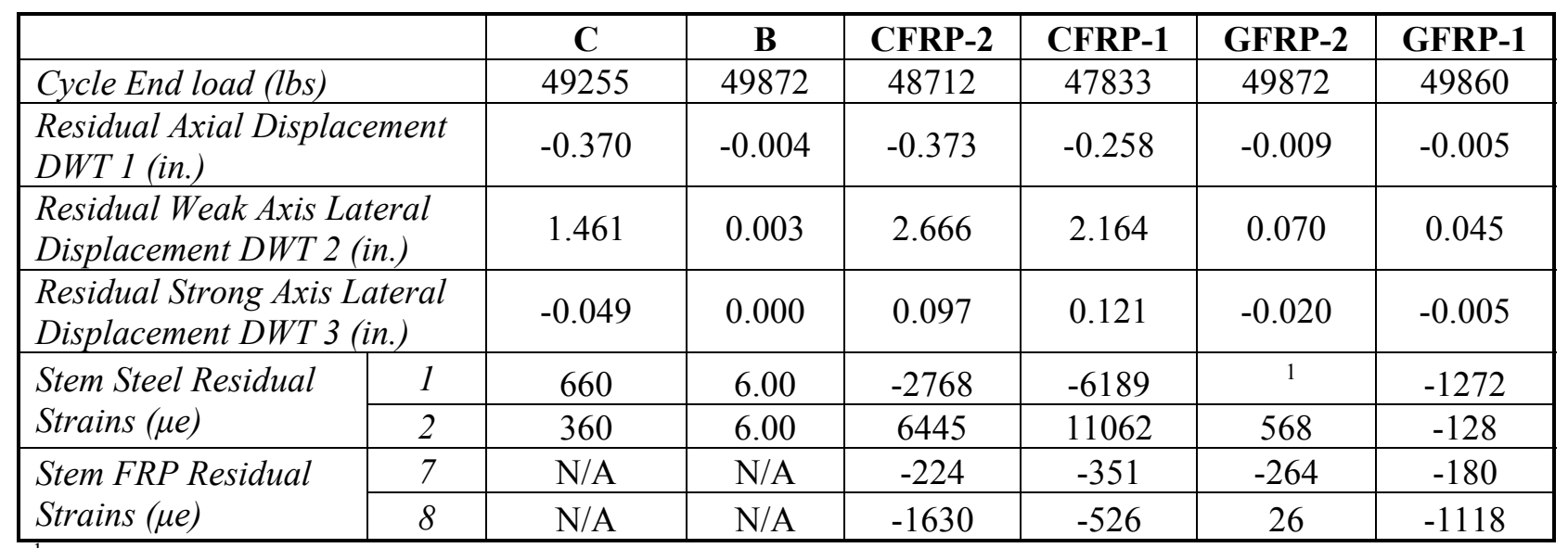

${ }^{1}$ Strain gage lost during unloading

*NOTE $-1 \mathrm{lb}=4.45 \mathrm{~N}, 1$ in $=0.0254 \mathrm{~m}$

Figures 5.7 through 5.9 show that the CFRP retrofit specimens demonstrated significant residual displacements after the $50,000 \mathrm{lb}(222.4 \mathrm{kN})$ loading cycle. While the residual axial displacements of the CFRP retrofit members were comparable to the control specimen C's in Figure 5.7, specimens GFRP-2 and GFRP-1 demonstrated a 97\% and 98\%, respectively, decrease in residual axial displacements.

Both CFRP retrofit specimens exhibited greater weak-axis lateral displacements compared to the control specimen C. It must be noted as well that the location of the buckling within specimen $\mathrm{C}$, and therefore maximum weak-axis lateral displacement, was 20 " (508 mm) above the lower end of the brace $(12 \mathrm{3} / 4$ " $(323.9 \mathrm{~mm})$ below brace mid-height) and reported displacements were taken at mid-height. If deflections were reported at the location of the buckle for specimen $\mathrm{C}$ it is estimated that they would be very similar to the CFRP retrofit specimens performances. Again, both GFRP retrofit specimens exhibited significant decreases in residual weak-axis lateral displacements of 95\% and 97\% of specimen C's for GFRP-2 and GFRP-1, respectively. 
As seen in Figure 5.9, the CFRP retrofit specimens as well as the control specimen C experienced significant residual strong-axis lateral displacements. The GFRP retrofit specimens when compared with the control specimen $\mathrm{C}$ experienced a decrease in residual strong-axis lateral displacements of 59\% and 90\% for specimens GFRP-2 and GFRP-1 respectively.

Overall, the braces retrofitted with GFRP proved to mitigate the residual displacements seen in the control specimen $\mathrm{C}$. This performance is significant because a reduction in residual displacements at cycles of high loading will decrease the likelihood of a kink forming in the member which ultimately contributes to the degradation of brace's compressive capacity. These results may suggest that a softer material, such as GFRP, is better suited for this application, contrary to conventional perceptions that the retrofit stiffness should be similar to that of steel. This conclusion was suggested by Accord (2005) and apparently demonstrated here.

\subsection{FRP DEBONDING}

Table 5.4 presents the strains in the FRP strips for the retrofit specimens at the onset of debonding. The load at which debonding occurs and the corresponding cycle, and displacements are also shown. 
Table 5.4 FRP debonding strains and occurence

\begin{tabular}{|c|c|c|c|c|c|c|c|c|c|}
\hline & \multirow{2}{*}{$\begin{array}{c}\text { Peak } \\
\text { Strain } \\
(\mu e)\end{array}$} & \multirow{2}{*}{$\begin{array}{c}\text { Strain at } \\
\text { Debond } \\
(\mu e)\end{array}$} & \multirow[b]{2}{*}{ Cycle } & \multicolumn{4}{|c|}{ Corresponding Readings } & \multirow[b]{2}{*}{ Debond Location } \\
\hline & & & & & $\begin{array}{l}\text { Load } \\
\text { (lbs) }\end{array}$ & $\begin{array}{c}D W T 1 \\
\text { (in) }\end{array}$ & $\begin{array}{c}D W T 2 \\
\text { (in) }\end{array}$ & $\begin{array}{l}\text { DWT } 3 \\
\text { (in) }\end{array}$ & \\
\hline \multirow{2}{*}{ 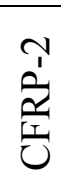 } & 7 & 7126 & 4139 & $\begin{array}{c}10^{\text {th }} \text { after } \\
\text { max }\end{array}$ & 23129 & -0.637 & 3.591 & -0.074 & 17 ' from bottom \\
\hline & 8 & -6432 & -6000 & $\begin{array}{c}10^{\text {th }} \text { after } \\
\text { max }\end{array}$ & 23135 & -0.636 & 3.591 & -0.074 & $\begin{array}{l}93 / 4 \text { " from bottom, } \\
21 \frac{1 / 2 \text { " from top }}{}\end{array}$ \\
\hline \multirow{2}{*}{$\begin{array}{l}\overline{1} \\
\frac{a}{4} \\
\frac{1}{u}\end{array}$} & 7 & 7532 & 7532 & $\begin{array}{l}10^{\text {th }} \text { after } \\
\text { max }\end{array}$ & 31010 & -0.395 & 2.897 & -0.061 & 14 " from top \\
\hline & 8 & -2806 & -2774 & $\begin{array}{c}10^{\text {th }} \text { after } \\
\text { max }\end{array}$ & 44586 & -0.127 & 1.190 & -0.017 & $131 / 2 "$ from top \\
\hline \multirow{2}{*}{ 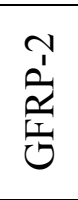 } & 7 & -975 & 438 & $\begin{array}{c}10^{\text {th }} \text { after } \\
\max \end{array}$ & 25473 & -0.56 & 2.417 & -0.282 & $231 / 4$ " from bottom \\
\hline & 8 & -2352 & -955 & $\begin{array}{c}10^{\text {th }} \text { after } \\
\text { max }\end{array}$ & 37450 & -0.457 & 1.940 & -0.263 & $15^{1 / 4 " \text { " from bottom }}$ \\
\hline \multirow{2}{*}{ 离 } & 7 & 6581 & 5986 & $\begin{array}{l}11^{\text {th }} \text { after } \\
\text { max }\end{array}$ & 10829 & -1.562 & 6.527 & 0.697 & $3 "$ from bottom \\
\hline & 8 & -5821 & -5815 & $\begin{array}{l}11^{\text {th }} \text { after } \\
\text { max }\end{array}$ & 15688 & -0.945 & 4.966 & 0.216 & 10 " from top \\
\hline
\end{tabular}

$*$ NOTE $-1 \mathrm{lb}=4.45 \mathrm{~N}, 1 \mathrm{in}=0.0254 \mathrm{~m}$

FRP debonding occurred after the peak of the last loading cycle for each specimen. The observed debonding was brittle for each specimen as described in Chapter 4. In the case of specimen GFRP-1, excessive deflections were imposed in order to induce debonding of the GFRP. Specimen CFRP-1 debonded at the lowest displacement readings of all of the specimens tested, soon after the maximum compressive load was reached. This may have been due to excessive demands placed on that CFRP strip from initial load eccentricities.

The FRP-1 specimens recorded the largest debonding strains. All specimens, with the exception of GFRP-2, debonded at strains close to their observed maximum strains and no FRP strain approached their rupture strains. Specimen GFRP-2 reported low strain readings at the time of debonding. This may suggest poor bond conditions in this specimen. 
With the exception of GFRP-2, debonding strains were generally relatively high indicating good bond quality. On all specimens, debonding propagated along the adhesive-steel substrate interface leaving only a small amount of adhesive on the steel, captured by the striations resulting from the surface grinding. This behavior is typical of sound adhesive bond to a metallic substrate.

\subsection{EFFECT UPON THE RADIUS OF GYRATIONS, $\mathbf{r}_{\mathrm{y}}$}

A compressive member's slenderness ratio is dependent upon the length of the member and it's radius of gyration, $r_{y}$. As referenced in the literature review, maximum compressive loads deteriorate more rapidly for slender members subjected to axial cyclic loading. The current study attempted to increase a bracing member's $r_{\mathrm{y}}$ value as well as the maximum compressive load resulting in an increase in compressive hysteretic behavior. The stem of the WT $6 \times 7$ member is locally very slender and presents a specific region at which to concentrate a retrofit application. Table 5.5 presents the expected increase in $\mathrm{r}_{\mathrm{y}}$ at a local level for the stem itself (the stem height is taken as $5.735 \mathrm{in}$. in these calculations) as well as for the entire WT 6x7 section. 
Table 5.5 Predicted $r_{y}$ data table

\begin{tabular}{|c|c|c|c|c|c|c|}
\hline & & & CFRP-2 & CFRP-1 & GFRP-2 & GFRP-1 \\
\hline \multirow{6}{*}{$\frac{\vec{a}}{\underline{a}}$} & $t_{\mathrm{FRP}}$, in & & 0.055 & 0.110 & 0.075 & 0.150 \\
\hline & $b_{\mathrm{FRP}}$, in & & 2.00 & 1.00 & 2.00 & 1.00 \\
\hline & $\mathrm{d}$, in & $=\mathrm{t}_{\mathrm{FRP}} / 2+\mathrm{t}_{\mathrm{stem}} / 2$ & 0.128 & 0.155 & 0.138 & 0.175 \\
\hline & $\mathrm{A}_{\mathrm{FRP}}, \mathrm{in}^{2}$ & $=2 t_{\mathrm{FRP}} b_{\mathrm{FRP}}$ & 0.22 & 0.22 & 0.30 & 0.30 \\
\hline & $\mathrm{I}_{\mathrm{FRP}}, \mathrm{in}^{4}$ & $=(1 / 12) \mathrm{b}_{\mathrm{FRP}} \mathrm{t}_{\mathrm{FRP}}{ }^{3}+\mathrm{nA}_{\mathrm{FRP}} \mathrm{d}^{2}$ & 0.00282 & 0.00427 & 0.00120 & 0.00202 \\
\hline & $\mathrm{n}$, modular ratio & $=\mathrm{E}_{\mathrm{FRP}} / \mathrm{E}_{\text {steel }}$ & 0.776 & 0.776 & 0.207 & 0.207 \\
\hline \multirow{9}{*}{ 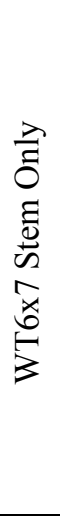 } & $t_{\text {stem }}$, in & $($ AISC, 2005a) & 0.200 & 0.200 & 0.200 & 0.200 \\
\hline & $\mathrm{d}_{\text {stem }}$, in & $=\mathrm{d}-\mathrm{t}_{\mathrm{f}}$ & 5.735 & 5.735 & 5.735 & 5.735 \\
\hline & $\mathrm{A}_{\text {stem }}$, in $^{2}$ & $=\mathrm{t}_{\text {stem }} \mathrm{d}_{\text {stem }}$ & 1.147 & 1.147 & 1.147 & 1.147 \\
\hline & $\mathrm{I}_{\mathrm{Y} \text {-stem }}, \mathrm{in}^{4}$ & $=(1 / 12) \mathrm{d}_{\text {stem }} \mathrm{t}_{\mathrm{stem}}{ }^{3}$ & 0.00382 & 0.00382 & 0.00382 & 0.00382 \\
\hline & $r_{y-\text { stem }}$, in & $=\left(\mathrm{I}_{\mathrm{y} \text {-stem }} / \mathrm{A}_{\text {stem }}\right)^{1 / 2}$ & 0.0577 & 0.0577 & 0.0577 & 0.0577 \\
\hline & $\mathrm{A}_{\text {stem comp }}, \mathrm{in}^{2}$ & $=\mathrm{A}_{\text {stem }}{ }^{(1)}$ & 1.147 & 1.147 & 1.147 & 1.147 \\
\hline & $\mathrm{I}_{\mathrm{y} \text {-stem comp }}$, in $^{4}$ & $=\mathrm{I}_{\mathrm{y} \text {-stem }}+\mathrm{nI}_{\mathrm{FRP}}$ & 0.0066 & 0.0081 & 0.0050 & 0.0058 \\
\hline & $\mathrm{r}_{\mathrm{y} \text {-stem comp }}$, in & $=\left(\mathrm{I}_{\mathrm{y} \text {-stem comp }} / \mathrm{A}_{\text {stem comp }}\right)^{1 / 2}$ & 0.0710 & 0.0784 & 0.0645 & 0.0695 \\
\hline & increase in $r_{y}$ & $=\mathrm{r}_{\mathrm{y} \text {-stem comp }} / \mathrm{r}_{\mathrm{y} \text {-stem }}$ & 1.230 & 1.358 & 1.117 & 1.204 \\
\hline \multirow{7}{*}{ 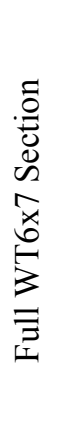 } & $\mathrm{A}_{\mathrm{WT} 6 \times \mathrm{x}}, \mathrm{in}^{2}$ & $(A I S C, 2005 a)$ & 2.08 & 2.08 & 2.08 & 2.08 \\
\hline & $\mathrm{I}_{\mathrm{y}}, \mathrm{in}^{4}$ & $(A I S C, 2005 a)$ & 1.18 & 1.18 & 1.18 & 1.18 \\
\hline & $r_{y}$, in & $(A I S C, 2005 a)$ & 0.753 & 0.753 & 0.753 & 0.753 \\
\hline & $\mathrm{A}_{\text {comp }}$, in $^{2}$ & $=\mathrm{A}_{\text {stem }}{ }^{(1)}$ & 2.080 & 2.080 & 2.080 & 2.080 \\
\hline & $\mathrm{I}_{\mathrm{y} \text { comp }}, \mathrm{in}^{4}$ & $=\mathrm{I}_{\mathrm{y}}+\mathrm{nI}_{\mathrm{FRP}}$ & 1.1822 & 1.1833 & 1.1802 & 1.1804 \\
\hline & $\mathrm{r}_{\mathrm{y} \text { comp }}$, in & $=\left(\mathrm{I}_{\text {comp }} / \mathrm{A}_{\text {comp }}\right)^{1 / 2}$ & 0.7539 & 0.7543 & 0.7533 & 0.7533 \\
\hline & increase in $\mathbf{r}_{\mathrm{y}}$ & $=\mathrm{r}_{\mathrm{y} \text { comp }} / \mathrm{r}_{\mathrm{y}}$ & 1.001 & 1.002 & 1.000 & 1.000 \\
\hline
\end{tabular}

(1) $\mathrm{A}_{\text {stem comp }}=\mathrm{A}_{\text {comp }}=\mathrm{A}_{\text {stem }}$ due to the low compressive modulus of FRP.

*NOTE -1 in $=0.0254 \mathrm{~m}$

The theoretical increase in $\mathrm{r}_{\mathrm{y}}$ for the stem is significant, ranging from 1.117 to 1.358 . This would suggest the prospect of increasing stability on a local level. However, a negligible increase in $r_{y}$ is predicted for the entire WT cross section indicating a lack of effect on global cross section behavior. The FRP-retrofitted members seem to mimic this predicted behavior. The GFRP retrofit specimens in particular seemed to increase resistance to lateral displacement of the 
stem, while minimally increasing the member's axial compressive capacity suggesting a localized effect. 


\subsection{SUMMARY, CONCLUSIONS, AND RECOMMENDATIONS}

This chapter reports and discusses conclusions of the experimental program. A summary of the test procedure and recommendations for future work are also presented.

\subsection{SUMMARY OF TEST PROGRAM}

A total of six A992 Grade 50 WT 6x7 steel brace specimens were tested under cyclic compressive loading. Of these, one was encased in a circular steel HSS $7 \times 0.125$ pipe section filled with grout creating a buckling restrained brace (BRB), four were retrofitted with FRP pultruded strips, and one was tested as an unretrofit control specimen. Of the four FRP-retrofit braces, CFRP strips were applied to two and GFRP strips were employed for the remaining two. The width and number of layers of FRP were varied for each retrofit specimen: in one case a single layer of 2" (50.8 $\mathrm{mm})$ wide strip was used and in the other two 1" $(25.4 \mathrm{~mm})$ wide strips were stacked on top of each other. These strips were applied to both sides of the stem of the WT section.

The brace specimens were tested under cyclic compressive loading to failure. Each brace was initially subjected to a small tensile force of approximately $2000 \mathrm{lbs}(8.9 \mathrm{kN})$ to allow the loading sequence to pass through zero in each cycle. For all braces, with the exception of the $\mathrm{BRB}$, the first loading cycle imposed a maximum $5000 \mathrm{lbs}$. $(22.2 \mathrm{kN})$ compressive load and then 
returned to the initial $2 \mathrm{kip}(8.9 \mathrm{kN})$ tensile load. The following cycles incrementally increased the maximum compressive load by 5 kips $(22.2 \mathrm{kN})$ each cycle and each returned to the initial 2 kip $(8.9 \mathrm{kN})$ tensile load upon cycle completion. The BRB, expected to achieve a higher load capacity, was cycled in increments of 10 kips $(44.5 \mathrm{kN})$. Each brace specimen reached at least 45 kips $(200 \mathrm{kN})$ in this manner and cyclic loading was continued until failure occurred as defined by either excessive lateral deflection and/or FRP strip debonding.

\subsection{CONCLUSIONS}

All specimens exhibited lateral torsional buckling followed by local buckling within the cross section. Strip debonding was a secondary failure response of the FRP-retrofit specimens. The results of testing the six brace specimens subjected to cyclic compressive loads are as follows:

1. The FRP retrofit specimens did not provide a significant increase in axial capacity. The GFRP-2 and GFRP-1 specimens provided a $6 \%$ and $9 \%$ axial capacity increase, respectively, while the CFRP retrofit specimens showed a slight decrease. These effects are nominal when contrasted with the $91 \%$ increase in axial capacity provided by the buckling-restrained brace, Specimen B.

2. The variation of axial capacity between specimens is believed to be largely due to eccentric loading conditions which resulted from a cumulative effect of real load eccentricity and initial imperfections in the section.

3. Specimens GFRP-2, GFRP-1, and CFRP-2 exhibited an increase in initial stiffness in terms of weak-axis lateral deflections when compared with the control specimen C. 
Specimen CFRP-1 did not exhibit such an increase, likely due to a high initial loading eccentricity.

4. FRP retrofitted specimens exhibited greater control over weak-axis lateral displacement response and bifurcation load. A $9.6 \%$ to $51.4 \%$ increase in load corresponding to a 0.1 " weak-axis lateral deflection was observed for the FRP retrofit specimens with specimen GFRP-2 providing the greatest increase. Similarly, a $7.0 \%$ to $20.1 \%$ increase in load corresponding to a 0.3 " weak-axis lateral deflection was observed for the FRP retrofit specimens with again, specimen GFRP-2 providing the greatest increase.

5. The FRP retrofit specimens showed a loss of ductility in the brace with the displacements corresponding to the end of the plateau of the load vs. weak-axis lateral displacements plot decreasing when compared to the control specimen C. This loss of ductility is likely a result of the increase in stiffness and the brittle nature of the FRP bond to the steel substrate, but may also reflect the difference in the location of local buckling along the brace length between Specimen $\mathrm{C}$ and the FRP-retrofit specimens.

6. The bifurcation load determined from weak-axis lateral displacement readings showed an increase ranging from $109 \%$ to $279 \%$ for specimens GFRP-2, CFRP-2 and GFRP-1. Specimen CFRP-1 demonstrated a 1.5\% decrease in bifurcation load which is believed to be a result of its larger initial eccentricity. The bifurcation load determined based on strain measurements showed an increase ranging from $4.3 \%$ to $12.3 \%$ for all FRP retrofitted specimens.

7. The FRP retrofit specimens showed an increase in the strong-axis bifurcation load based on displacement readings ranging from $94 \%$ to $116 \%$, suggesting that the stabilization of the stem also mitigates the onset of strong-axis buckling. 
8. The GFRP retrofitted specimens exhibited significant reductions in residual displacements after a single loading cycle to 50,000 lbs. While the CFRP retrofitted specimens exhibited similar residual displacements to the control specimen C, the GFRP specimens reduced residual axial displacements from $97 \%$ to $98 \%$ of those seen with control specimen C. The GFRP specimens similarly exhibited a $95 \%$ to $97 \%$ decrease in residual weak-axis lateral displacements, and a $59 \%$ to $90 \%$ decrease in residual strongaxis lateral displacements. This reduction in residual displacements is significant and suggests that at cycles of high compressive loading the likelihood of a kink forming in the member, which ultimately contributes to the degradation of brace's compressive capacity, is decreased leaving greater compressive capacity for subsequent cycles. Figure 6.1 presents a figure previously presented in chapter 2 that has been modified to illustrate the suggested enhanced subsequent compressive capacity of a member in which no kink has formed.

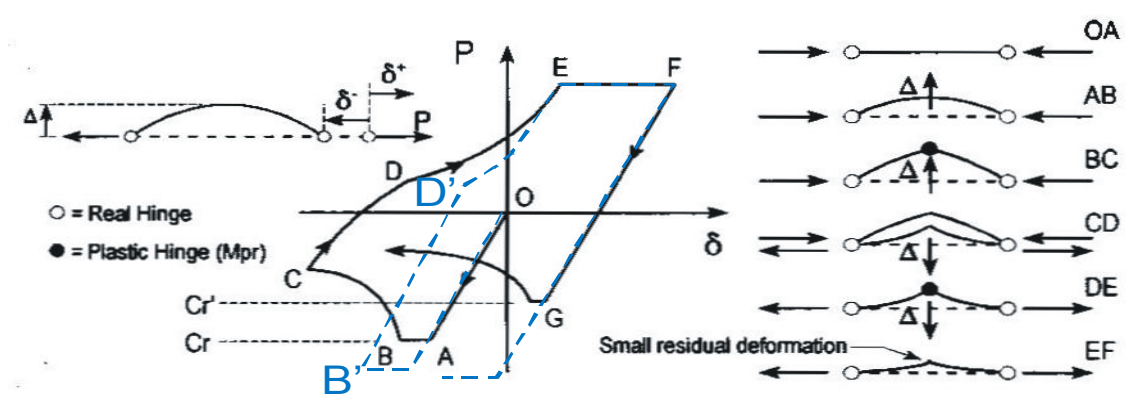

Figure 6.1 Modified sample hysteresis of brace under cyclic loading to illustrate the effect of the absence of kink formation (original from Bruneau, 1998).

This behavior is interpreted to result from the elastic behavior of the GFRP providing a restraining load, allowing the buckled steel section to more efficiently "unbuckle" or straighten, mitigating the formation of a plastic "kink". Furthermore, the lower stiffness 
of the GFRP allowed it to provide this restraint through greater substrate strain levels. This ultimately suggests that a softer FRP material is better suited for this application contrary to previous perceptions that the retrofit stiffness should be similar to that of steel.

9. All FRP retrofit specimens debonded at strains close to the maximum recorded strain after the maximum load was observed. Specimen GFRP-2 reported low strain readings suggesting poor bond conditions for that specimen. All other specimens exhibited good bond quality.

10. Significant localized effects were seen in the stem of the retrofit specimens with the decrease in cyclic lateral displacements as well as overall residual displacements. Considering only the WT stem, the increase in weak-axis radius gyration $\left(\mathrm{r}_{\mathrm{y}}\right)$ due the application of the FRP ranged from 1.117 to 1.358 . However, a negligible increase in $\mathrm{r}_{\mathrm{y}}$ is determined when the entire WT cross section is considered; thus there is a negligible effect on the global brace behavior.

11. The concept of strategically applying FRP material to a steel brace to create a Partially Buckling Restrained Brace as presented in this thesis may not hold promise as a viable retrofit option. The nominal affect of the addition of small amounts of FRP has little effect on the elastic buckling behavior of the long brace sections found in a CBF. The FRP retrofit is able to affect local behavior, however local behavior will not dominate the overall brace behavior of long CBF braces enough for the application to be effective. Perhaps application to a shorter brace section, such as those used for cross frames between bridge girders, where global behavior is not critical would present a more appropriate application of an FRP stabilized steel member. 


\subsection{RECOMMENDATIONS}

This thesis presents the investigation, testing and results of a previously untested concept.

While noting that the initial objective to increase the brace's compressive hysteretic behavior was not achieved, it was observed that this retrofit measure can significantly increase the local behavior of a steel member. The proposed retrofit showed an increase in the stem's local radius of gyration, but little effect on the radius of gyration of the whole cross section. Some recommendations for future study are:

1. Further study of FRP-to-steel bond behavior under various loading conditions is required

2. Further research should be conducted to investigate the effect of FRP retrofit braces in which the FRP material is applied at a distance from the brace local axes to increase the radii of gyration for the whole section. This research would be similar to that performed by Tremblay et al. (2006) which studied the addition of steel tubes to restrain brace buckling.

3. The application of FRP to steel members for enhancement of local behavior should be studied in a practical context. This research might directly follow the analytical work performed by Accord et al. (2006) in which GFRP material was strategically applied to the flanges of a steel beam to mitigate local buckling.

The study of FRP retrofit of steel members is still in its infancy. It is evident that further work should be performed to further quantify the behavior and interaction of these materials and their bond. The use of FRP materials for enhancement of local stability of steel members holds promise and should be investigated further. 


\section{APPENDIX A}

\section{CONNECTION DESIGN}

This appendix provides the mathcad calculations for the connection design of the test set-up.

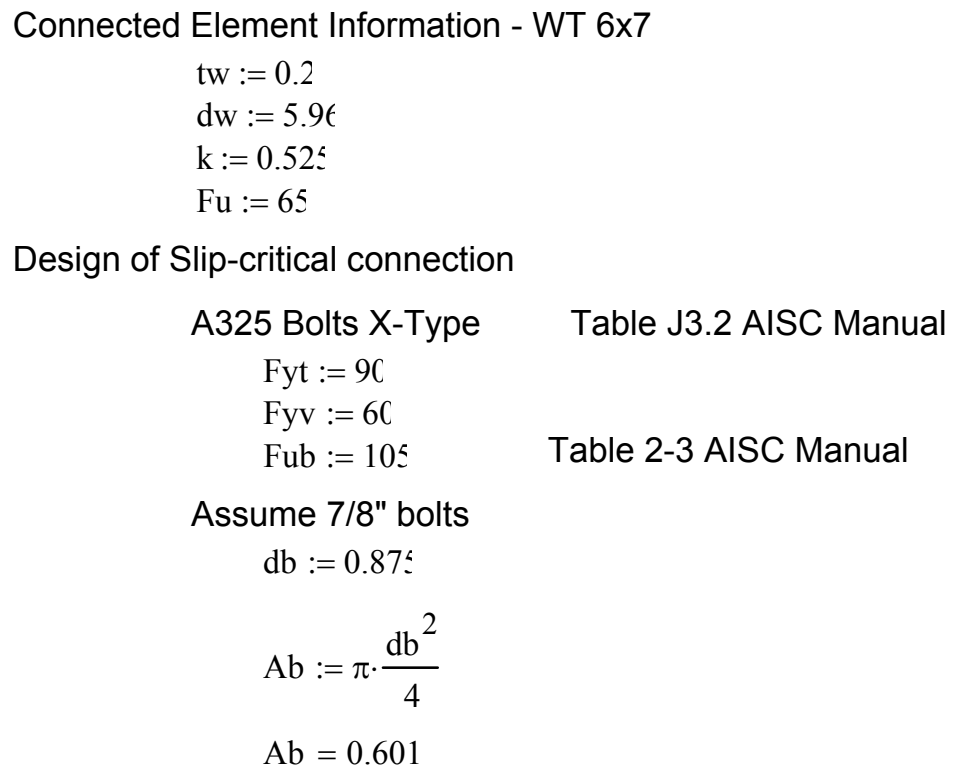

Minimum Bolt Pretension - Table J3.1 AISC Manual

$$
\begin{aligned}
\mathrm{Tb} & :=0.7 \cdot \mathrm{Fyt} \cdot \mathrm{Ab} \\
\mathrm{Tb} & =37.883
\end{aligned}
$$


Minimum Spacing - J3.3 AISC Manual

$$
\begin{aligned}
& \text { Smin }:=2.667 \cdot \mathrm{db} \\
& \text { Smin }=2.334 \\
& \text { Spref }:=3 \cdot \mathrm{db} \quad \text { Preferred Min. Spacing is 3d } \\
& \text { Spref }=2.625 \\
& \text { Minimum Edge Distance - Table J3.4 AISC } \\
& \text { Manual } \quad:=1.5 \quad \text { distance from center of std. hole } \\
& \text { Maximum Spacing - J3.5 AISC Manual } \\
& \text { Lemax }:=12 \cdot \mathrm{tw} \\
& \text { Lemax }=2.4 \\
& \text { Smax }:=14 \cdot \mathrm{tw} \\
& \text { Smax }=2.8
\end{aligned}
$$

Overview of Connection Design - See attached drawing

Double Angle L8x4x7/16

$37 / 8$ " bolts through 8 " leg, $27 / 8$ " bolts through 4 " leg connecting to the base plate

ta $:=0.438$

$\mathrm{S}:=2.33$

Both spacing and edge distance satisfy req'd max and min

Le: $:=1.62$

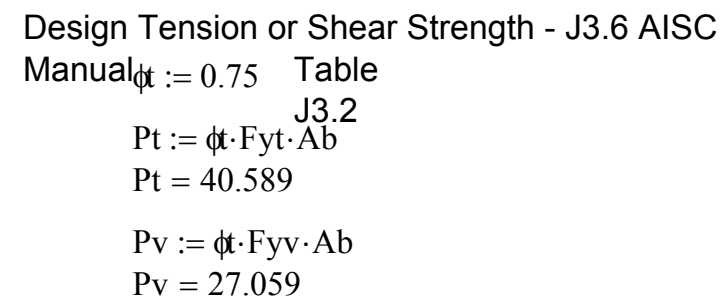

Slip-Critical Connections Designed at Factored Loads - J3.8a AISC

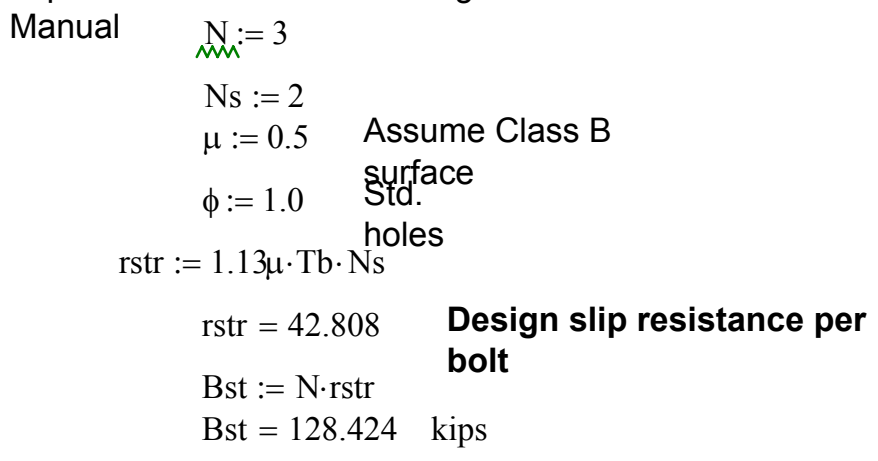


Slip-Critical Connections Designed at Service Loads - Appendix J3.8b AISC Manual Fv $:=17 \quad$ Table A-J3.2 AISC Manual, A325 Bolt, std. hole, $\begin{array}{ll}\text { Fvadj }:=F v \cdot \frac{0.5}{0.33} \quad \text { Value adjusted for class B } \\ \text { Fvadj }=25.758 \text { kips } & \text { surface }\end{array}$

$\operatorname{rsvr}:=\phi \cdot$ Fvadj $\cdot \mathrm{Ab}$ rsvr $=15.489 \quad$ Design slip resistance per bolt at service Bsv $:=\mathrm{N} \cdot \mathrm{rsvr} \quad$ loads Bsv $=46.466$ kips

Check AISC Manual

Tables Design Resistance to Shear at Service Loads Using Factored Loads, $\phi R n \quad$ adj $:=\frac{.5}{0.33} \quad$ adj $=1.515 \quad \begin{aligned} & \text { adjustment for Class } B \\ & \text { surface }\end{aligned}$

$\phi R n 1:=29.1 \cdot \mathrm{adj}$

$\phi R n 1=44.091$ per

Design Resistance lo bolt

$\phi R n \phi R n 2:=20.4$ adj $\phi R n 2=30.909$ per bolt

Check Bearing Strength on Bolts at Bolt Holes - J3.10 AISC

Manual

When deformation at the bolt hole at service load is a design consideration, J3.10(a)

$$
\begin{aligned}
& \mathrm{Lc}:=\mathrm{S}-\left[\mathrm{db}+\left(\frac{1}{16}\right)\right] \\
& \mathrm{Lc}=1.393 \\
& \phi \mathrm{b}:=0.75
\end{aligned}
$$

$\mathrm{Rn}:=1.2 \mathrm{Lc} \cdot \mathrm{tw} \cdot \mathrm{Fu}$

$\mathrm{Rn}=21.723$

$\phi b \cdot R n=16.292 \quad$ Design Bearing Strength at bolt holes

$\mathrm{N} \cdot \phi \mathrm{b} \cdot \mathrm{Rn}=48.877 \mathrm{kips} \quad$ Total Design Bearing Strength of Connection

$\mathrm{Bdbi}:=\phi b \cdot 2.4 \cdot \mathrm{Fu} \cdot \mathrm{db} \cdot \mathrm{tw}$

$\mathrm{Bdbi}=20.475$

Rdbw := Bdbi $\cdot \mathrm{N}$

$\mathrm{Rdbw}=61.425$ kips 


\section{APPENDIX B}

\section{TEST SET-UP DRAWINGS}

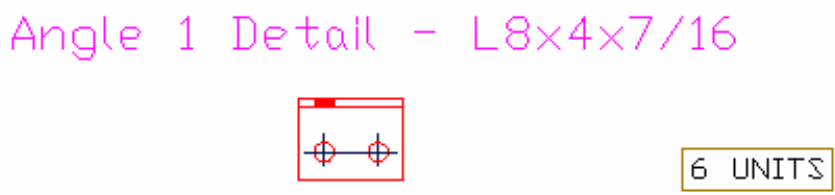

Dverhead View

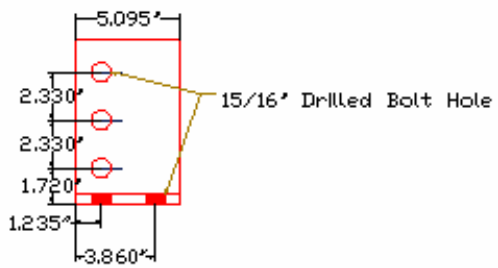

Elevation Vlew

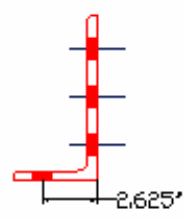

Side View 


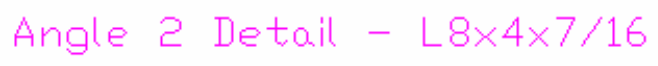

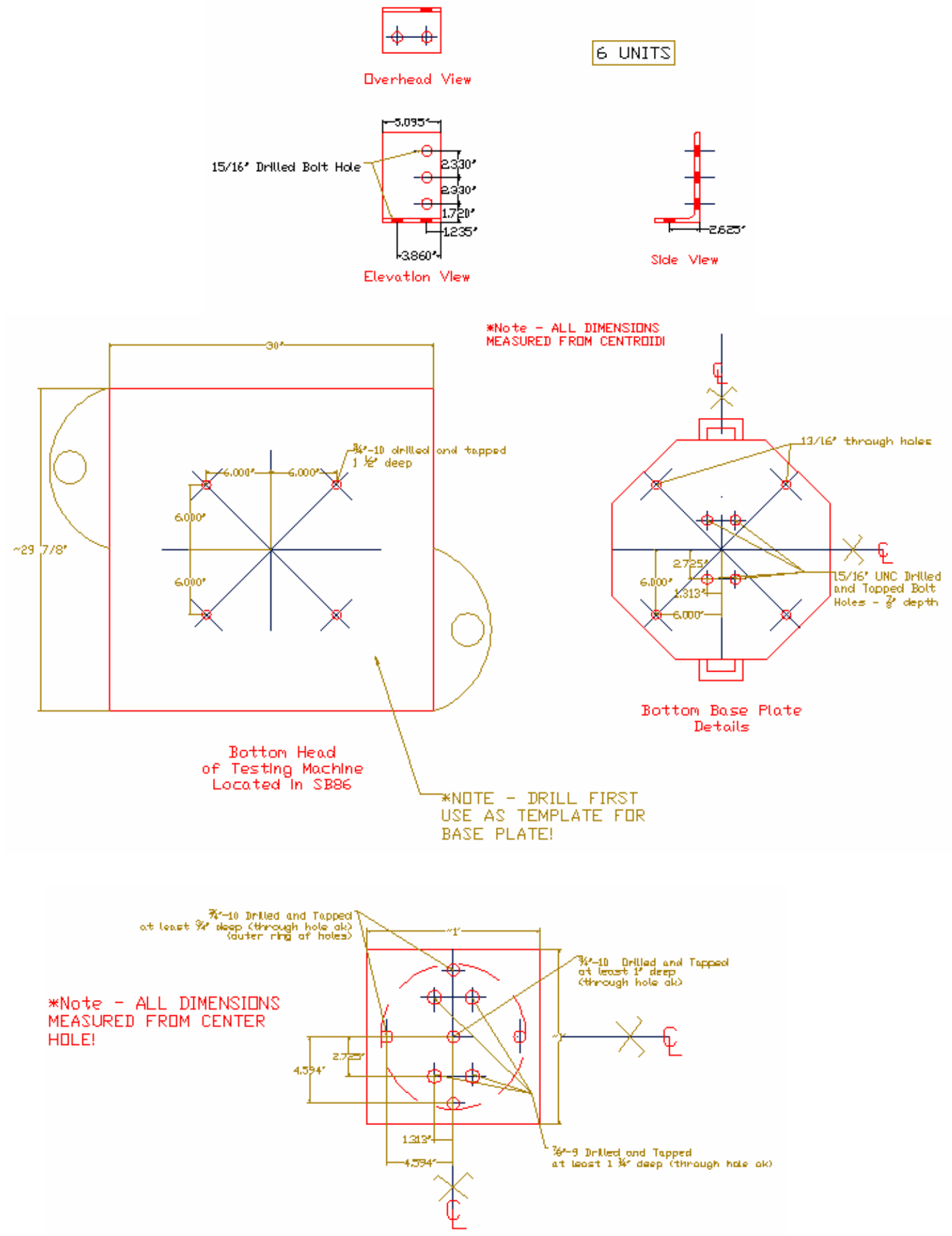

Top Base Plate Detalls 
APPENDIX C

BRACE LIMIT STATE CALCULATIONS

\section{C.1 WT 6X7 BRACE BEHAVIOR CALCULATIONS}

\section{WT 6x7 Ultimate Load Check}

\section{Section Properties}

$\begin{array}{lllll}\text { Ag }:=2.08 & \text { tf }:=0.225 & \text { Ix }:=7.67 & \text { rx }:=1.92 & \text { E }:=29000 \\ \text { d }:=5.96 & \text { bf }:=3.97 & \text { Iy }:=1.18 & \text { ry }:=.753 & \text { Fy }:=50 \\ \text { tw }:=.20 & & & & \\ \text { ybar }:=1.76 & & & & \end{array}$

\section{Local Buckling Check}

AISC Manual (3rd Edition)- Table B5.1

Limiting $\mathrm{d} / \mathrm{t}$ ratio for stem of tee $=\quad \begin{aligned} & \text { limit: }:=0.75 \sqrt{\frac{\mathrm{E}}{\mathrm{Fy}}} \\ & \text { limit }=18.062\end{aligned} \quad \frac{\mathrm{d}}{\mathrm{tw}}=29.8 \quad \frac{\mathrm{d}}{\mathrm{tw}}>$ limit

Slender Element Compression Member, go to Appendix B5.3 Appendix B5.3a(d) for stems of tees

$$
\begin{gathered}
\text { limit2:=1.03 } \sqrt{\frac{\mathrm{E}}{\mathrm{Fy}}} \\
\text { limit2 }=24.806 \\
\text { Qs }:=0.69 \frac{\mathrm{E}}{\mathrm{Fy} \cdot\left(\frac{\mathrm{d}}{\mathrm{tw}}\right)^{2}} \\
\text { Qs }=0.451 \\
\text { Qa }:=1
\end{gathered}
$$$$
\frac{\mathrm{d}}{\mathrm{tw}}>\text { limit } 2
$$$$
x:=1.21 \cdot \sqrt{\frac{E}{F y}}
$$$$
\mathrm{x}=29.141
$$

Appendix B5.3d for cross sections comprised of only unstiffened elements 
Design Compressive Strength for Flexural Buckling AISC Manual Chapter E2

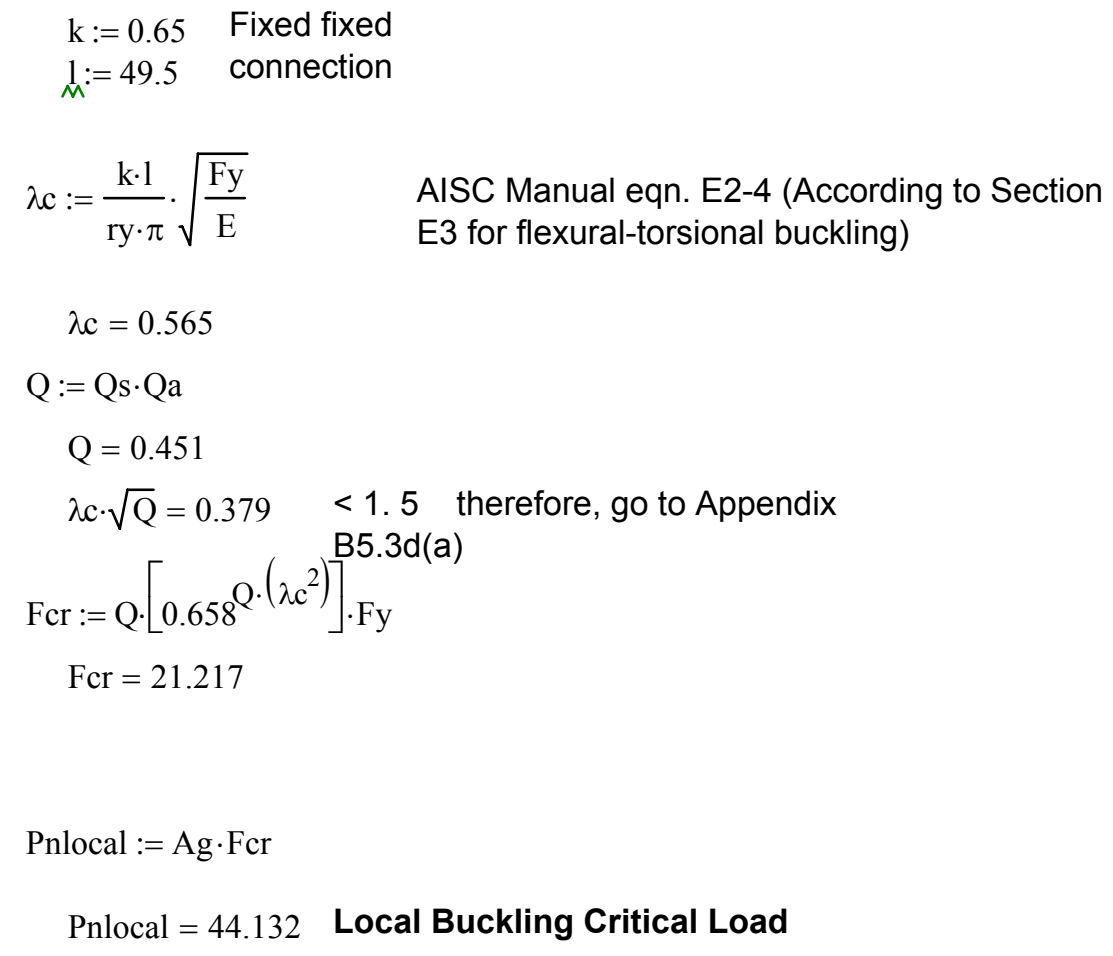

\section{Flexural Torsional Buckling Check - AISC Manual E3}

Table 1-32 AISC Manual

$$
\begin{aligned}
\text { ro }:=2.64 \\
\mathrm{~J}:=0.035 \\
\mathrm{H}:=0.611 \\
\mathrm{U}:=0.3 \\
\mathrm{G}:=\frac{\mathrm{E}}{2 \cdot(1+\mathrm{v})} \\
\mathrm{G}=1.115 \times 10^{4} \\
\text { Fcrz }:=\frac{\mathrm{G} \cdot \mathrm{J}}{\mathrm{Ag} \cdot\left(\mathrm{ro}^{2}\right)} \\
\mathrm{Fcrz}=26.929 \\
\text { Fcrft }:=\left(\frac{\text { Fcr }+ \text { Fcrz }}{2 \cdot \mathrm{H}}\right) \cdot\left[1-\sqrt{1-\frac{4 \cdot \text { Fcr } \cdot \text { Fcrz } H}{(\text { Fcr }+ \text { Fcrz })^{2}}}\right] \\
\text { Fcrft }=14.556 \\
\text { Pnft }:=\text { Ag } \cdot \text { Fcrft } \\
\text { Pnft }=30.276 \quad \text { Flexural Torsional Buckling Critical Loa d }
\end{aligned}
$$




\section{Elastic Buckling Load}

$$
\begin{gathered}
\text { Pex }:=\pi^{2} \cdot \mathrm{E} \cdot \frac{\mathrm{Ix}}{(\mathrm{k} \cdot \mathrm{l})^{2}} \\
\text { Pex }=2.121 \times 10^{3} \\
\text { Pey }:=\pi^{2} \cdot \mathrm{E} \cdot \frac{\mathrm{Iy}}{(\mathrm{k} \cdot \mathrm{l})^{2}} \\
\text { Pey }=326.244
\end{gathered}
$$




\section{C.2 BRB BEHAVIOR CALCULATIONS}

\section{BRB}

Stability

According to Black et. al 2004

Global Flexural Buckling - of the outer tube - HSS 7x0.125 Steel Tube

$$
\begin{aligned}
& \mathrm{Ai}:=2.08 \\
& \mathrm{k}:=1 \\
& \mathrm{~L}:=48.875 \\
& \mathrm{Eo}:=29000000 \\
& \mathrm{Io}:=14.9 \quad \sigma \mathrm{cr} 1:=\frac{\pi^{2} \cdot \mathrm{Eo} \cdot \mathrm{Io}}{\mathrm{Ai} \cdot(\mathrm{k} \cdot \mathrm{L})^{2}} \\
& \quad \sigma \mathrm{cr} 1=8.583 \times 10^{5} \mathrm{psi}
\end{aligned}
$$

Critical Load due to Buckling of the inner core in higher modes

$$
\begin{aligned}
& \mathrm{fc}:=5000 \text { psi } \\
& \mathrm{Ec}:=57000 \sqrt{\mathrm{fc}} \\
& \mathrm{Ec}=4.031 \times 10^{6} \\
& \mathrm{v}:=0.2 \\
& \beta:=\mathrm{Ec} \cdot \frac{1-\mathrm{v}}{(1+\mathrm{v}) \cdot(1-2 \cdot \mathrm{v})} \\
& \beta=4.478 \times 10^{6} \\
& \mathrm{Et}:=29000000 \\
& \mathrm{Ii}:=1.18 \\
& \quad \quad \sigma \mathrm{cr} 2:=\frac{2 \cdot \sqrt{\beta \cdot \mathrm{Et} \cdot \mathrm{Ii}}}{\mathrm{Ai}} \\
& \quad \quad \sigma \mathrm{cr} 2=1.19 \times 10^{7} \mathrm{psi}
\end{aligned}
$$

$$
\begin{aligned}
& \operatorname{Pcr} 1:=\sigma c r 1 \cdot \frac{\mathrm{Ai}}{1000} \\
& \operatorname{Pcr} 1=1.785 \times 10^{3} \mathrm{k}
\end{aligned}
$$

Torsional Buckling of the portion of the inner core that extends beyond the confining tube

$$
\operatorname{Pcr} 2:=\sigma c r 2 \cdot \frac{\mathrm{Ai}}{1000}
$$

$\operatorname{Pcr} 2=2.476 \times 10^{4} \quad \mathrm{k}$ 
Torsional Buckling of the portion of the inner core that extends beyond the confining tube

$$
\begin{aligned}
& \mathrm{b}:=5.96 \quad \sigma \mathrm{y}:=50000 \\
& \mathrm{t}:=.2 \\
& 1:=.5625 \\
& \begin{array}{l}
\sigma c r 3:=\frac{E t}{3} \cdot\left(\frac{\pi^{2} \cdot b^{2}}{3 \cdot 1^{2}}+1+\frac{3 \cdot \sigma y}{E t}\right) \cdot \frac{t^{2}}{b^{2}} \\
\sigma c r 3=4.031 \times 10^{6} \quad \mathrm{psi}
\end{array}
\end{aligned}
$$

Squash Load of a WT 6x7 section

$$
\begin{aligned}
& \text { Pcr4 }:=A i \cdot \frac{\sigma y}{1000} \\
& \text { Pcr4 }=104 \quad k \quad \text { Limiting value for the WT } 6 \times 7 \text { BRB }
\end{aligned}
$$

$$
\begin{aligned}
\sigma c r 4 & :=\frac{\pi^{2} \cdot E t}{12 \cdot\left(1-v^{2}\right)} \cdot \frac{t^{2}}{b^{2}}\left(\left(\frac{b^{2}}{1^{2}}+6 \cdot \frac{1-v}{\pi^{2}}\right)\right) \\
\sigma c r 4 & =3.155 \times 10^{6} \\
\operatorname{Pcr} 4 & :=\sigma c r 4 \cdot \frac{\mathrm{Ai}}{1000} \\
\operatorname{Pcr} 4 & =6.561 \times 10^{3}
\end{aligned}
$$




\section{APPENDIX D}

\section{LOADING LOCATION CALCULATIONS}

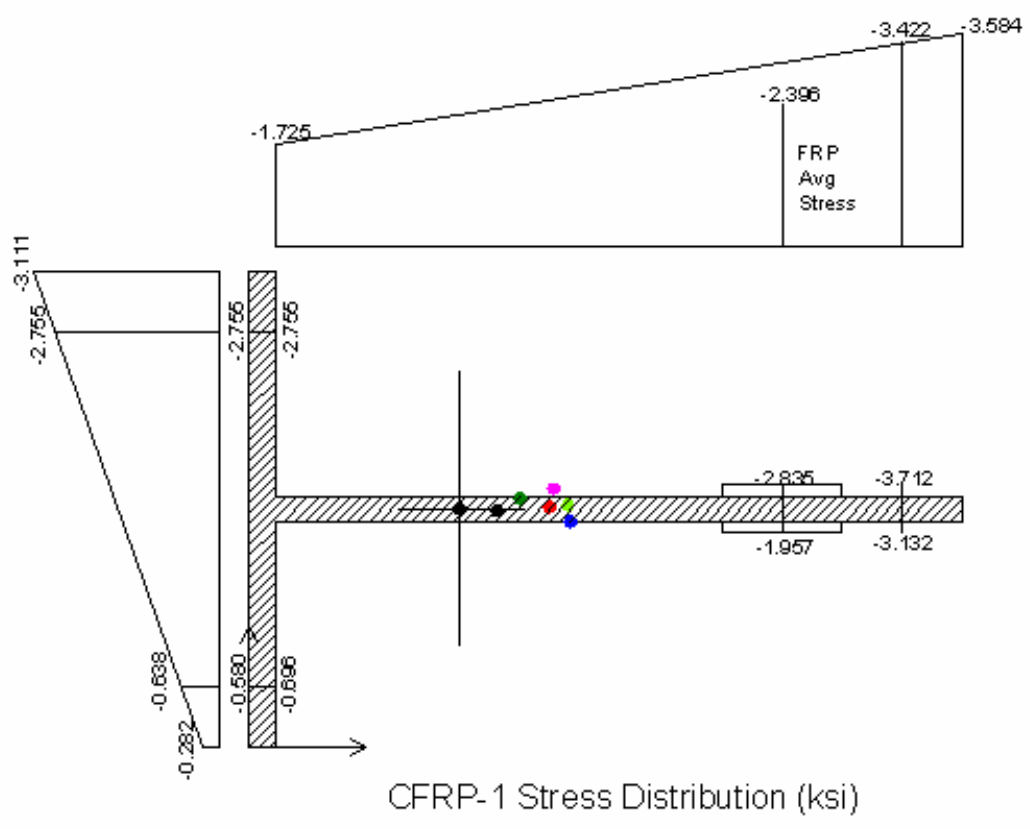




\section{Loading Location for CFRP-1}

Es $:=29000$

Egfrp $:=6000$

Ecfrp $:=22500$
$\varepsilon 1:=-128$
$\varepsilon 5:=-95$
$\varepsilon 2:=-108$
$\varepsilon 3:=-24$
$\varepsilon 4:=-20$
$\varepsilon 6:=-95$
$\varepsilon 7:=-87$
$\varepsilon 8:=-126$
$\sigma 1:=\frac{\varepsilon 1 \cdot \text { Es }}{10^{6}}$
$\sigma 2:=\frac{\varepsilon 2 \cdot \text { Es }}{10^{6}}$
$\sigma 1=-3.712$
$\sigma 3:=\frac{\varepsilon 3 \cdot \mathrm{Es}}{10^{6}}$
$\sigma 2=-3.132$
$\sigma 3=-0.696$
$\sigma 4:=\frac{\varepsilon 4 \cdot \mathrm{Es}}{10^{6}}$
$\sigma 5:=\frac{\varepsilon 5 \cdot \text { Es }}{10^{6}}$
$\sigma 4=-0.58$
$\sigma 5=-2.755$
$\sigma 6:=\frac{\varepsilon 6 \cdot \text { Es }}{10^{6}}$
$\sigma 6=-2.755$
$\sigma 7:=\frac{\varepsilon 7 \cdot \text { Ecfrp }}{10^{6}}$
$\sigma 7=-1.957$
$\sigma 8:=\frac{\varepsilon 8 \cdot \text { Ecfrp }}{10^{6}}$
$\sigma 8=-2.835$

Avg4a $:=5.735 \cdot \frac{\operatorname{Avg} 4-\operatorname{Avg} 3}{5.235}+\operatorname{Avg} 3$

$\operatorname{Avg} 4 \mathrm{a}=3.584$

Avg1a $:=-3.47 \cdot \frac{\operatorname{Avg} 2-\operatorname{Avg} 1}{2.97}+$ Avg2

Avg1 $\mathrm{a}=0.282$

$\operatorname{Avg} 2 \mathrm{a}:=3.47 \cdot \frac{\operatorname{Avg} 2-\operatorname{Avg} 1}{2.97}+\operatorname{Avg} 1$

$\operatorname{Avg} 2 \mathrm{a}=3.111$
$\operatorname{Avg} 1:=\frac{-(\sigma 3+\sigma 4)}{2}$

$$
\begin{aligned}
& \text { tf }:=0.225 \\
& \text { tw }:=0.2 \\
& \text { tgfrp }:=0.075 \\
& \text { tcfrp }:=0.055
\end{aligned}
$$

bgage $:=0.25$

bf $:=1.985$

bw $:=5.735$

bfrp $1:=1$

bfrp $2:=2$

Input Strains (e) from first cycle at 5000lb.

Averaging the stress on each side of the steel for a simplicity

$\operatorname{Avg} 4:=\frac{-(\sigma 1+\sigma 2)}{2}$

$\operatorname{Avg} 4=3.422$

$\operatorname{Avg} 1=0.638$

$\operatorname{Avg} 2:=\frac{-(\sigma 5+\sigma 6)}{2}$

$\operatorname{Avg} 2=2.755$

$\operatorname{Avgf}:=\frac{-(\sigma 7+\sigma 8)}{2}$

$\operatorname{Avg} 3:=\frac{-(\sigma 3+\sigma 6)}{2}$

$\operatorname{Avgf}=2.396$

$\operatorname{Avg} 3=1.725$

Linearly interpret stresses at the tips of the flanges an stem 


$\begin{array}{lll}\text { force d1 acts at }(0.1125,1.2425) & \mathrm{d} 1 \mathrm{x}:=0.1125 & \mathrm{~d} 1 \mathrm{y}:=0.9925 \\ \text { force d2 acts at }(0.1125,1.49) & \mathrm{d} 2 \mathrm{x}:=0.1125 & \mathrm{~d} 2 \mathrm{y}:=1.323 \\ \text { force d3 acts at }(0.1125,2.7275) & \mathrm{d} 3 \mathrm{x}:=0.1125 & \mathrm{~d} 3 \mathrm{y}:=2.9775 \\ \text { force d4 acts at }(0.1125,2.975) & \mathrm{d} 4 \mathrm{x}:=0.1125 & \mathrm{~d} 4 \mathrm{y}:=3.3083 \\ \text { force d5 acts at }(2.8425,2,085) & \mathrm{d} 5 \mathrm{x}:=3.0925 & \mathrm{~d} 5 \mathrm{y}:=1.985 \\ \text { force d6 acts at }(3.715,2.085) & \mathrm{d} 6 \mathrm{x}:=4.04833 & \mathrm{~d} 6 \mathrm{y}:=1.985 \\ \text { force d7 acts at }(4.46,2.085) & \mathrm{d} 7 \mathrm{x}:=4.46 & \mathrm{~d} 7 \mathrm{y}:=1.985\end{array}$
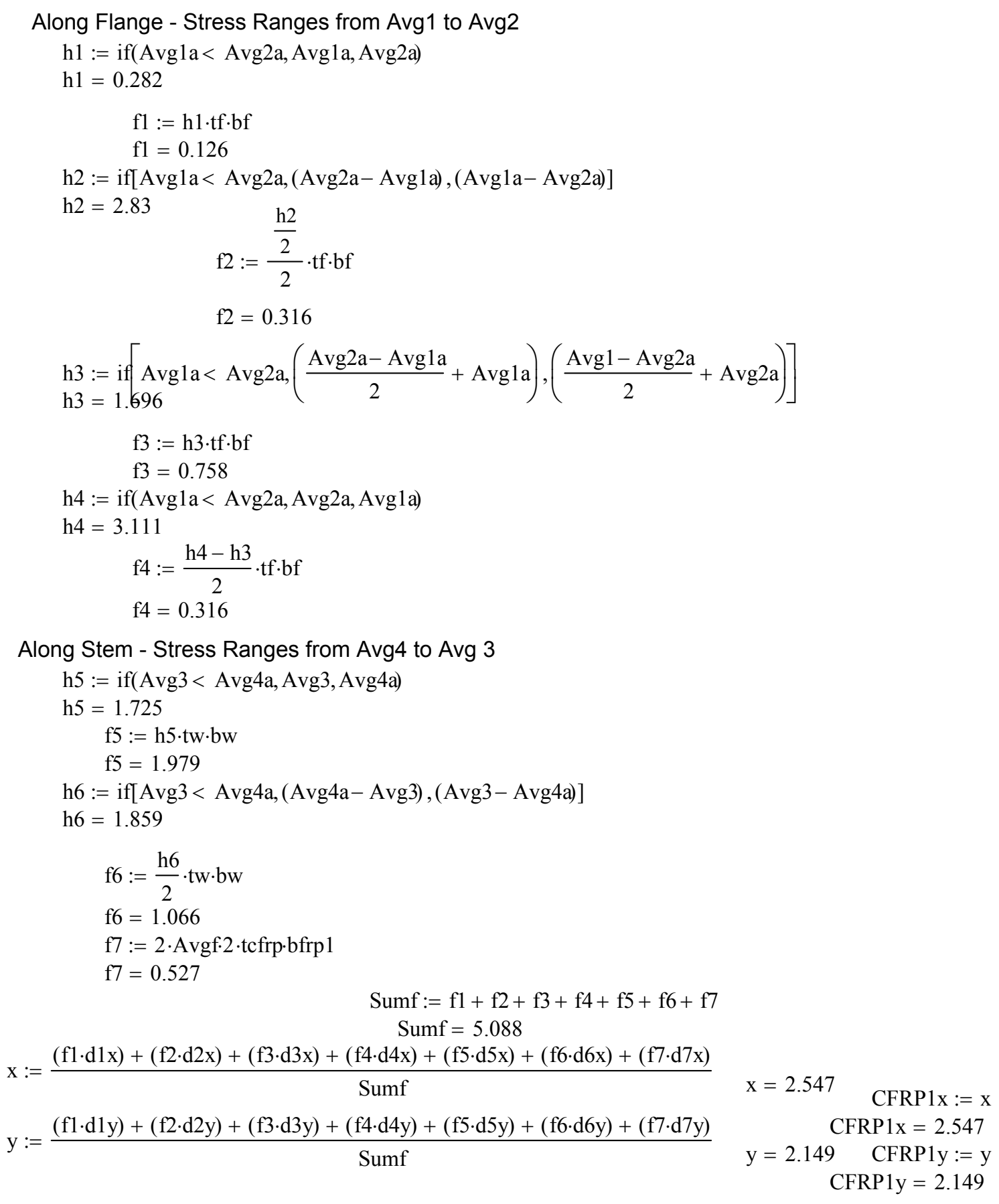


\section{BIBLIOGRAPHY}

Accord, N.B., Earls, C.J., and K.A. Harries. (2006). "On the use of Fiber Reinforced Composites to Improve Structural Ductility in Steel Flexural Members." Proceedings

of the 2006 SSRC-AISC Joint AISC-NASCC Conference, San Antonio, February 2006.

Accord, N.B. (2005). "On the use of Fiber Reinforced Composites to Improve Structural Ductility in Steel Flexural Members." MSc Thesis, Department of Civil and Environmental Engineering, University of Pittsburgh, Pittsburgh, PA.

Al-Emrani, M., Linghoff, D., and R. Kliger. (2005). "Bonding Strength and Fracture Mechanisms in Composite Steel-CFRP Elements." Proceedings of the International Symposium on Bond Behavior of FRP in Structures, pp 433-441.

Al-Saidy, A.H., Klaiber, F.W., and T.J. Wipf. (2004). "Repair of Steel Composite Beams with Carbon Fiber-Reinforced Polymer Plates." Journal of Composites for Construction, 8(2), 163-172.

American Society of Civil Engineers (ASCE). (2002). Minimum Design Loads for Buildings and Other Structures, SEI/ASCE 7-02, American Society of Civil Engineers, Reston, VA.

American Institute of Steel Construction (AISC). (2005a). Steel Construction Manual, 13 ${ }^{\text {th }}$ Edition.

American Institute of Steel Construction (AISC). (2005b). ANSI/AISC 341-05 Seismic Provisions for Structural Steel Buildings.

Black, C. J., Makris, N., and I. D. Aiken. (2002). "Component Testing, Stability Analysis and Characterization of Buckling-Restrained Unbonded Braces." Rep. No. PEER 2002/08, Univ. of California, Berkeley, CA.

Black, C. J., Makris, N., and I. D. Aiken. (2004). "Component Testing, Seismic Evaluation and Characterization of Buckling-Restrained Braces." Journal of Structural Engineering, 130(6), 880894.

Black, G.R., Wenger, W.A., and E.P. Popov. (1980). "Inelastic Buckling of Steel Struts Under Cyclic Load Reversals." Report No. UCB/EERC-80/40, Berkeley: Earthquake Engineering Research Center, University of California. 
Bouc, R. (1971). "Modèl Mathématique d'hysteresis.” Acustica, 24, 16-25.

Bruneau, M., Uang, C. M., and A. Whittaker. (1998). Ductile Design of Steel Structures, The McGraw-Hill Companies, Boston, Massachusetts, ISBN 0-07-008580-3.

Cadei, J.M.C., Stratford, T.J., Hollaway, L.C. and W.G. Duckett. (2004). "Strengthening Metallic Structures using Externally Bonded Fibre-Reinforced Polymers.” CIRIA Publication No. C595, CIRIA, London, $233 \mathrm{pp}$

Canadian Standards Association (CSA). (2001). CAN/CSA S16.1 Limit States Design of Steel Structures, CSA, Rexdale Ontario.

Carden, L.P., Ahmad, M.I., and I.G. Buckle. (2006a). "Seismic Performance of Steel Girder Bridges with Ductile Cross Frames Using Single Angle X Braces.” Journal of Structural Engineering, 132(3), 329-337.

Carden, L.P., Ahmad, M.I., and I.G. Buckle. (2006b). "Seismic Performance of Steel Girder Bridges with Ductile Cross Frames Using Buckling-Restrained Braces.” Journal of Structural Engineering, 132(3), 338-345.

Chacon, A., Chajes, M., Swinehart, M., Richardson, D., and G. Wenczel. (2004). "Applications of Advanced Composites to Steel Bridges: A Case Study on the Ashland Bridge." Proceedings of the $4^{\text {th }}$ Advanced Composites for Bridges and Structures Conference, Calgary Canada.

Dawood, M., Sumner, E., Rizkalla, S., and D. Schnerch. (2006a). "Strengthening Steel Bridges with New High Modulus CFRP Materials." accepted for publication in the Proceedings of the Third International Conference on Bridge Maintenance, Safety, and Management (IABMAS '06), Portugal, July 16-19, 2006.

Dawood, M., Sumner, E. and S. Rizkalla. (2006b). "Fundamental Characteristics of New High Modulus CFRP Matrials for Strengthening Steel Bridges and Structures." accepted for publication in the Proceedings for Structural Faults \& Repair 2006, Edinburgh, Scotland, June 13-15, 2006.

Ekiz, E., El-Tawil, S., Parra-Montesinos, G., and S. Goel. (2004). "Enhancing Plastic Hinge Behavior in Steel Flexural Members Using CFRP Wraps." Proceedings of the $13^{\text {th }}$ World Conference on Earthquake Engineering, Vancouver, August 2004.

Fahnestock, L.A., Sause, R., and J.M. Ricles. (2003). "Analytical and Experimental Studies on Buckling Restrained Composite Frames." Proceedings of the International Workshop on Steel and Concrete Composite Construction, Taipei, Taiwan, October 2003, pp 177-188.

FEMA (Federal Emergency Management Agency). (2000). Prestandard and Commentary for the Seismic Rehabilitation of Buildings (FEMA 356), Washington DC.

FEMA. (2003). NEHRP Recommended Provisions for New Buildings and Other Structures (FEMA 450), Federal Emergency Management Agency, Washington, D.C. 
Goel, S.C. (1998). "A Commentary on Seismic Provisions for Special Concentrically Braced Frames and Special Truss Moment Frames." Proceedings of the $76^{\text {th }}$ Annual AISC Meeting, Paper $\# 17,12 \mathrm{pp}$.

Harries, K., and S. El-Tawil. (2006). Steel-FRP Composite Structural Systems: State of the Art, Submitted to the ASCE Composites for Construction Committee.

Hollaway, L.C., and P.R. Head. (2001). Advanced Polymer Composites and Polymers in the Civil Infrastructure, Elsevier Science Ltd., Oxford, UK, ISBN: 0080436617.

Hollaway, L.C. (2005). "Advances in Adhesive Joining of Dissimilar Materials with Special Reference to Steels and FRP Composites." Proceedings of the International Symposium on Bond Behavior of FRP in Structures, pp 12-21.

International Council of Building Officials (ICBO). (2003). International Building Code 2003.

Jones, S.C., and S.A. Civjan. (2003). "Application of Fiber Reinforced Polymer Overlays to Extend Steel Fatigue Life.” Journal of Composites for Construction, 7(4), 331-338.

Karbhari, V.M., and S.B. Shulley. (1995). "Use of Composites for Rehabilitation of Steel Structures - Determination of Bond Durability." Journal of Materials in Civil Engineering, 7(4), 239-245.

Kim, J., and Y. Seo. (2004). "Seismic design of low-rise steel frames with buckling-restrained braces." Engineering Structures, 26, pp 543-551.

Kim, J., and H. Choi. (2004). "Behavior and design of structures with buckling-restrained braces." Engineering Structures, 26, pp 693-706.

Kimura, K., Takeda, Y., Yoshioka, K., Furuya, N., and Y. Takemoto. (1976). "An experimental study on braces encased in steel tube and mortar." Proc. Annual Meeting of the Architectural Institute of Japan, Japan (in Japanese).

Lee, K., and M. Bruneau. (2005). "Energy Dissipation of Compression Members in Concentrically Braced Frames: Review of Experimental Data." Journal of Structural Engineering, 131(4), 552559.

Liu, H.B., Zhao, X.L., and R. Al-Mahaidi. (2005). "The Effect of Fatigue Loading on Bond Strength of CFRP Bonded Steel Plate Joints." Proceedings of the International Symposium on Bond Behavior of FRP in Structures, pp 459-464.

Meier, U., Deuring, M., Meier, H., and G. Schwegler. (1993). Strengthening of Structures with Advanced Composites. Alternative Materials for the Reinforcement and Prestressing of Concrete, EMPA Duebendorf, CH-8600 Duebendorf, Switzerland, pp 153-171. 
Merritt, S., Uang, C., and G. Benzoni. (2003). "Subassemblage Testing of CoreBrace BucklingRestrained Braces, Final Report to CoreBrace, LLC." Report No. TR-2003/01, Department of Structural Engineering, University of California, San Diego, San Diego, CA.

Mertz, D.R. and J.W. Gillespie Jr. (1996). "Rehabilitation of Steel Bridge Girders Through the Application of Advanced Composite Materials." Contract NCHRP-93-ID011, Transportation Research Board, Washington, D.C.

Miller, T.C., Chajes, M.J., Mertz, D.R., and J.N. Hastings. (2001). "Strengthening of Steel Bridge Girder Using CFRP Plates." Journal of Bridge Engineering, 6(6), 514-522.

Mochizuki, S., Murata, Y., Andou, N., and S. Takahashi. (1979). "An experimental study on buckling of unbonded braces under centrally applied loads." Proc., Annual Meeting of the Architectural Institute of Japan, Japan (in Japanese).

Nozaka, K., Shield, C.K., Hajjar, J.F. (2005). "Effective Bond Length of Carbon-Fiber-Reinforced Polymer Strips Bonded to Fatigued Steel Bridge I-Girders.” Journal of Bridge Engineering, 10(2), 195-205.

Photiou, N.K., Hollaway, L.C., and M.K. Chryssanthopoulos. (2006). "Strengthening of an Artificially Degraded Steel Beam Utilising a Carbon/Glass Composite System." Construction and Building Materials, 20, pp 11-21.

Quattlebaum, J., Harries, K.A. and Petrou, M.F. (2005). "Comparison of Three CFRP Flexural Retrofit Systems Under Monotonic and Fatigue Loads." ASCE Journal of Bridge Engineering. 10(6), 731-740.

Sabelli, R. (2004). "Recommended Provisions for Buckling-Restrained Braced Frames," Engineering Journal, AISC, Fourth Quarter 2004, pp 155-175.

Sabelli, R., Mahin, S., and C. Chang. (2003). "Seismic Demands on Steel Braced Frame Buildings with Buckling Restrained Braces.” Engineering Structures, 25, pp 655-666.

Sayed-Ahmed, E.Y. (2004). "Strengthening of Thin-walled Steel I-Section Beams Using CFRP Strips." Proceedings of the $4^{\text {th }}$ International Conference on Advanced Composite Materials in Bridges and Structures, Calgary, Canada.

Schnerch, D., Stanford, K., Sumner, E., and S. Rizkalla. (2005). "Bond Behavior of CFRP Strengthened Steel Bridges and Structures." Proceedings of the International Symposium on Bond Behavior of FRP in Structures, pp 443-451.

Sen, R., Libby, L., and G. Mullins. (2001). "Strengthening Steel Bridge Sections Using CFRP Laminates." Composites Part B: Engineering, 39, pp 309-322. 
Shaat, A., and A. Fam. (2004). "Strengthening of Short HSS Steel Columns Using FRP Sheets." Proceedings of the $4^{\text {th }}$ International Conference on Advanced Composite Materials in Bridges and Structures, Calgary, June 2004, paper No. 093.

Shaat, A., and A. Fam. (2006). "Axial Loading Test on Short and Long Hollow Structural Steel Columns Retrofitted Using Carbon Fibre Reinforced Polymers." Canadian Journal of Civil Engineering, 33, 458-470.

Stratford, T.J., and J.F. Chen. (2005). "Designing for Tapers and Defects in FRP-Strengthened Metallic Structures." Proceedings of the International Symposium on Bond Behavior of FRP in Structures, pp 453-458.

Tavakkolizadeh, M., and H. Saadatmanesh. (2003a). "Strengthening of Steel-Concrete Composite Girders Using Carbon Fiber Reinforced Polymers Sheets." Journal of Structural Engineering, $129(1), 30-40$.

Tavakkolizadeh, M., and H. Saadatmanesh. (2003b). "Repair of Damaged Steel-Concrete Composite Girders Using Carbon Fiber-Reinforced Polymer Sheets." Journal of Composites for Construction, 7(4), 311-322.

Tavakkolizadeh, M., and H. Saadatmanesh. (2003c). "Fatigue Strength of Steel Girders Strengthened with Carbon Fiber Reinforced Polymer Patch." Journal of Structural Engineering, 129(2), 186-196.

Timoshenko, S. (1936). Theory of Elastic Stability, McGraw-Hill Book Company, Inc., New York and London.

Tremblay, R. (2001). "Seismic Behavior and Design of Concentrically Braced Steel Frames." Engineering Journal, AISC, Third Quarter 2001, pp 148-166.

Tremblay, R., Degrange, G., and J. Blouin. (1999). "Seismic Rehabilitation of a Four-Storey Building with a Stiffened Bracing System." Proceedings of the $8^{\text {th }}$ Canadian Conference on Earthquake Engineering, Vancouver, pp 549-554.

Tremblay, R., Bolduc, P., Neville, R. and R. DeVall. (2006). "Seismic Testing and Performance of Buckling-Restrained Bracing Systems.” Canadian Journal of Civil Engineering, 33, pp 183-198.

Wada, A., Saeki, E., Takeuch, T., and A. Watanabe. (1989). "Development of unbonded brace." Column Technical Publication No. 115 1989.12, Nippon Steel, Japan.

Wakabayashi, M., Nakamura, T., Katagihara, A., Yogoyama, H., and T. Morisono. (1973). "Experimental Study on the Elasto-Plastic Behavior of Braces Enclosed by Precast Concrete Panels Under Horizontal Cyclic Loading - Parts 1 \& 2." Summaries of technical papers of annual meeting, Vol. 10, Architectural Institute of Japan, Structural Engineering Section, pp 1041-1044 [in Japanese]. 
Wakabayashi, M., Nakamura, T., Katagihara, A., Yogoyama, H., and T. Morisono. (1973). "Experimental Study on the Elasto-Plastic Behavior of Braces Enclosed by Precast Concrete Panels Under Horizontal Cyclic Loading - Parts 1 \& 2." Summaries of technical papers of annual meeting, Vol. 6, Kinki Branks of the Architectural Institute of Japan, pp 121-128 [in Japanese].

Watanabe, A., Hitomoi, Y., Saeki, E., Wada, A., and M. Fujimoto. (1988). "Properties of braces encased in buckling-restraining concrete and steel tube." Proceedings of the $9^{\text {th }}$ World Conf. on Earthquake Engineering, Vol. IV, Tokyo-Kyoto, Japan, 719-724.

Watanabe, A., and H. Nakamura. (1992). "Study on the behavior of buildings using steel with low yield point." Proceedings of the $10^{\text {th }}$ World Conf. on Earthquake Engineering, Balkema, Rotterdam, The Netherlands, 4465-4468.

Wen, Y.-K. (1975). “Approximate Method for Nonlinear Random Vibration.” Journal of Engineering Mechanics, 101(4), pp 389-401.

Wen, Y.-K. (1976). "Method for Random Vibration of Hysteretic Systems." Journal of Engineering Mechanics, 102(2), pp 249-263.

Xia, S.H., and J.G. Teng. (2005). "Behaviour of FRP-to-Steel Bonded Joints." Proceedings of the International Symposium on Bond Behavior of FRP in Structures, pp 419-426.

Xie, Q. (2004). "State of the art of buckling-restrained braces in Asia." Journal of Constructional Steel Research, 61, pp 727-748.

Yang, Y.X., Yue, Q.R., and F.M. Peng. (2005). "Experimental Research on Bond Behavior of CFRP to Steel." Proceedings of the International Symposium on Bond Behavior of FRP in Structures, pp 427-431.

Yoshino, T., and Y. Karino. (1971). "Experimental study on shear wall with braces: Part 2." Summaries of technical papers of annual meetings, vol. 11, Architectural Institute of Japan, Structural Engineering Section, (in Japanese). 